\author{
WALDEN \\ UNIVERSITY \\ A higher degree. A higher purpose.
}

Walden University ScholarWorks

Walden Dissertations and Doctoral Studies

2017

\title{
Effective Strategies Small Retail Leaders Use to Engage Employees
}

Dr. Janet Lynn Deskins

Walden University

Follow this and additional works at: https://scholarworks.waldenu.edu/dissertations

Part of the Advertising and Promotion Management Commons, Business Administration, Management, and Operations Commons, Entrepreneurial and Small Business Operations Commons, Management Sciences and Quantitative Methods Commons, and the Marketing Commons

This Dissertation is brought to you for free and open access by the Walden Dissertations and Doctoral Studies Collection at ScholarWorks. It has been accepted for inclusion in Walden Dissertations and Doctoral Studies by an authorized administrator of ScholarWorks. For more information, please contact ScholarWorks@waldenu.edu. 


\title{
Walden University
}

\author{
College of Management and Technology
}

This is to certify that the doctoral study by

\section{Janet Deskins}

has been found to be complete and satisfactory in all respects, and that any and all revisions required by the review committee have been made.

\author{
Review Committee \\ Dr. Gergana Velkova, Committee Chairperson, Doctor of Business Administration \\ Faculty \\ Dr. Robert Miller, Committee Member, Doctor of Business Administration Faculty \\ Dr. Scott Burrus, University Reviewer, Doctor of Business Administration Faculty
}

Chief Academic Officer

Eric Riedel, Ph.D.

Walden University

2017 


\begin{abstract}
Effective Strategies Small Retail Leaders Use to Engage Employees

by

Janet L. Deskins
\end{abstract}

MBA, Western Governors University, 2014

BS, Western Governors University, 2013

\author{
Doctoral Study Submitted in Partial Fulfillment \\ of the Requirements for the Degree of \\ Doctor of Business Administration
}

Walden University

December 2017 


\begin{abstract}
Research suggests that $70 \%$ of North American employees are disengaged in the workplace. Some small retail managers lack strategies for engaging employees. Using the employee engagement framework, the purpose of this descriptive case study was to explore successful strategies that small retail managers use to engage employees. The target population was small retail leaders, purposefully selected because of their success with engaging employees at an Orlando, Florida, company. Data collection was through face-to-face interviews with 5 leaders; and a review of archived organizational documents, including company memorandums, central email software, and online customer reviews through social media websites such as Google, Yelp, and Facebook posts. Data were analyzed using inductive coding of phrases and words from participant interviews, whereas secondary data were collected from participant memorandums, the company website, central email software, and online social media posts supporting the theme interpretation through methodological triangulation. The findings on these Orlando leaders revealed that supportive leaders improved employee engagement, direct communication improved employee engagement, and training improved employee performance. Improving employee engagement contributes to social change because small retail managers can use the findings to improve employee engagement through the implementation of effective strategies, direct communication, and training initiatives.
\end{abstract}


Effective Strategies Small Retail Leaders Use to Engage Employees

by

Janet L. Deskins

MBA, Western Governors University, 2014

BS, Western Governors University, 2013

\author{
Doctoral Study Submitted in Partial Fulfillment \\ of the Requirements for the Degree of \\ Doctor of Business Administration
}

Walden University

December 2017 


\section{Dedication}

I dedicate this doctoral study to my Lord and Savior Jesus Christ for His grace and giving me the strength to complete this doctoral program. I also dedicate this degree to my loving husband Nelson for continually encouraging and providing me an opportunity to maintain a balance between my education, professional, and personal life. Your understanding, support, prayers, and wisdom allowed for my success. You never let me give up and continued to encourage me to keep pressing forward. You believed in me in my darkest hours. Your faith in our Lord has been my constant beacon. Additionally, my dedication goes to my mother and father, Peggy and Edward Laney. I include my sisters, Sherry and Lori, my mother-in-law, Blanca Deskins, and my entire family who continued to encourage me. I know there were times you had no clue of what I was talking about, but you smiled and let me ramble. Thank you all for praying for my continuing progress as well as believing in me. This journey has been long, yet rewarding, and would not have been possible without your prayers and encouragement. Finally, I dedicate this study to Dr. Gergana Velkova who became a household name. Without your guidance and setting the example from day one, I would not have completed this journey. 


\section{Acknowledgments}

I thank my committee members for their respective and professional efforts that guided me through this doctoral process. My extreme appreciation goes to my chair and mentor, Dr. Gergana Velkova, for providing timely replies and feedback, visual guidance, and constant encouragement to keep me engaged; particularly at times I felt like giving up. To my second committee member, Dr. Robert Miller, as my second professor at Walden University, your instruction made an impression on me, and I had to request you for the end of this journey. Thank you both for making me think deeper into what I wrote and for sparking reflective thinking with a new perspective on my interpretations. To the University Research Reviewer, Dr. Scott Burrus, for ensuring that my research study complied with the requirements of the university and the research community. Without the three of you and various other professors, this journey would not have been successful. Additional appreciation goes to Fred Walker, whose reassurance during my residencies inspired me to never give up this journey. Mr. Walker, you shared stories with me and provided an encouraging note of, "You are a role model for others, probably some people you may not realize". Also, to Dr. Al Endres for explaining that a "terminal degree' did not intend that I made a 'bad' decision. Dr. Endres, you made me laugh at myself and provided notable reminders during my first residency and in providing methodological guidance for my study. Furthermore, I thank Dr. Freda Turner for your kind assistance during both residency programs and your prompt feedback and encouragement to me throughout my time at Walden. I wish you all the best in your recent retirement. 
Table of Contents

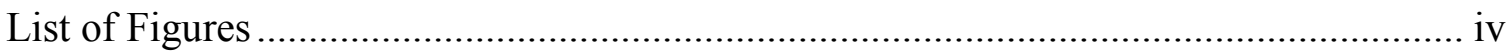

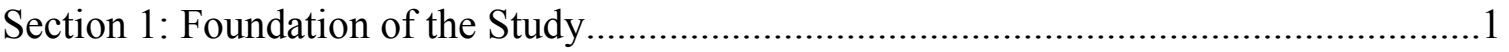

Background of the Problem ..................................................................................

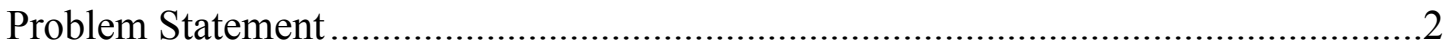

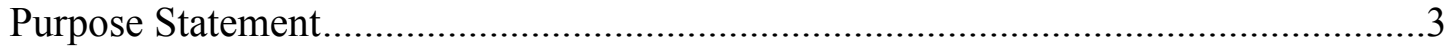

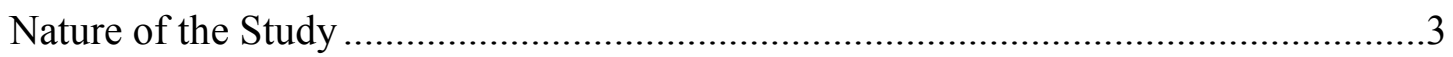

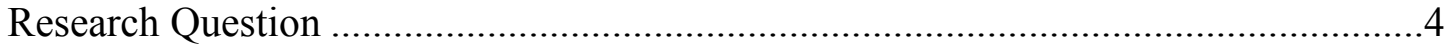

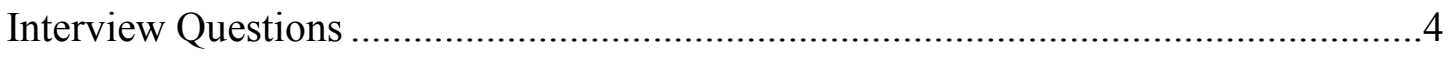

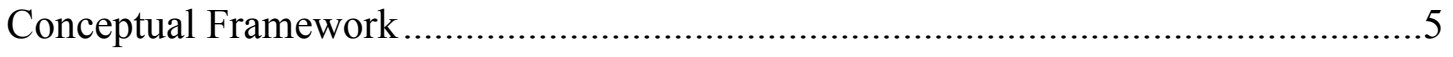

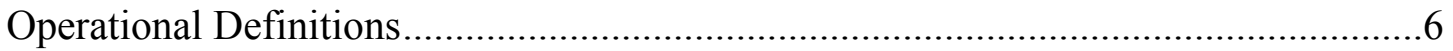

Assumptions, Limitations, and Delimitations.................................................

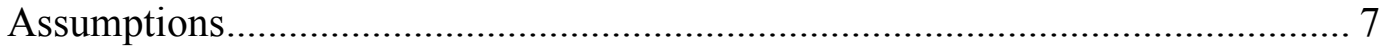

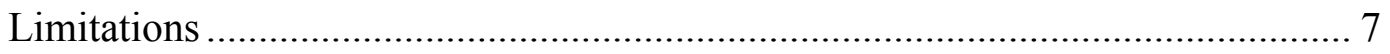

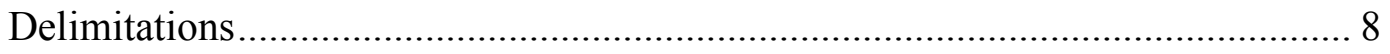

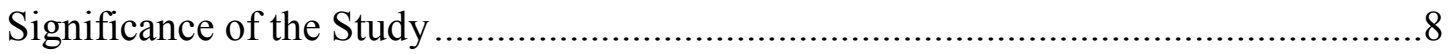

Contribution to Business Practice .................................................................. 9

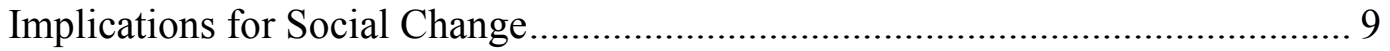

A Review of the Professional and Academic Literature.......................................... 10

Organization of the Literature Review ..................................................... 12

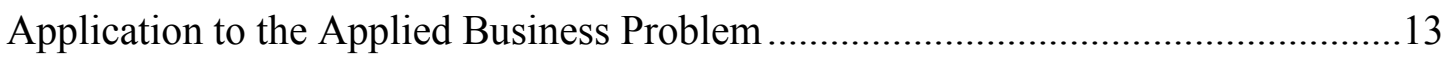

Kahn's Personal Engagement Theory ....................................................... 14 
Broaden-and-Build Positive Engagement Theory ............................................... 17

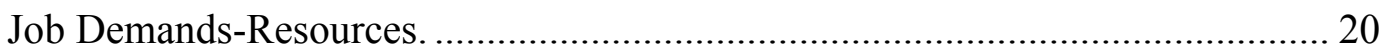

Employee Engagement Theory.............................................................................2

The Effects of Disengaged Employees ....................................................................29

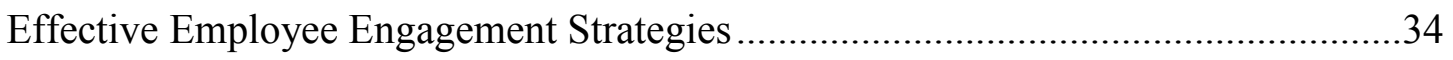

Factors That Enhance Employee Engagement ……………........................................40

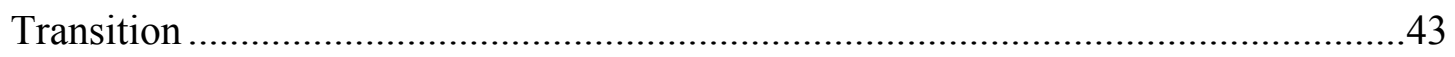

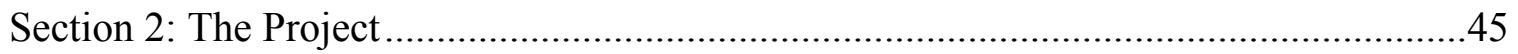

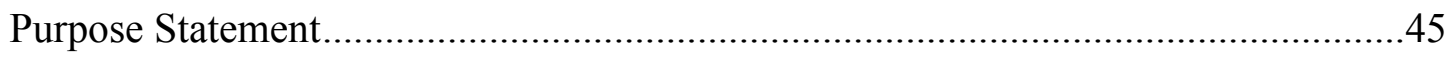

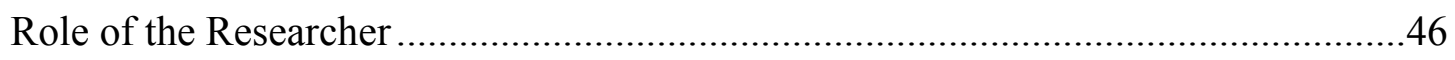

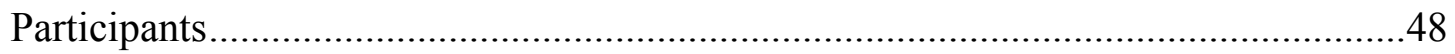

Research Method and Design .............................................................................50

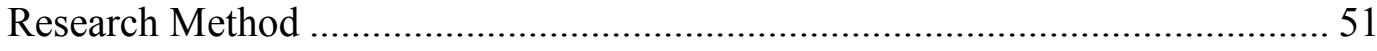

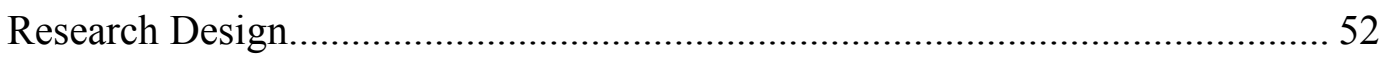

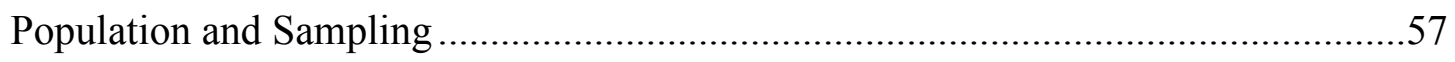

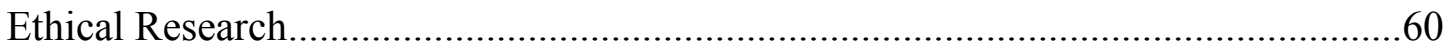

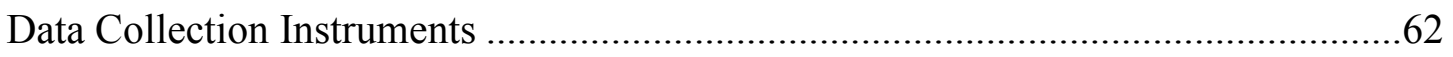

Data Collection Technique …………………………......................................64

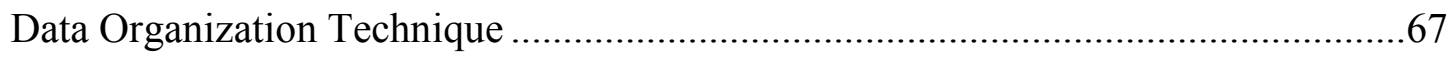

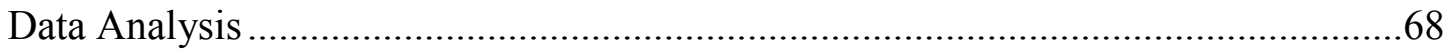

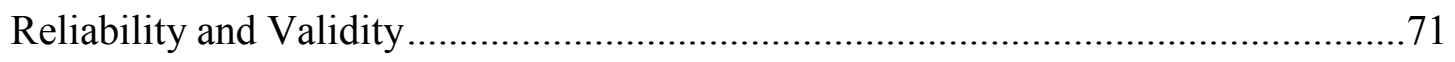

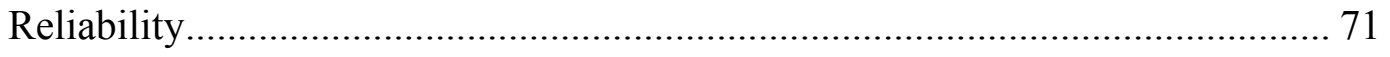


Validity 73

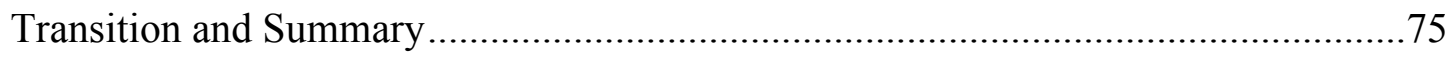

Section 3: Application to Professional Practice and Implications for Change ……...........77

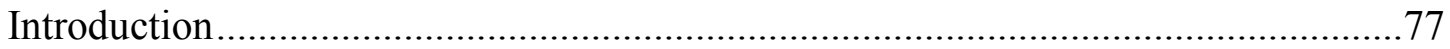

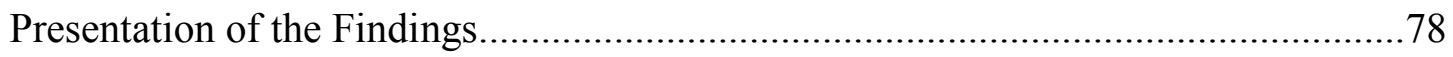

Applications to Professional Practice …………………............................................91

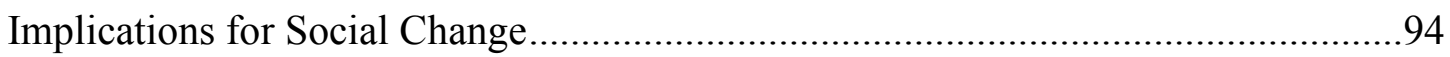

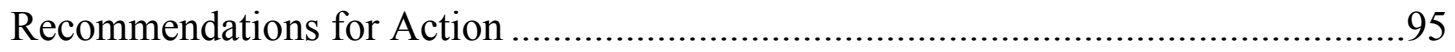

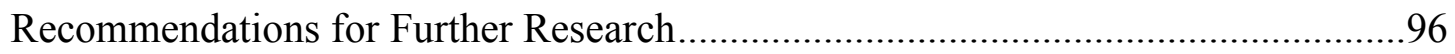

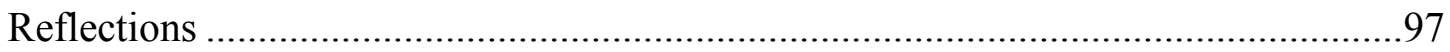

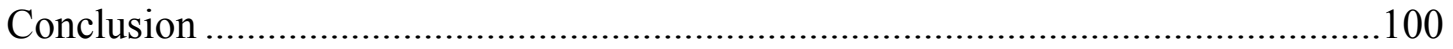

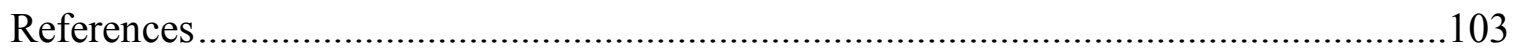

Appendix A: Interview Questions .............................................................................145

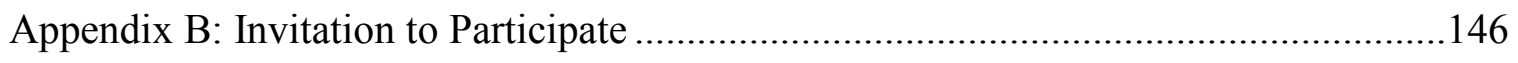

Appendix C: National Institutes of Health Office of Extramural Research

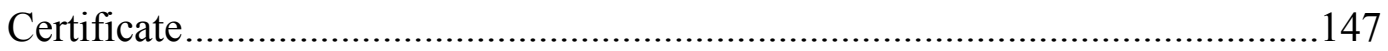

Appendix D: Interview Protocol.........................................................................148 


\section{List of Figures}

Figure 1. 5-year (2012-2016) employee engagement increases in the company .............82 
Section 1: Foundation of the Study

Employee disengagement is at an all-time high in the North American workplace and leads to what is known as an engagement gap (Saks \& Gruman, 2014).

Disengagement hinders the productivity of the employee and prohibits an effective workplace environment (Hollis, 2015). When employees become disengaged, they withdraw and defend themselves and promote a lack of connectedness and emotional absence (Shuck, Adelson, \& Reio, 2016). High levels of employee engagement provide enhanced job performance, effective commitment, and organizational citizenship behavior, which improve workplace productivity (Albrecht, Bakker, Gruman, Macey, \& Saks, 2015).

\section{Background of the Problem}

Researchers have discovered that employee engagement provides a positive working environment in terms of productivity and competitiveness (Shuck \& Reio, 2011). Managers who choose to attract and retain high-caliber, committed, productive, and engaged employees should provide strategic methods to meet the working contexts of the role expectations and a subsequent working environment (Albrecht, Bakker, Gruman, Macey, \& Saks, 2015). An ethical leadership style from managers creates a moral guidance and encourages employees to interact with coworkers respectfully, thereby, developing and building a trustworthy workplace environment (Babalola, Stouten, Euwema, \& Ovadje, 2016).

Companies that have been studied have revealed an increase in employee engagement when managers provided safe workplace practices and a genuine concern for 
the well-being of their employees (Vitt, 2014). Employees have displayed improved personal accomplishments and an overall connection to well-being when company managers implemented a healthy workplace climate through strategic leadership practices (Shuck \& Reio, 2014). Organizations that provided managers with clear, effective, and principled leadership training provide employees with stability, safety, and psychological meaning to their work tasks (Nel, Stander, \& Latif, 2015).

Employee engagement is a positive tool to aid organizational leaders to strive and gain a competitive advantage (Anitha, 2014). Companies can gain a competitive advantage when their employees are engaged in their work and believe they can positively influence the success of the organization (Kumar \& Pansari, 2016). Employee engagement influences the organizational climate when managers embed strategic practices such as personnel selection, socialization, performance management, and training and development of the employees (Albrecht et al., 2015). Job and organizational engagement indicate positive job satisfaction, organizational commitment, reduced intentions to quit, and organizational citizenship behavior (Saks \& Gruman, 2014).

\section{Problem Statement}

Approximately $70 \%$ of North American workers are disengaged in the workplace, which results in low productivity (U. S. Merit Systems Protection Board, 2015). Disengaged employees cost businesses between $\$ 450$ to $\$ 550$ billion annually (Vitt, 2014). The general business problem that I addressed in this study is that disengaged employees contribute to decreased productivity, which can negatively affect 
organizations' profits. The specific business problem that I addressed in this study is that some small retail business leaders lack strategies to engage employees in the workplace.

\section{Purpose Statement}

The purpose of this qualitative descriptive study was to explore strategies that some small retail business leaders use to engage employees in the workplace. The population of the study consisted of five small retail business managers located in Orlando, Florida, who have implemented strategies to engage employees. The implications for positive social change include the potential to enhance leaders' understanding of effective strategies necessary to increase employee engagement, which may lead to positive social behaviors of employees who can volunteer their time to assist people in the community and society.

\section{Nature of the Study}

The qualitative approach is a method researchers use for exploring and gaining knowledge of how individuals have experienced a phenomenon (Baskerville \&WoodHarper, 2016). In a quantitative method, researchers test predetermined hypotheses (Yin, 2014). Researchers who use a mixed-method approach combine qualitative and quantitative data and paradigms to develop plausible answers to research questions (Wong \& Cooper, 2016). The quantitative method was not appropriate for this study because I did not test hypotheses. The mixed method was also not appropriate for this study because of the quantitative component requirement to examine relationships or differences among variables. 
The design that I selected for this study was a single case study. Using the narrative design approach allows the researcher to gather and restate the life stories from individuals (Lewis, 2015). Narrative design was not appropriate because participant life and family experiences were not the focus of my study. A phenomenological design involves the researching and understanding of the participants lived experiences in a specific phenomenon (Gustafsson, Nyström, \& Palmer, 2017). The phenomenological design was not appropriate for this study because the focus of this study was not on the lived experiences of participants. A researcher conducts a case study as an empirical inquiry to investigate the case or cases and understand a phenomenon (Yaghmaei \& Brem, 2015). By conducting a single case study design, I collected data from multiple participants to explore the strategies managers use to improve employee engagement in the workplace. Researchers use a case study design to gather in-depth information from participants to identify, explore, or examine a critical problem (Koenitz, Ferri, Haahr, Sezen, \& Sezen, 2015).

\section{Research Question}

The central research question for this study was as follows: What strategies do some small retail business leaders use to engage employees in the workplace?

\section{Interview Questions}

1. What engagement strategies do you use to engage the employees in your company?

2. How have the employees responded to the utilized engagement strategies?

3. How has employee engagement affected productivity? 
4. What engagement strategies have you discovered to be the most successful?

5. What engagement strategies have you revealed to be the least successful?

6. How has employee engagement affected employee morale in their work tasks?

7. How do you assess the effectiveness of the strategies for employee engagement?

8. What barriers did you encounter to implementing the strategies, and how did you address the implementation barriers?

9. What additional information would you like to provide regarding the engagement strategies utilized to improve employee engagement?

\section{Conceptual Framework}

Shuck and Reio's (2011) employee engagement theory served as the conceptual framework of the study. Shuck and Reio (2014) expanded on Fredrickson's (1998) broaden-and-build theory of positive emotions and Kahn's (1990) theory of engagement, because the employee engagement theory pertains to the workplace climate, employee engagement, and indicators of employee well-being. The employee engagement theory suggests that employees engage in their workplace environment when upper-echelon leaders orchestrate the firm's resources into a unique motivational capability (Barrick, Thurgood, Smith, \& Courtright, 2015). The three key constructs underlying the employee engagement theory are (a) cognitive engagement, (b) emotional engagement, and (c) behavioral or physical engagement at work (Barrick et al., 2015). Rana, Ardichvili, and Tkachenko (2014) noted that organizational leaders use Shuck and Reio's (2011) theory to predict financial performance levels based on employee engagement. Sarti (2014) noted that an employee's opportunities for development in learning and personal growth 
could affect employee engagement. Furthermore, Shuck and Reio (2014) observed that the key employee engagement constructs represent the intention to act and encompass motivation-like qualities separate from constructs such as job satisfaction and organizational commitment. The employee engagement theory served as a potential lens through which I explored participants' perceptions and experiences to improve employee engagement. Shuck and Reio's (2011) employee engagement theory aligns with my study by providing a potential means for understanding the strategies that retail leaders use to improve employee engagement.

\section{Operational Definitions}

Employee engagement: Employee engagement is the level of commitment and involvement an employee adheres to within the organization and toward his or her work roles (Anitha, 2014).

Employee productivity: Employee productivity refers to the worker's ability to meet or exceed the agreed upon job duties with the provide resources (Bufquin, DiPietro, Orlowski, \& Partlow, 2017).

Personal engagement: Personal engagement is the harnessing of an employee's self to their work roles through physical, cognitive, and emotional means (Kahn, 1990). Profitability: Profitability refers to the revenues that an organization makes after deducting expenses (Janský \& Prats, 2015).

Strategies: Strategies are the conscious application of movement or actions made in planning the organization of one's learning (Frese \& Keith, 2015). 


\section{Assumptions, Limitations, and Delimitations}

\section{Assumptions}

Assumptions in research are the internal beliefs and assumptions that the scholar brings to the exploratory effort (Seidman, 2013). Butler, Delaney, and Spoelstra (2017) noted that the researcher should root their presupposed understanding of validity in the problematized assumptions of qualitative research and institute valid approaches to his or her interpretation of the data. I made the following assumptions for this study: (a) some small retail managers use effective strategies to engage employees in the workplace, (b) the participants provided truthful responses about their workplace experiences, and (c) interviewees provided truthful information that helps answer the central research question.

\section{Limitations}

Limitations are potential weaknesses in research studies (Deb et al., 2016). In qualitative research, limitations are inadequacies, circumstances, or influences that place restrictions on the researcher's study (Silverman, 2013). The limitations in research prohibit a perfect or unbiased quality of judgment (Haustein \& Larivière, 2015). Clement et al. (2015) deliberated that the researcher should focus the limitations in a study specifically on the problem under review. One limitation of this study is that participants may not recollect all the specifics related to the strategies used to implement employee engagement in the workplace. Another limitation is a participant's episodic memory, which may limit the individual to reconstruct their response, based on memory (Szpunar, Addis, McLelland, \& Schacter, 2013) and create a false response during the interview. 
Limits to a person's episodic memory reveal an inability to construct and mentally reexperience past incidents (Lind, Williams, Bowler, \& Peel, 2014). The limitations in replicating past events can be time-consuming and present challenges to the early researchers' findings (Clement et al., 2015).

\section{Delimitations}

Delimitations can be defined as the scope or boundaries that the researcher sets for the investigative study (Svensson \& Doumas, 2013). A researcher has control over the delimitations of the research project. The first delimitation in this research was the geographical locations; all participants were from Orlando, Florida. Another delimitation was the target population. Only small retail business managers who had experience implementing effective employee engagement strategies participated in this study. The third delimitation was sample size. A restriction of qualitative research is in the small sample size addressed because a researcher needs more time to collect the qualitative data (Yin, 2014). The final delimitation was the industry; I investigated only effective employee engagement strategies in the small retail industry bounds or scope of the study.

\section{Significance of the Study}

Employee engagement is essential to productive business practices because employee engagement influences productivity and sustainability (Shuck \& Reio, 2011). Engaged employees bring three essential elements to the organization through productivity, reduced attrition, and profitability (Saxena \& Srivastava, 2015). Productive and profitable companies can bring positive change to their communities through social investment programs, such as sponsorships, charitable donations, and programs where 
specific dollar amounts allocate monies (Adams, Potter, Singh, \& York, 2016). Employee engagement is crucial to the success of retail businesses because employee engagement leads to increased productivity (Shuck \& Reio, 2011), which enables organizations to affect their communities through positive social change.

\section{Contribution to Business Practice}

Although researchers are exploring employee engagement, the concept is underdeveloped and still emerging in scholarly research with minimal agreed-upon definition and few validated measures (Shuck \& Reio, 2011). Employee engagement, according to Shuck and Reio (2011), has become the keystone to business success. Employee disengagement has a negative effect on the profitability and productivity of retail businesses (Karatepe \& Aga, 2016). Disengaged employees cost companies billions of dollars in lost productivity and negatively affect the atmosphere of other workers (Hollis, 2015). The findings from this study could provide new insights on effective employment engagement strategies that might assist retail leaders to improve employee engagement and increase profitability and productivity.

\section{Implications for Social Change}

Successful businesses create opportunities that can bring positive social change to

the communities they serve (Crane, Palazzo, Spence, \& Matten, 2014). Organizations can bring positive social change in many ways, such as motivating and training community members, receiving input on projects for improvements, and creating new employment (Stephan, Patterson, Kelly, \& Mair, 2016). Employee disengagement threatens organizational profitability and productivity (Hollis, 2015) and affects companies' ability 
to contribute to their communities. Employee disengagement reduces the revenue of small retail businesses and prohibits revenues intended for organizational activities, such as increasing the efficiency of the value chain and pricing power, sustainability initiatives, creating goodwill in the communities, and addressing the needs of low-income populations (Santos, Pache, \& Birkholz, (2015). Improving employee engagement enables leaders within an organization to enhance company profitability and productivity, which in turn can lead to new opportunities in employment and sustainability efforts to serve low-income families and their communities.

\section{A Review of the Professional and Academic Literature}

The purpose of this qualitative descriptive study was to explore strategies that some small retail business leaders use to engage employees in the workplace. Employee engagement, as described by Anitha (2014), is an effective tool that organizational managers can strive to achieve to gain a competitive advantage within their industries. A researcher can gain knowledge on employee engagement but must understand how work conditions may encourage positive job performance that affects the employees' experience of being engaged (Shuck, Collins, Rocco, \& Diaz, 2016). Leaders who strategically implement positive employee engagement practices experience enhance employee job performance, organizational citizenship behaviors, higher productivity, and advanced levels of employee commitment (Popli \& Rizvi, 2016).

I reviewed published academic literature on employee engagement that appears in various peer-reviewed journals, websites, dissertations, government reports, and seminal scholarly books. Google Scholar links to Walden University's Library database and 
served as my primary resource for finding journal articles. I used Walden University’s Library database to acquire literature through Business Source Complete/Premier, EBSCO Primary, Academic Source Complete, ABI/INFORM Global, Psych ARTICLES, Emerald Management, ProQuest Central, Education Source, EBSCO Open Access Journals, Sage Premier Annual Reviews, SciDirect Subject Collections, and ScienceDirect. Key terms that I used in my search included effective employee engagement, manager strategies, employee productivity, and leader employee engagement strategies. The employee engagement theory, as described by Shuck and Reio (2011), is the basis for the discussion of the literature review. I used themes in the organization of the literature review. These themes include management strategies in employee engagement, effective leadership practices in employee engagement, employee engagement, and employee productivity.

I gave preference to Google Scholar, which connects to the Walden Library's database and provides peer-reviewed articles for my investigation. The literature review consists of 103 studies, of which 97 (94.17\%) were published between 2013 and 2017; six $(5.83 \%)$ of the studies were older than 5 years. The entire study consists of 273 citations; 93.8\% were from peer-reviewed articles published between 2013 and 2017; 1\% was from dissertations, and the remaining 5.2\% consisted of non-peer-reviewed sources or articles published before 2013. Although there is extensive information on employee engagement, I discovered a gap in studies examining managers who use effective strategies to improve employee engagement in the workplace. 


\section{Organization of the Literature Review}

The literature review section begins with an opening narrative that includes a brief discussion of the literature with a critical analysis and synthesis of various sources from scholarly articles, journals, and seminal books. In the next section, I focus on the application of the literature as it pertained to the research question and include a brief description of the purpose of the study. The themes that I selected to research and discuss in this literature review included management strategies in employee engagement, effective leadership practices in employee engagement, employee engagement, and employee productivity through engagement. I reviewed previous research and findings and implemented similarities with this study.

The management strategies in the employee engagement theme included a detailed investigation and synthesis of the framework for employee engagement, which allowed me to use two supporting theories from relevant literature on the topic of employee engagement. The first theory includes a review of the relevant theory of personal engagement (Kahn, 1990). The second theory includes the in-depth employee engagement framework by Shuck and Reio (2011). In the employee engagement construct, I discuss shared findings by researchers which relate to the construct, as well as various definitions, antecedents, and strategies of effective employee engagement practices by managers. The antecedents uncovered may include both individual and organizational levels (Popli \& Rizvi, 2016). I conclude the section with a discussion on employee engagement and focus on effective management strategies toward effective employee engagement. 


\section{Application to the Applied Business Problem}

The purpose of this qualitative descriptive study was to explore strategies that some small retail business leaders use to engage employees in the workplace. Researchers have found that approximately $30 \%$ of North American workers are engaged in the workplace (U. S. Merit Systems Protection Board, 2015). My primary focus during this research study was not to assess engagement levels, but to develop a thorough understanding of employee engagement strategies that managers use in the retail industry workplace. Developing an understanding of employee engagement strategies requires a qualitative approach, more specifically a descriptive single case study. The findings from my study could deliver insight into the lived experiences and the underlying meaning of employee engagement from managers' perspectives.

The findings of this study may assist managers with the creation and implementation of effective employee engagement strategies. The understanding, creation, and implementation of strategic practices may help managers use operative employee engagement approaches in the workplace. Managers who increase employee engagement provide a strategy for organizational success (Popli \& Rivzi, 2016). For example, managers who train employees improve the service accuracy of those employees and therefore affect service performance and employee engagement practices (Anitha, 2014). Firm-sponsored activities offer managers an effective means to initiate strategies towards encouraging employee engagement (Glavas, 2016). The findings from the study might improve managements' business practices by identifying industry specific strategies that lead to highly engaged employees in the workplace. The 
implications for positive social change include the potential to enhance leaders' understanding of effective strategies necessary to increase employee engagement, which may lead to positive social behaviors of employees who can volunteer their time to assist people in the community and society.

According to research findings, more than $70 \%$ of employees in the United States do not feel engaged and withdraw from their roles in the workplace (Kahn, 1990; U.S. Merit Systems Protection Board, 2015). Actively engaged employees reveal a level of involvement and commitment towards the organization and its values (Srivastava, 2015). The engaged employee is more likely to be productive, remain with their current employer, and interact in a positive manner with customers (Shuck \& Reio, 2014).

\section{Kahn's Personal Engagement Theory}

Kahn (1990) first defined the personal engagement theory as the harnessing of the employees' selves to their work roles through engagement and in the expression of themselves in a physical, cognitive, and emotional manner of work performance. Organizational leaders encounter a challenge when they attempt to engage employees to improve productivity through job commitments (Hollis, 2015). The personal engagement concept integrates the idea that people need both self-expression and self-employment in their work lives (Kahn, 1990). In the engagement theory, employees are more engaged when they perceive congruence with the organization's values and purpose while feeling their own purpose matters (Glavas, 2016).

Kahn (1990) based his personal engagement theory on the 1960s works of Goffman, who suggested employees act out momentary attachments and detachments in 
their work role performances. Research involving the psychological workplace climate was developed from Kahn's engagement theory (Shuck \& Reio, 2014). Employee workplace beliefs include personal evaluations of their work and the interaction between their personal and social circumstances (Karimi, Brazier, \& Paisley, 2017).

Transitory face-to-face encounters allow scholars a desired concept to fit within the realm of the organizational work life (Kahn, 1990). Kahn began investigating the works of the 1922 psychologist Freud, 1961 sociologist Goffman, and 1957 sociologist Merton. People are intrinsically ambivalent about belonging to a group and continually pull and push themselves between internal and external conditions (Kahn, 1990). The concept of Kahn's personal engagement theory represents a comprehensive description where one invests affective, behavioral, and cognitive energies in the workplace and therefore provides a holistic view of their investment of self toward their work connection and work role (Barrick et al., 2015). Highly engaged employees prove to fulfill the requirements of their jobs effectively and researchers have indicated that engaged employees enjoy serving customers and prove to be emotionally stable when dealing with stressful situations (Karatepe \& Aga, 2016).

Huang et al. (2016) investigated the effect of the workplace climate on engagement and employee job satisfaction. Employee job satisfaction and job engagement are related concepts, but affective individual dimensions (Huang et al., 2016). According to Huang et al., engagement is an active or direct state whereby employees invest resources to reach a goal, and satisfaction is more of a passive feeling towards attaining an established goal. Kahn's (1990) theory of personal engagement was 
used by researchers to explain why employees become disengaged from their job or organization (Ford, Myrden, \& Jones, 2015). According to Offord, Gill, and Kendal (2016) Kahn's personal engagement theory to be an antecedent for workplace engagement and team performance.

George and Joseph (2014) expanded on Kahn's (1990) theory of personal engagement and realized managers need to work toward attaining engaged employees if they want the organization to survive. Employee engagement is one of a positive, fulfilling, work-related state of mind that characterizes vigor, dedication, and absorption (Kim, Khan, Wood, \& Mahmood, 2016). Job crafting can help reduce job boredom and increase workplace engagement (Harju, Hakanen, \& Schaufeli, 2016). Harju et al. (2016) found job crafting to psychologically generate meaning for an employee's current work and redefine his or her cognitive, task, and relational aspects of the job functions. Kahn's theory of personal engagement increases positive organizational behavior and drives the mental health or organizational citizenship behavior of employees (Chen \& Huang, 2016). Job engagement ebbs and flows because of how employees view their roles and in how they cope with internal ambivalences and external conditions (Hernandez \& Guarana, 2016). Researchers indicated that job crafting engages employees in their work and relational manners to develop a person-to-job fit ( $\mathrm{Lu}$, Wang, $\mathrm{Lu}, \mathrm{Du}, \&$ Bakker, 2014). Researchers argued that employees who proactively build their own work engagement using job crafting develop a source of personal satisfaction and development (Petrou, Bakker, \& den Heuvel, 2016).

Researchers have linked organizational trust and psychological empowerment to 
employee engagement, which aligns with Kahn's (1990) theory involving the individual's self-image (Ugwu, Onyishi, \& Rodríguez-Sánchez, 2014). A trusting environment can provide a mechanism through which an employee's sense of engagement is practiced in his or her job function (Downey, Werff, Thomas, \& Plaut, 2015). Employees who trust their supervisor resulted in higher work engagement and positive role models for employees to follow (Chughtai, Byrne, \& Flood, 2015).

According to Vaara, Sonenshein, and Boje (2016), storytelling involves an active exchange between the storyteller (supervisor) and the audience (employee). Corporate storytelling can be a valuable tool for supervisors to use to heighten employee engagement (Gill, 2015). Employees benefit the most from corporate storytelling by learning through their supervisor and ensuring efficiency and effectiveness through continuous efforts on the part of the employee and manager (Hillon \& Boje, 2017).

\section{Broaden-and-Build Positive Engagement Theory}

Fredrickson's (1998) broaden-and-build theory of positive emotions posits that an individual's physical, intellectual, and social resources support the model of positive emotions reviewed. People tend to grow vague when their emotions are positive and therefore became inactive through contentment (Frijda, 2016). Fredrickson noted that Frijda proved that employees transition toward what was termed free activation in an aimless method of engagement through the emotion of joy. Whereas joy creates the urge for people to play or be playful not only in physical and social play, but also intellectual and artistic play. Positive emotions build intellectual resources, according to Fredrickson, whose study is based off the attachment theory. The attachment theory involves the 
perspective of an early love relationship between an infant and caregiver, just as there should be such a positive attachment between the employee and organization (Fredrickson, 1998). Fredrickson stated that securely attached people have proved to engage in more independent exploration of their physical environment, thereby being more productive. Work environments need to provide protective boundaries for employees, so they can experience a non threatening or welcoming place of work without emotional fear or psychological harm (Shuck et al., 2016).

Positive engagement allows the employee an antithesis to job burnout and allows the work to become pleasant, fulfilling, and meaningful (Nimon, Shuck, \& Zigarmi, 2016). Optimistic leaders can empower their employees through short training programs and individual coaching by displaying examples of positive behavior toward a successful and positive employee engagement experience (Nel, et al., 2015). Positive organizational behavior is defined as the study and application of positively oriented individual strengths and psychological capacities that managers can measure, develop upon, and effectively manage for employee performance improvements in the workplace (Agarwal, 2014).

According to Isget, Algoe, Boulton, Way, and Fredrickson (2016), employee engagement is both cognitive and affective in nature. Kahn (1990) further noted how employees who experience a positive emotion are more likely to positively engage in their work. Lu et al. (2014) based their study on Fredrickson's (1998) broaden-and-build theory of positive emotion. Lu et al. discovered that Fredrickson's theory can broaden the 
momentary thought-action repertories of employees and aid in building a positive workplace of engagement (Albrecht et al., 2015).

Successful organizations provide managers who implement positive leadership that is supportive to employees and develops pathways toward positive employee engagement (Gill, 2014). Airila et al. (2014) used Fredrickson's (1998) theory and revealed that job resources and self-esteem coincide with an increase in positive work engagement. Ugwu et al. (2014) noted that employees link organizational trust and psychological empowerment to their positive behaviors of engaged within the organization. Fredrickson's study on the broaden-and-build theory inspired Mikulincer and Shaver (2017) to develop the engagement cycle to include attachment security. Through attachment security, a positive relation to higher levels of engagement can reduce anxiety and avoidance from employees (Byrne, Albert, Manning, \& Desir, 2017).

Employee engagement provides a fulfillment in work engagement and influences employee innovative work behavior (Agarwal, 2014). Lin, Chen, and Filieri (2017) divulged that the broaden-and-build theory suggests the experience of positive affect widens the scope of thoughts and actions, which build upon personal resources. The broaden-and-build theory of positive emotions allows researchers to find possible theoretical explanations that link work engagement and work ability (Airila et al, 2014). Employees develop personal resources over time when individuals are encouraged to explore and interact with the positive work environment (Gawke, Gorgievski, \& Bakker, 2017). 
Job demands-resources. Researchers consider the job demands-resources (JD-R) model as a leading job stress model among employee engagement (Schaufeli \& Taris, 2014). Researchers use the JD-R model to understand employee health and well-being factors by revealing a balance between positive resources and negative job demands (Schaufeli \& Taris, 2014). The JD-R theory is a flexible construct that a researcher uses in the work environment and allows him or her to examine either job burnout or work engagement (Bakker, Demerouti, \& Sanz-Vergel, 2014). Bakker et al. (2014) noted the JD-R model allows researchers to understand employee job burnout, explain, and predict work engagement outcomes.

Gordon, Demerouti, Bipp, and Le Blanc (2015) discovered that the JD-R model suggests the regulation of job demands is important to positively influence work performance. According to Trépanier, Fernet, Austin, Forest, and Vallerand (2014), the JD-R model proves how employees internalize their work experiences and helps predict the psychological gains or costs at work. Researchers who have used the JD-R model could predict that high job demands and low job resources create emotional exhaustion and burnout among employees within a year (Frins, van Ruysseveldt, van Dam, \& van den Bossche, 2016). Some researchers reported how organizational leaders may create favorable working environments that promote employee development and retention rates, as predicted by using the JR-R model (Gabel-Shemueli, Dolan, Suárez Ceretti, \& Nuñez del Prado, 2015).

Job resources are crucial influencers, as proven through empirical analyses by researchers who examined the determinants of work engagement (Sarti, 2014). 
Supervisor support, innovativeness, appreciation, and organizational climate are all key factors in providing job resources for employees and help them cope with the demands of their work load (Bakker, 2011). Lu et al. (2014) reported that engaged employees are not passive receivers of their work environment, but are proactive in creating changes and taking initiatives. The positive emotions or events that occur within individual resource building can become stronger under adverse conditions (Fredrickson, 1998). Researchers must be mindful in understanding that the JD-R model does not restrict itself to specific job resources and any demand or resource may affect employee engagement (Schaufeli \& Taris, 2014).

\section{Employee Engagement Theory}

Shuck and Reio (2011) introduced the employee engagement theory in human resource development. Byrne et al. (2017) noted there is no single definition of employee engagement and most researchers rely on Kahn's (1990) theory of personal engagement. Shuck and Reio based their theory on Kahn's personal engagement concept and created three separate facets: cognitive engagement, emotional engagement, and behavioral engagement. Shuck and Reio revealed that leaders must remain at the forefront of the emerging engagement conversation. In 2008, academy-sponsored conferences began publishing engagement proceedings and in 2009, the first article termed the phrase employee engagement in an Academy of Human Resource Development sponsored journal (Shuck \& Reio, 2011). Shuck and Reio remarked that employee engagement lacks a certain level of consistency in definition and application where some scholars view the term as a reconceptualization of other well-researched variables. Other 
researchers advocate and address the distinctiveness of employee engagement and leave a gap for scholarly exploration (Shuck \& Reio, 2011). A working relationship exists between employee engagement and job performance (Shuck \& Reio, 2014).

Shuck and Reio readdressed the development of employee engagement and found that poor workplace engagement deemed detrimental to organizations because of a decrease of employee well-being and productivity (Shuck \& Reio, 2014). Shuck and Reio's (2011) employee engagement theory includes the cognitive, emotional, and behavioral energy of the employee, and the authors found a transition beyond the traditional predictors of workplace performance and into employee job attitudes. The findings of the researchers revealed employee engagement as more predictive of task performance than intrinsic motivation, job immersion, and job fulfillment (Shuck \& Reio, 2014). The researchers noted a link of higher levels of employee engagement with an organization's overall revenue (Shuck \& Reio, 2014). Gilbert, Laschinger, and Leiter (2010) suggested evidence-based strategies where managers can empower employees and emphasize individual contributions toward organizational goals as pertinent steps in producing a positive workplace environment toward engagement.

Shuck and Reio (2014) claimed the consensus of employee engagement proved positive for organizations. Company leaders who implemented employee engagement strategies through enhanced recruitment and safe workplace practices revealed excellent retention rates, stronger customer relationships, and deeper organizational expertise by their employees (Vitt, 2014). Anitha (2014) identified work environment, leadership, team and co-worker relationships, training and career development, compensation, 
organizational policies, and workplace well-being as the driving factors towards employee engagement.

Employee engagement through a critical lens is one of privilege and power on who (a) controls the context of the work, (b) determines the experience of engagement, (c) defined the value of engagement, and (d) benefits from high levels of engagement (Shuck et al., 2016). Shuck et al. declared both the organization and employee benefit from the outcomes associated with the experiences of employee engagement. Employee engagement is a separate construct from job satisfaction, as it relates to the active, workrelated positive psychological state of the employee (Nimon et al., 2016). Barrick et al. (2015) revealed engagement as an organizational-level construct influenced by organizational practices that are motivationally focused. Sarti (2014) stated engagement as a characterization of vigor, dedication, and absorption.

Researchers communicated how a positive leadership has an indirect effect on the work engagement and job satisfaction of employees with life fulfillment through a psychological empowerment (Nel et al., 2015). Other empirical research has provided evidence on the utility of employee engagement beyond the traditional workplace performance, such as job attitudes (Shuck \& Reio, 2014). Leaders can address the workplace environment by evaluating the needs of the employees and create a positive impact of staff productivity (Hollis, 2015).

Bakker (2011) suggested that engaged employees could create their own personjob (P-J) relationship and increase their P-J fit perceptions. Even so, engaged employees might learn to increase their skills at work and meet or exceed the job requirements more 
effectively through a positive environment of psychological or financial rewards (Lu et al., 2014). Similarly, researchers discovered that employees recognized the importance of well-being, positive psychological, and eudemonic dimensions of engagement (Schaufeli \& Taris, 2014).

Employees are the backbone of the organization and workplace engagement is vital to the organization's success (George \& Joseph, 2014). Airila et al. (2014) studied work engagement over 10 years and found resourceful jobs and positive self-esteem play an important role in maintaining and promoting work ability and possibly decreasing employees' intentions to retire early from the organization. Successful employee engagement results in improved financial revenues to the organization as a positive construct and predictor of contextual performance above and beyond the positive effects of job satisfaction (Byrne et al., 2017).

Development of successfully engaged employees requires a certain amount of investment on behalf of the organization and its leaders (Shuck \& Rose, 2014). The investment from the organization goes beyond a monetary one and involves the strategic application by the company managers. Leadership strategies may be required by managers to challenge employees in difficulties and hardships for workplace success (Gawke et al., 2017). The service triangle indicates a relationship among the organization, the employee, and the customer (Popli \& Rizvi, 2017). Popli and Rizvi found engagement has a positive relationship to customer satisfaction. Therefore, a positive customer experience is derived from a more productive employee, improves customer service, and remains in their job longer (Byrne et al., 2017). 


\section{Employee Engagement}

Kahn (1990) created a distinction between the physical, cognitive, and emotional paths in which employees engage and disengage personally. The three facets of employee engagement suggest the construct consists of cognitive engagement, emotional engagement, and behavioral engagement (Shuck \& Reio, 2011). Shuck and Reio combined the works of researchers on the newly developing topic of employee engagement and set out to assist organizations in developing strategic methods of capturing their employees' attention, dedication, and longevity. By leaders implementing the facets of cognitive engagement, emotional engagement, and behavioral engagement, employees may experience positive emotions that draw them into an expansion of their human capital (Fredrickson, 1998). The three constructs of employee engagement are necessary conditions for employee engagement; mostly towards psychological meaningfulness, workplace safety, and employee availability (Barrick et al., 2015).

Cognitive engagement. The concept of cognitive engagement construct involves employees appraising their work environment on whether the work is meaningful and safe, as well as if there are adequate resources to complete their work (Kahn, 1990). Cognitive engagement is a delicate phenomenon that is both challenging to develop and tough to sustain because of the interpretation of the work environment (Shuck \& Reio, 2014). Shuck and Reio stated employees use the cognitive decision-making process to determine the overall worth of the circumstances in a silent effort to begin the process of work engagement. An employee's cognitive or intellectual resources may improve through a manager's strategic engagement within the workplace and may provide 
employees with a means of inspired exploration on the job (Fredrickson, 1998).

Employees become physically involved in their work tasks and cognitively vigilant while empathically connecting to others through their performance of the job and how they display what they think and feel (Kahn, 1990). An employees' cognitive engagement revolves around the way the employee understands their job, the company, and the environment of the workplace (Shuck \& Reio, 2011). Shuck and Reio (2011) stated that cognitive resources allow the employee to experience positive emotions to momentarily draw on the expansion of their human capital. Therefore, a joyous employee is more apt to be flexible, creative, and use critical thinking skills on the job (Shuck \& Reio, 2014). Researchers have discovered that cognitive flexibility presents a positive association between the employee's thoughts and manner of mental processing to complete the assignment (Wong et al., 2016). Once employees appraise the circumstances as a positive work encounter, they can move to the next process of emotional engagement (Shuck \& Reio, 2014).

Cognitive engagement is not a momentary or specific state, but a more persistent state that does not involve the focus on any one person, object, or behavior (Saks \& Gruman, 2014). The interactions are responsive and provide supportive attachments imparting a sense of safety, and provoke positive emotions (Mikulincer \& Shaver, 2017). Bakker (2011) noted that job resources become salient when high job demands expand employees' emotional and cognitive abilities.

Emotional engagement. Employee satisfaction is an emotional reaction of the employee engaging in the job circumstances and other work factors, such as the 
leadership qualities of the manager and cohesion of the co-workers (Kumar \& Pansari, 2016). The participation of engagement is a role of performance for the employee (Rana et al., 2014). Researchers suggest the level in which an employee engages on the job includes an emotional factor of engagement in work-related tasks (Shuck \& Reio, 2014). An employee's emotional bond in their work creates a willingness to involve personal resources such as pride, belief, and knowledge (Shuck \& Reio, 2011).

An employee's emotional engagement is a bond with their organization and is an important determinant of commitment and loyalty (Shuck \& Reio, 2011). An emotionally engaged employee has a positive attitude in the workplace, values the system, and goes beyond the call of duty to perform their role in excellence (Anitha, 2014). The selfmanagement process requires an employee to use and make sound decisions on the meaningfulness or purpose of their job and in the manner of making the right choice and in the right way (Saxena \& Srivastava, 2015). Researchers have proved that formally negative emotions from employees have been reversed into positive emotions of engagement with psychological actions of readiness (Fredrickson, 1998).

Researchers discovered the emotional engagement of employees to be a collective phenomenon which spreads from individual to individual (Rana et al., 2014). Other researchers' findings exposed that employees thrive on intrinsic rewards the employee may receive from the work performed and act as reinforcements to keep the employee actively self-managing and engaged in their work (Saxena \& Srivastava, 2015). Emotional engagement produces emotional responses from employees that lead to behavior patterns, or behavioral engagement actions on the job (Karatepe \& Aga, 2016). 
Behavioral engagement. Behavioral engagement is the most evident form of employee engagement (Shuck \& Reio, 2011). Researchers observed that cognitive and emotional engagement spawns the physical manifestation of discretionary behavioral engagement (Shuck et al., 2016). Circumstances within the job appear as fleeting contracts to the employee and if certain conditions are met, the employee deems these conditions as acceptable and can personally engage in moments of task behaviors (Kahn, 1990). The employee's perception of the job objective allows for a positive reaction of behavior based on the motivation from encouraging managers (Hackman \& Oldham, 1976).

Leaders who identify a style that works best for a situation and matches the expectations of the employees brings forth high levels of engagement for better work performance through improved employee behavior (Popli \& Rizvi, 2016). Changes in behavioral patterns occur during positive emotions and broaden a person's momentary thought-action repertoire (Fredrickson, 1998). Behavioral engagement allows the employee to broaden their available resources and openly display these behaviors in the workplace (Shuck \& Reio, 2014). Fredrickson further claimed certain positive emotions prompt individuals to abandon instinctive behavioral scripts and pursue innovative, creative, and unscripted paths of thoughts and actions. Positive behavioral engagement from employees may create an interaction with customers who may talk positively about the brand and recommend the brand or service to their family and friends (Kumar \& Pansari, 2016). Employee job performance satisfaction and high levels of commitment benefit the organization through positive behavioral engagement actions (Rana et al., 
2014). The social implications of behaviorally engaged employees predict a health working environment that reflects the social impact of the organization (Anitha, 2014).

\section{The Effects of Disengaged Employees}

Disengagement is a separation of the employee's self from work roles and a withdrawal from people and a need to defend themselves physically, cognitively, or emotionally in the workplace (Kahn, 1990). Disengaged employees are dangerous individuals who do not perform well on the job and demotivate other employees within the organization (Anitha, 2014). Disengaged employees withdraw physically and mentally in the workplace and fail to connect with co-workers (Kahn, 1990). When the employee does not believe in a perceived organizational support system, the employee becomes disengaged (Glavas, 2016). A form of bullying occurs in the workplace when a manager fails to analyze and address the disengaged employee (Hollis, 2015).

The disengaged employee focuses on the tasks they are to perform, rather than the goals of the organization (Anitha, 2014). When employees become disengaged, researchers have reported organizational revenue decreases because employees are not providing effective customer service (Kumar \& Pansari, 2016). Disengagement causes a personal, individual cost to the employee, as well as a detrimental revenue loss to the organization (Shuck \& Reio, 2014). As a petty thief steals cash, the disengaged employee steals the productivity of the organization (Hollis, 2015). Workplace disengagement cost American institutions $\$ 64$ billion annually (Hollis, 2015).

Even though Kahn (1990) coined the term of personal engagement, Buckingham and Coffman (1999) first referenced the term of employee engagement. Researchers 
conducted studies on how disengagement and knowledge sharing from supervisors compared engagement theory versus adaptive cost theory (Ford et al., 2015). Researchers use the moral disengagement theory to examine the relationship between a supervisor's moral disengagement and employee engagement perceptions of ethical leadership (Bonner, Greenbaum, \& Mayer, 2016). According to Ford et al. (2015) the relationship between engagement theory and the disengagement of employees come from a lack of knowledge sharing by managers who are too busy to share information with their staff. The lack of knowledge sharing by supervisors created disengaged employees in the workplace (Ford et al., 2015).

The reference to employee disengagement produces an uncoupling of selves from work roles (George \& Joseph, 2014). Disengaged employees struggle in work responsibilities and performance, morale, and in employees not taking advantage of available work resources (Offord, Gill, \& Kendal, 2016). The disengagement plight of employees reduces creativity and participation in the workplace and hinders innovation (Martinez, 2015). The cause of disengagement is imperative to supervisors because disengagement can lend itself to employees justifying unfair working conditions or high demands (Valentin, 2014). Disengagement is a critical element for supervisors to acknowledge and strategically work to achieve a sustainable organization (Kim et al., 2016). Researchers noted self-efficacy to have a stronger negative impact on disengagement than commitments to goals (Khan, Tang, \& Joshi, 2014). A weak association between employee satisfaction and workplace engagement creates a disconnect (Suriyankietkaew \& Avery, 2014). Disengaged workers create negative 
effects with financial and non-financial consequences to the organization (Byrne et al., 2017).

Disruptive employees. Workplace aggression has grown over the past 25 years and refers to both physical and psychological negative acts carried out against other employees or the organization (Suriyankietkaew \& Avery, 2014). Mobbing is a term used by behavioral scientists when unfriendly behavior occurs by employees in the workplace (Qureshi et al., 2015). Negative emotions intensify when people are under performanceoriented rules by management (Petrou et al., 2016). Mental distress contributes to be the underlying psychological effects of low self-esteem and causes disruptive patterns by the aggressive employee (Simpson, Byrne, Gabbay, \& Rannard, 2015).

Disruptive conflict behaviors require managers who implement resolution tactics with open discussions, respect for employees, and a moral awareness to address the disruptive behaviors (Babalola et al., 2016). Dissatisfied employees are more likely to express disruptive behaviors if they believe their current wages for the work they perform are too low (John, Lowenstein, \& Rick, 2014). According to Larkin and Pierce (2016), disengaged employees may be prone to illegal behaviors of misconduct of fraud, theft, and other wrongdoing. Employees can learn about unethical behavior from other coworkers and by the organizational acceptability of this behavior type (Larkin \& Pierce, 2016).

Poor employee performance. Inattentive employees are emotionally disconnected and lack concentration to perform their job in the workplace (Martinez, 2015). Ford et al. (2015) reported that employees who determined their job meaningless 
became disengaged in their work and organizational goals. Employees who lack responsibility for their work role do not go beyond the demands of the job task (Paillé et al., 2014). Disengaged employees are not able to identify with their work and therefore perform poorly (Bakker et al., 2014). When job demands are high, employees decrease their work performance and do not achieve their work goals (Schaufeli \& Taris, 2014). Employee job performance is indicative of the organization's financial or nonfinancial outcome and based on the direct link with the performance and success of the organization (Anitha, 2014). Employee performance may be hindered if the manager is overly judgmental towards the employee and fails to allow the employee to adapt and evaluate their own work performance (Petrou et al., 2016). A lack of managerial feedback and social support also contributes to poor employee performance on the job (Bakker, 2011). When workers have insufficient opportunities for development, do not receive regular feedback from supervisors, or cannot work on various tasks, they may become disengaged (Bakker et al., 2014).

Low self-esteem is another consequence of poor job performance and the way an employee evaluates themselves affects how engaged they are in their role and how they assess their work ability (Airila et al., 2014). Bonner et al. (2016) stated that moral disengagement of the supervisor leads to employees' perceptions of unethical leadership and poor job functions. A negative work relationship between the manager and employee, or the employee and other employees can lead to job burnout and poor work performance (Shaukat, Yousaf, \& Sanders, 2017). Disengaged employees underperform in their workplace roles (Saxena \& Srivastava, 2015). 
Simpson et al. (2015) noted that managers who continually criticized employees for poor work performance contributed towards the employee experiencing work-related stress that resulted in the deficient performance. Many companies have changed from instructor lead training programs for employees, to e-learning programs and rely on the employees to train themselves (Charlier, Guay, \& Zimmerman, 2016). Charlier et al. (2016) further stated that e-learning programs are only effective if the employee uses the software and applies what they learned to their job.

Financial consequences of disengaged employees. Wong, Soh, Chong, and Karia (2015) reported that evidence showed the financial health and viability of firms are directly impacted by employee engagement. The financial consequences of the organization are directly related to the disengaged employee (Christian \& Ellis, 2014). Disengaged employees demonstrate lower levels of daily engagement in the workplace and this disengagement reduces the organization's financial returns (Bakker, 2011). Rao (2017) found that employees who do not enjoy returning to the organization do not contribute their best and decrease the organization's bottom lines.

Researchers have proved that self-interest on the part of the employee is the blame for corporate financial ruin (Kish-Gephart, Detert, Treviño, Baker, \& Martin, 2014). Rose, Shuck, Twyford, and Bergman reported disengaged employees cost the United States economy approximately \$24 million annually in lost revenue, production, and innovation. Leaders who exhibit dysfunctional behavior patterns can cause the organization its most costly financial ruin (Rose et al., 2015). Brammer, He, and Mellahi (2015) associated corporate social responsibility with employee disengagement and 
documented that negative employee attitudes produce declined financial returns. Compensation systems and extrinsic incentives may generate perverse economic incentives as well as psychological and social responses that lead an employee towards illegal misconduct that costs the organization financial penalties (Larkin \& Pierce, 2015).

Companies with a weak organizational culture of disengaged employees do not generate healthy revenue (Samnani \& Singh, 2014). According to Rajini (2016), disengaged workers contribute to low revenues because of low productivity and scarce innovative ideas. Poor decision-making by management also leads to disengagement and reduces the organization's revenue (Miles \& Clieaf, 2017). Therefore, management's responsibility to find strategic ways to engage employees in the workplace and protect the organization's financial resources (Wong et al., 2015).

\section{Effective Employee Engagement Strategies}

Effective employee engagement strategies may include managers who implement meaningful work characteristics like self-actualizing work, social impact, feelings of personal accomplishment, and perceived ability to meet the employee's projected career goals (Shuck \& Reio, 2011). Gilbert et al. (2010) suggested engagement strategies to empower employees and emphasize individual contributions to organizational goals as important steps in producing positive workplace environments. Managers who focus on engaging employees may also engage customers through listening, servicing, and treating the customer in the best manner (Kumar \& Pansari, 2016). However, organizational leaders should ensure all levels of hierarchy are involved in fostering employee engagement to improve the cultural setting (Rana et al., 2014). 
Workplace practices of enhanced recruitment and safe work environments showed an increase of employee engagement with excellent retention, stronger customer relationships, and a deeper understanding of organization (Vitt, 2014). Managers who empower employees enhance employee feelings of self-efficacy (Nel et al., 2015). Researchers also proved that engaged employees present a competitive advantage in the marketplace for the organization (Glavas, 2016).

Moreover, engaged employees who analyze the strategic structure of their firm generate shared perceptions and collectively engage as a group (Barrick et al., 2015). Managerial support presents a positive contribution to the organization and a feeling of value to the employees (Shuck \& Reio, 2014). The role performed by employees reveals a dimension of self-expression and the use of skills within their designated roles (Kahn, 1990). Therefore, managers who offer a positive perception of the work environment present a supportive workplace for employee engagement (Anitha, 2014). Managers who reengage their employees through a thoughtful change intervention benefit the entire organization (Shuck \& Reio, 2011).

Effective employee engagement can lead to higher individual and organizational performance and outcomes (Albrecht et al., 2015). Managers are responsible for interpreting and executing organizational strategies, facilitating workplace changes, generating effective working environments, ensuring operations run efficiently, building up and motivating teams and individuals (Agarwal, 2014). Self-efficacy is partially the mediator between the manager's rated effectiveness and employee engagement (Ugwu et al., 2014). 
Communicate with employees. Communicating with people is a means to the manager figuring out the best method to respond to certain situations with employees (Kahn, 1990). Technology offers managers an effective way to communicate and engage with their employees (Men \& Hung-Baesecke, 2015). Managers can build trust with employees by implementing internal campaigns such as kick-off meetings, flyers and announcements via the company's intranet, and publishing articles in the company's magazine (Schaufeli \& Taris, 2014). Strategic managers work with employees to improve time management skills and help them learn effective communication skills to increase their job effectiveness (Byrne et al., 2017). According to Gordon et al. (2015), communication helps employees perform their daily work tasks and enhance both their and other's professional development.

Share knowledge. Communication of the manager's knowledge allows for knowledge sharing of the company's procedures with employees (Ford et al., 2015). Leadership traits include the manager's motives, values, social and cognitive ability, and knowledge; which they share with their employees (Offord et al., 2016). Researchers have found knowledge sharing and innovation encourage creativity and participation among employees (Martinez, 2015). Kahn (1990) stated effective leaders share their personal philosophy and vision with employees to build relationships. Knowledge sharing among team members also fosters individual and team creativity and employee engagement (Dong, Bartol, Zhang, \& Li, 2016). Internal knowledge sharing promotes proactive work behaviors where the behavioral characteristics of the employees reveal initiative, risk taking, and the introduction of innovative ideas (Gawke et al., 2017). 
Provide employee resources. Job resources refer to the physical, psychological, social, or organizational aspects of the job function that help the employee achieve their work goals (Balunde \& Paradnike, 2016). Sufficient job resources may provide employees with a sense of security to improve their engagement practices (Byrne et al., 2017). Job resources provide employees with greater learning opportunities and have direct effects on increasing work engagement (Sarti, 2014). Managers should seek resources to positively associate with employee engagement practices where employees can seek challenges to associate adaptivity and reduce demands from a negative environment (Petrou, Demerouti, \& Schaufeli, 2016). Job resources, along with the employees' personal resources, help to balance the employee's personal abilities and needs (Gawke et al., 2017).

Empower employees. Empowerment allows a person to feel the need to serve, aspire, and respect the power and receive the support of their supervisor (Mikulincer \& Shaver, 2017). Social media outlets allow employees to articulate their opinions and engage in a more personalized and intimate relationship with the organization (Men \& Hung-Baesecke, 2015). Transformational leaders empower their employees, and provide a leader-member exchange, influence forms of engagement in the workplace (Saks \& Gruman, 2014). Therefore, empower your employees and give them freedom to make decisions, respect their failures, and let them learn lessons from those failures so they can become successful leaders (Rao, 2017).

Encourage employees. Employees with low morale are likely to view their manager as disengaged and unethical (Bonner et al., 2016). Adequate salary and career 
opportunities may provide employees with the motivation to engage in high work performance (Balunde \& Paradnike, 2016). Some managers may use a reward system to encourage and stimulate employees to engage in their job functions (Peng et al., 2016). Managers should pay attention to improving their personal integrity as employees soon discover their manager's integrity builds their own engagement and improves citizenship behaviors (Reunanen, Penttinen, \& Borgmeier, 2017).

Build trustworthiness. Researchers noted that without trust, employees focus on placing blame on others, miss deadlines, fail to service customers efficiently and fail to deliver positive results (Rao, 2017). Transparency among management builds a relationship of trust with the employees (Men \& Hung-Baesecke, 2015). Employee engagement, as an organizational strategy should be a leadership goal of managers that involves all members of the organization and one that offers a supportive culture and builds on trust (Popli \& Rizvi, 2017). When managers provide consistent responsiveness and attention, individuals develop positive internal processes of trustworthiness (Byrne et al., 2017). Trust in the supervisor creates the development of an employee's social capital outcome and positive attitudes and behaviors (Lapointe \& Vandenberghe, 2016). Employees who believe in the wow factor in their work environment are more likely to lead results and transfer the excitement and engagement forward to others (Reunanen et al., 2017). Trust allows individuals to fulfill their job roles in an efficient manner (Trépanier, 2014).

Link engagement to high performance. Employee engagement is a motivational state where employees invest themselves emotionally, cognitively, and physically in their 
work role (Kahn, 1990). Employees who demonstrate high performance skills in their job are more likely to further develop their cohesion levels and be a benefit to the entire organization in future tasks (Rodríguez-Sánchez, Devloo, Rico, Salanova, \& Anseel, 2016). Managers can customize individual performance levels for each employee and in turn, create influence follower development by communicating lofty expectations and stimulate followers' intrinsic needs for growth (Dong et al., 2016). High performers want to believe their work is meaningful and believe they can give and receive in their work role (Kahn, 1990). Superior job performance boosts employee engagement and selfefficacy because it encourages motivation-enhancing experiences of excellence and success (Schaufeli \& Taris, 2014).

Lead by example. Managers who lead by example provide the most effective implementation of employee engagement (Bernard, 2016). Leaders need to lead by example if they are to expect their employees to engage in their job role (Fortenberry \& McGoldrick, 2016). Effective leaders emphasize common grounds, shared values, and ideology to employees by articulating a compelling vision, developing acceptance of collective goals, and establishing themselves as a role model for the team (Dong et al., 2016). Employees observe managers and respond well to leaders who lead through example (Zhu, Treviño, \& Zheng, 2016).

A responsive leader repeats interactions with responsive and supportive actions to their employees and creates a cohesive pattern where the employees can psychologically function on the job (Mikulincer \& Shaver, 2017). Effective leaders also leverage the talents of others so business-oriented leaders can focus on their business roles within the 
organization and perform their tasks more efficiently (Rucker, 2017). A leadership strategy with a scheme of effective nurturing and collaborative capabilities draws employees towards engagement in their work roles (Beckmann, 2017). Inspirational leaders close the gap between themselves and employees and develop positive employee engagement in the workplace (Rao, 2017).

\section{Factors That Enhance Employee Engagement}

Employee engagement is a level of commitment and involvement an employee has towards their organization and company values (Anitha, 2014). According to researchers, many leaders are turning to scholars to test strategies on how to develop an engaged workforce (Shuck \& Reio, 2011). Job crafting links work engagement and opens opportunities for individuals to expand their career (Lu et al., 2014). A fair pay structure creates a sense of self-efficacy for the employee and promotes employee engagement (Olafsen, Halvari, Forest, \& Deci, 2015). Shuck, Adelson, and Reio (2016) noted how engaged employees bring their whole selves into their work roles. Kahn's (1990) personal engagement foundation reveals that engaged employees show cognitive attentiveness, become emotionally vested, and are physically energetic in the work environment.

Leadership. Leadership was an important criterion identified through research as a fundamental factor to employee engagement (Anitha, 2014). Researchers suggested leadership as one of the largest factors affecting employee perceptions and the workplace and workforce engagement actions (Popli \& Rizvi, 2016). Effective leaders translate 
organizational systems to their employees and reinforce their behaviors to create different degrees of supportiveness and openness (Kahn, 1990). Kahn further stated supportive managers create a supportive environment that allow employees to try and to fail without fear of the consequences. Leaders who inspire employees create trust through civility, honest communication, and concern towards a healthy workplace (Hollis, 2015). Managers should recognize and implement focal areas of employee development that require immediate attention (Kumar \& Pansari, 2016).

Organizational leaders can enhance employee engagement through effective use of current resources or in purchasing external resources and develop new capabilities to create improved employee and customer value (Barrick et al., 2015). The positive leadership role of managers in an organization help develop reliable and valid perceptions by the employees towards their work environment (Nel et al., 2014). Managers need the ability to facilitate directions to employees in a manner of collaboration; instead of enforcing the power of one over another (Shuck et al., 2016). When employees are encouraged and supported by their managers, they are willing to engage in the workplace environment to help their organization achieve functional and social success (Paillé et al., 2014).

Fair pay. Workers associate fair compensation with task assignment and task completion (Borromeo, Laurent, Toyama, \& Amer-Yahia, 2017). Fair compensation systems attract and retain valuable employees based on their heterogeneous ability, motivation levels, and social relationships (Larkin \& Pierce, 2015). Samnani and Singh (2014) reported that performance-enhancing compensation practices help to increase 
employee productivity through greater accountability.

Employees tend to engage in their work efforts based on what they consider fair wages (Cohn, Fehr, Herrmann, \& Schneider, 2014). According to Borromeo et al. (2017), engaged workers may contribute more than their disengaged counterparts if they believe their wages are fair. Larkin and Pierce (2016) noted that fair wages encourage engaged employees to work harder, obtain promotions in the workplace, and increase their psychological well-being.

Responsible organizational leaders influence a culture that drives employee engagement and compensates their workers to ensure fairness and employee satisfaction in the workplace (Taneja, Sewell, \& Odom, 2015). Compensation motivates an employee to achieve more and therefore focus more on their work and personal development within the organization (Anitha, 2014). Therefore, compensation systems represent a critical influence and driver of employee attitudes and behaviors towards employee engagement in the workplace (Samnani \& Singh, 2014).

Cultural diversity. A healthy working environment should consist of a moral cultural diversity that includes an effective team, an attentive manager, job security, a sustainable compensation package, proper resources, and a safe working environment (Anitha, 2014). Productive and successful firm cultures are comprised of skillful employees who perform routines with knowledge of organizational processes and a full understanding of the daily operations (Charlier et al., 2016). Kish-Gephart et al. (2014) stated that fairness generates moral standards and honest motives across corporate culture. 
Effective employee engagement affects all work groups, industries, and organizational cultures and requires dedication from managers and employees (Shuck et al., 2016). Employee engagement combines an affective commitment and intrinsic motivation between an employee's attachment and relationship with the organizational culture and colleagues (Taneja et al., 2015). Organizational culture influences whether an employee chooses to engage in their work and is based on the work environment (Reis, Trullen, \& Story, 2016). The key competitive advantage of a firm is to attract top talent, apply strategic practices, develop respectable leadership, and engage employees within a healthy organizational culture of motivated employees (Evangeline \& Ragavan, 2016).

\section{Transition}

In this section, I introduced the business problem and provided context for the study. The section included the problem statement and the purpose statement as well as a discussion of the nature of the study, the central research question, interview questions, the conceptual framework supporting this study, and the contribution the research makes toward social change and strategies managers can use to engage employees. Operational definitions relevant to the study, as well as the assumptions, limitations, and delimitations for the study provided context. The literature review includes an exhaustive analysis of current research relevant to strategic employee engagement theories and includes several additional theories for contrast toward the development of employee engagement practices, as well as themes used in the literature review to gain a thorough understanding of the research topic. Section 2 includes supplementary information on the research methods and designs, population and sampling, ethical matters, the role of the procedures 
chosen for this study. Additional components contained in this section revealed my role as the data collection instrument and provide detailed information about the data collection, data collection technique, data organization techniques, and the data analysis process. Furthermore, I identified and discussed strategies for increasing reliability and validity toward the research. Section 3 includes a presentation of the findings, applications to professional practice, implications for social change, recommendations for action and further research, and the reflections and conclusion. 
Section 2: The Project

The engagement level of employees in the organization affects the levels of their organizational productivity (Shuck \& Rose, 2014). The purpose of conducting this qualitative case study was to examine the strategies that small retail business managers use to engage employees in the workplace. I selected participants based on their years of experience working in the retail industry. In Section 2, I begin with the purpose statement for the study. A discussion on my role as the researcher follows, followed by an overview of the participant criteria. Included in this section are the research methodology, research design, population and sampling, participants, ethical research, data collection instruments, data collection technique, data organization technique, data analysis, and reliability and validity of the research.

\section{Purpose Statement}

The purpose of this qualitative descriptive study was to explore strategies that some small retail business leaders use to engage employees in the workplace. The population of the study consisted of five small retail business managers located in Orlando, Florida, who implemented strategies to engage employees. The implications for positive social change include the potential to enhance leaders' understanding of effective strategies necessary to increase employee engagement, which may lead to positive social behaviors of employees who can volunteer their time to assist people in the community and society. 


\section{Role of the Researcher}

The role of a researcher in a qualitative study is one where the researcher locates a problem and begins to gather substantive data through participant interview and observation (Katz, 2015). A researcher adopts a methodology during the design of his or her research and associates the assumptions that they make when collecting, analyzing, and interpreting their data (Moon et al., 2016). Researchers should take initiatives to ensure the achievement of rigor in the study to avoid the subjective view of events (Hamdani, Valcea, \& Buckley, 2016). Yin (2014) further noted that a qualitative researcher serves as the primary data compilation instrument. In qualitative studies, as well as quantitative and mixed-methods studies, the researcher is responsible for gathering and analyzing data from human subjects (Abildgaard, Saksvik, \& Nielsen, 2016; Schoenherr, Ellram, \& Tate, 2015), protecting the participants' rights (Goldenberg, Brouwer, Jimenez, Miranda, \& Mindt, 2016), safeguarding identifiable data (Wong, Hassed, Chambers, \& Coles, 2016), and ensuring that study results accurately convey participant responses (Nilsson et al., 2016).

Qualitative inquiry allows a researcher with prior knowledge of the topic to provide relevant understanding to the situation (Male, 2016). The researcher-participant relationship requires an anti-authoritarian connection between the two parties and a minimization of distance within that relationship (Råheim et al., 2016). Olsen, Lehto, and Chan (2016) noted that a researcher should build a trusting relationship with participants. The goal of my relationship with the participants is to build a trusting rapport and gain their input and knowledge on the topic under review. My career has allowed me to 
participate in successful employee engagement experiences in the workplace. However, I have also observed a lack of strategic engagement by some organizational leaders in their employee's work engagement. Because of these professional experiences, I decided to research effective employee engagement strategies within workplaces.

Researchers need to incorporate ethical practices and prevent bias throughout their investigations (Kouchaki \& Gino, 2015). I adhered to the three ethical principles outlined in the Belmont Report by the National Commission for the Protection of Human Subjects of Biomedical and Behavioral Research (1979). In accordance with the Belmont Report, these ethical practices include a researcher demonstrating respect for individuals, beneficence, and justice by (a) ensuring participants receive the informed consent, (b) assessing the risks and inflicting no harm to the participants, and (c) treating participants with fairness and equality.

Researchers must disclose the details of the study to the participants and reveal the tools used to prevent bias (Garg, 2016). A researcher can control bias by setting aside any prejudices and knowledge gained through personal or scholarly sources (Johnston, Wallis, Oprescu, \& Gray, 2017). A researcher may have prior knowledge of the topic under study, known as bracketing, but should control interjecting that information during the research and interview process (MacFarlane, Veach, Grier, Meister, \& LeRoy, 2016). By using bracketing techniques, I overlooked my personal experiences, beliefs, attitudes, culture, and generational views when interpreting data. Because their interpretation is a key factor to their investigations, qualitative researchers sometimes encounter difficulty in separating themselves from their research (Fusch \& Ness, 2015). To avoid viewing 
data through a personal lens, I paid close attention to and discerned my worldviews from the behavior and reflections of the participants.

To ensure ethical research and prevent bias, I used an interview protocol (see Appendix D) and interviewed participants using open-ended, in-depth questions, audio records the interview, reviewed and scrutinized data, and interpreted findings. I attempted to refrain from interjecting bias into my investigation by following the interview protocol to ensure systematic treatment of participants. Researchers follow an interview protocol as a procedure with prompts to follow throughout the interview process (Li et al., 2014). By following such protocol, researchers can establish rapport, obtain consent, and ensure rich data collection (Doody \& Noonan, 2013). Prompts may include a short introduction of the study, an informed consent reminder, and cues to obtain other necessary information (Li et al., 2014). By using this protocol, I attempted to establish a rapport with participants and gathered relevant data.

\section{Participants}

Participants who perform a specific role in the organization should meet the set conditions of the researcher because they match eligibility criteria (Palinkas et al., 2015). A qualitative researcher locates and selects participants who have extensive knowledge on the topic (Ibrahim \& Sigani, 2014). Researchers should recruit and select participants using inclusion and exclusion criteria (Khidir et al., 2016). The purpose of the study is for me to explore strategies that some small retail business leaders use to engage employees in the workplace efficaciously. Participants for this study must be leaders who manage at least two employees in a small retail business and have demonstrated effective employee 
engagement patterns. Information from the participants and organizational documentation provided data to support claims of effective employee engagement. Participants had at least one year of managerial experience in the business.

The researcher-participant interview involves a critical two-way interaction of information (Farago, Zide, \& Shahani-Denning, 2013). Gaining access to the participants may require the researcher to conduct continuous negotiations to ensure the agreement and consent of participants and gatekeepers, and by demonstrating transparency regarding the researcher's identity and the nature of the findings (Høyland, Hollund, \& Olsen, 2015). A researcher should secure permission from an individual who has access to channels of communication used within the organization (Robinson, 2014). After the delegating authority at my proposed study site grants permission, I sent participants a consent form to sign in advance of their interviews. A researcher uses the consent form to outline the purpose of the study and explain why the research is important and beneficial for the individual, business, and community (Nel et al., 2015). By working with my study organization's leadership team, I gained access to the names of the participants who fit my study eligibility criteria. Interview discussions occurred after receiving a signed letter of cooperation, which authorized data collection process from managers at my study site. Another means of gaining access to participants was through a formal written request via email notification. I obtained consent to speak with and interview potential subjects via a phone conversation. I arranged scheduled interview dates, times, and a suitable meeting location at the company's place of business. 
A working relationship between a researcher and participant creates an environment of reciprocity, representation, and cultural considerations (Lloyd et al., 2016). A researcher should not pressure participants to respond and allow for their willingness to answer the interview questions in an honest and open manner (Marshall et al., 2014). To ensure an effective working relationship, I provided a statement of purpose and maintain transparency. Individual participation was voluntary. Each participant received a copy of the consent form. All information will be stored on an external hard drive and a separate flash drive and kept in a secure, locked location for five years. After five years, I will destroy all information about the study.

Walden's Institutional Review Board (IRB) requirements postulate a scholar develop their study around a central research question. Participants' characteristics should also align with the developed central research question (Klein et al., 2014; Roulston, 2014). To achieve alignment, I compared the purpose of the study with the participant criteria. A researcher uses the central research question as the overarching question to maintain alignment with the set criteria (Polikoff \& Porter, 2014). I used the interview protocol and interview questions to sustain the orientation of the results and ensure transparency.

\section{Research Method and Design}

Selecting an apt research method and design is dynamic in the scholar providing a detailed picture of a phenomenon (Ritchie, Lewis, Nicholls, \& Ormston, 2013). Scholars should pay careful consideration in choosing the appropriate research methodology and design that may be suitable for revealing the answer to the central research question 
(Hartley, 2016). I used a qualitative method with a single case study design for this research study. The qualitative researcher uses netnography, personal interviews, and participant observations from a selected target audience (Guercini, 2014). Qualitative methodology used by a researcher should incorporate descriptive purposes which are mainly focused on areas of emerging theory or used to investigate individuals or explicit historical events copiously (De Massis \& Kotlar, 2014). In case study design, scholars investigate data to fulfill design purposes and follow the alignment of the research process toward the desired outcome while recognizing the value and considering that data influences positive change behaviors (Harland, 2014).

\section{Research Method}

The qualitative approach is a method that researchers use for the systematic collection, organization, and interpretation of textual data derived from an experienced phenomenon (Gale, Heath, Cameron, Rashid, \& Redwood, 2013). Qualitative researchers identify and articulate concepts and tactics to simplify what they offer in the study which leads to the enhancement and justification of the research findings and conclusions (Parker \& Northcott, 2016). A qualitative approach enables researchers to obtain and gather information which includes the participants' emotions, attitudes, and learning processes from a variety of individual perspectives (Hammel et al., 2015). I used a qualitative research method for this study to interview small retail managers and report their strategies to improve successful employee engagement.

Quantitative researchers test hypotheses and examine relationships between variables (Warner, 2016). The researcher's goal of the quantitative approach should be to 
maintain objectivity (Wright, O'Brien, Nimmon, Law, \& Mylopoulos, 2016).

Quantitative researchers may use a variety of procedures such as statistical data, random sampling, surveys, direct observation, or social network analysis to gather their findings (Marti, 2016). A quantitative approach would not have provided me with the necessary exploration and design required to encapsulate the environment of the managers' effective employee engagement strategies.

A mixed method approach in research is a methodological plurality used in psychology to refer to a combination of qualitative and quantitative methods (Sullivan, 2015). Mixed methodology combines qualitative focus groups and quantitative survey approaches to allow the researcher to identify and characterize groups with identical contributors (Weible, Christoph-Schulz, Salamon, \& Zander, 2016). The mixed research method tends to enrich the researcher's understanding of business problems and questions while advancing the research topic within the business field (Molina-Azorin, 2016). The mixed method was not appropriate for my study because of the requirement to combine qualitative and quantitative approaches in developing and testing existing theories and hypotheses.

\section{Research Design}

The selection of the qualitative method as five available design options of (a) narrative, (b) ethnography, (c) grounded theory, (d) case study, and (e) phenomenology (Palinkas et al., 2015). A case study is an empirical inquiry which allows the researcher to investigate the case or cases and understand how or why a phenomenon occurs (Yaghmaei \& Brem, 2015). A researcher selects a single case study design to critically 
evaluate data to determine if the topic has sufficient empirical support to be deemed evidence-based (Fallon, Collier-Meek, Maggin, Sanetti, \& Johnson, 2015). In the single case study, as defined by Yin (2015), the researcher is required to report all evidence fairly and without bias. Hott, Limberg, Ohrt, and Schmit (2015) found single case study design allows the researcher to report the results by using patterns of data. A researcher gains reliability in a single case design when agreement among the criteria is present throughout the data (Vannest \& Ninci, 2015). The phenomenon I explored for this study encompassed retail managers with experience in using successful strategies to engage employees within the workplace. A single case study design is the most appropriate choice for my research because the data I collected was consistent with the topic of the study and phenomenon of successful practices by managers in employee engagement.

The narrative design was not appropriate for the study because the researcher focuses on the examination of recent or current literature which can span over a wide range of subjects with multiple levels of completeness and comprehensiveness (Iversen et al., 2016). Narrative design is a preliminary framework and collection of stories developed by the participants (McLean, Shucard, \& Syed, 2017). Ethnography was not appropriate for the study because there was no need to conduct a systematic study of a specific culture or group of people (Vogel, 2016). Social science researchers use ethnography as a long tradition of representation of the relation between people and places (Eisenhardt, Graebner, \& Sonenshein, 2016). A phenomenological design was not appropriate for the study because there was no need to explore any specific experience and actions (Hamarat, 2016). A researcher uses a phenomenological design when the 
essence of phenomena is known, but which do not possess an in-depth understanding (Yilmaz, 2016).

The population for this qualitative single-case study included managers from a small business who were based in Orlando, Florida. Purposeful sampling is the desired sampling method choice of qualitative researchers, and the essence of purposeful sampling is to select information-rich cases that allow for the highest level and use of limited resources from diverse conditions (Duan Bhaumik, Palinkas, \& Hoagwood, 2015). Purposeful sampling is the exhaustive effort the researcher puts into developing data collected for the study (Benoot et al., 2016). A researcher uses purposeful sampling to recruit a certain number of participants to partake in the interview process and provide relevant data for the study (Stein et al., 2016). I used purposeful sampling to select the study participants.

Sample sizes are typically small in qualitative research studies; nevertheless, the researcher should address credibility, transferability, dependability, and confirmability (Brown, Strickland-Munro, Kobryn, \& Moore, 2017). The justification of sample size is evident in the data reaching the saturation point of redundancy, however a sample size may include three semistructured interviews (Campbell, 2015; Marshall, Cardon, Poddar, $\&$ Fontenot, 2013). In qualitative work, the sample size is generally small and based on similar research on the same topic (Karimi et al., 2017). A homogenous population should consist of six and 12 participants for the researcher to obtain data saturation (Saunders \& Townsend, 2016). However, my study consisted of five eligible managers 
from a retail business who implemented successful strategies to engage employees in the workplace.

Participants met the eligibility criteria as managers leading successful teams through strategic engagement practices. I collected data from five managers and used semistructured, open-ended, and in-depth interview questions. Managers who participated in the study had at least 1 year of leadership experience and met the criteria for inclusion in this study. Secondary data from company memorandums, central email software, and online customer reviews provided information towards data collection and validation for the past 5 years (2012-2016).

Fusch and Ness (2015) defined data saturation as a difficult task for the researcher, as the ability to reach data saturation depends on the varying available studies and willing participants. In qualitative inquiry, there is a purposeful strategy of ambiguities where the researcher examines the purpose of the inquiry, seeks what is at stake, provides useful data of credible input, provides information throughout the available time, and incorporates the obtainable resources as a method to reach redundancy (Marshall et al., 2013). The most suitable unit of investigation in reaching data saturation is sufficiently large enough, but small enough for the researcher to provide relevant meaning for the reader to evaluate the trustworthiness of the findings (Elo et al., 2014). A researcher achieves data saturation when their investigation can no longer reveal further information offered by the participants (Palinkas et al., 2015). My goal was to recruit and interview six participants until no new information emerged in the collected data. I reached data saturation with five participants and the data collection process 
ceased. The company did not have six participants, therefore, five participants assisted me to reach data saturation on the topic.

Participant eligibility includes a series of criteria which the researcher identifies to enable a consensual evaluation guide for a qualitative study (Santiago-Delefosse, Gavin, Bruchez, Roux, \& Stephen, 2016). The rationale of selecting participant criteria is for the researcher to strategically categorize areas of unique, different, or important perspectives on the phenomenon in question (Robinson, 2014). In qualitative methodology, the researcher selects participants who meet or exceed a specific set of criteria and who can share intimate knowledge of the phenomenon toward an information-rich case study (Palinkas et al., 2015). The informed consent process should contain clear information from the researcher so that participants can comprehend the research study and make informed decisions about their participation.

To determine the eligibility criteria, I based the experience of each participant with their employee engagement strategies in the retail industry. Eligible participants need at least one year of management experience and knowledge related to the phenomenon (Karimi et al., 2017). Flexibility in criteria allows the researcher to meet the needs and specificities of their study and present a consensual and explicit evaluation protocol of the participants (Santiago-Delefosse et al., 2016). I purposively selected the participants for this study among company managers from a business in Orlando, Florida, who effectively used strategies to improve employee engagement. The appropriate participants needed management experience and proven leadership skills to fulfill the requirements of my study. A suitable interview setting is one that is accessible and 
comfortable for the participants (Paulo, Albuquerque, Saraiva, \& Bull, 2015). I met the participants at the location of their choice and where they felt comfortable with the private interview process.

\section{Population and Sampling}

The population for this qualitative single-case study included managers from a small business who were based in Orlando, Florida. Purposeful sampling is the desired sampling method choice of qualitative researchers, and the essence of purposeful sampling is to select information-rich cases that allow for the highest level and use of limited resources from diverse conditions (Duan Bhaumik, Palinkas, \& Hoagwood, 2015). Purposeful sampling is the exhaustive effort the researcher puts into developing data collected for the study (Benoot et al., 2016). A researcher uses purposeful sampling to recruit a certain number of participants to partake in the interview process and provide relevant data for the study (Stein et al., 2016). I used purposeful sampling to select the study participants.

Sample sizes are typically small in qualitative research studies; nevertheless, the researcher should address credibility, transferability, dependability, and confirmability (Brown, Strickland-Munro, Kobryn, \& Moore, 2017). The justification of sample size is evident in the data reaching the saturation point of redundancy, however a sample size may include three semistructured interviews (Campbell, 2015; Marshall, Cardon, Poddar, \& Fontenot, 2013). In qualitative work, the sample size is generally small and based on similar research on the same topic (Karimi et al., 2017). A homogenous population should consist of six and 12 participants for the researcher to obtain data saturation 
(Saunders \& Townsend, 2016). However, my study consisted of five eligible managers from a retail business who implemented successful strategies to engage employees in the workplace.

Participants met the eligibility criteria as managers leading successful teams through strategic engagement practices. I collected data from five managers and used semistructured, open-ended, and in-depth interview questions. Managers who participated in the study had at least 1 year of leadership experience and met the criteria for inclusion in this study. Secondary data from company memorandums, central email software, and online customer reviews provided information towards data collection and validation for the past 5 years (2012-2016).

Fusch and Ness (2015) defined data saturation as a difficult task for the researcher, as the ability to reach data saturation depends on the varying available studies and willing participants. In qualitative inquiry, there is a purposeful strategy of ambiguities where the researcher examines the purpose of the inquiry, seeks what is at stake, provides useful data of credible input, provides information throughout the available time, and incorporates the obtainable resources as a method to reach redundancy (Marshall et al., 2013). The most suitable unit of investigation in reaching data saturation is sufficiently large enough, but small enough for the researcher to provide relevant meaning for the reader to evaluate the trustworthiness of the findings (Elo et al., 2014). A researcher achieves data saturation when their investigation can no longer reveal further information offered by the participants (Palinkas et al., 2015). My goal was to recruit and interview six participants until no new information emerged in the collected 
data. I reached data saturation with five participants and the data collection process ceased. The company did not have six participants, therefore, five participants assisted me to reach data saturation on the topic.

Participant eligibility includes a series of criteria which the researcher identifies to enable a consensual evaluation guide for a qualitative study (Santiago-Delefosse, Gavin, Bruchez, Roux, \& Stephen, 2016). The rationale of selecting participant criteria is for the researcher to strategically categorize areas of unique, different, or important perspectives on the phenomenon in question (Robinson, 2014). In qualitative methodology, the researcher selects participants who meet or exceed a specific set of criteria and who can share intimate knowledge of the phenomenon toward an information-rich case study (Palinkas et al., 2015). The informed consent process should contain clear information from the researcher, so that participants can comprehend the research study and make informed decisions about their participation.

To determine the eligibility criteria, I based the experience of each participant with their employee engagement strategies in the retail industry. Eligible participants need at least one year of management experience and knowledge related to the phenomenon (Karimi et al., 2017). Flexibility in criteria allows the researcher to meet the needs and specificities of their study and present a consensual and explicit evaluation protocol of the participants (Santiago-Delefosse et al., 2016). I purposively selected the participants for this study among company managers from a business in Orlando, Florida, who effectively used strategies to improve employee engagement. The appropriate participants needed management experience and proven leadership skills to fulfill the 
requirements of my study. A suitable interview setting is one that is accessible and comfortable for the participants (Paulo, Albuquerque, Saraiva, \& Bull, 2015). I met the participants at the location of their choice and where they felt comfortable with the private interview process.

\section{Ethical Research}

Heyler, Armenakis, Walker, and Collier (2016) defined ethical research as a process of recognizing a need, considering the alternatives, identifying a morally acceptable option, and implementing the process. In accordance with the requirements of ethical research, I conducted a study under the Walden University (IRB) approval number 06-06-17-0580697. A letter of consent given to each person contributed information in the study and contained a clear declaration concerning the purpose of the study, benefits of involvement for the researcher and participant, and the estimated time for the interview process (Mabery, Gibbs-Scharf, \& Bara, 2013).

All participants signed a consent form, found in Appendix B, before participating in the interview process. The informed consent is used by a researcher to incorporate the disclosure of information or a table of contents of (a) the protective comprehension of the participant to make an informed decision, (b) the participant's freedom from coercion, and (c) a participant's willing consent explicitly and formally in written format (Ssali, Polan, \& Seeley, 2016). For this study, I provided each participant with an invitation to participate. Subjects had the opportunity to withdraw at any time during the interview process through means of written email or in-person communication. Research participation incentives often improve response rates (Pederson \& Nielson, 2014). 
However, the participants in this study did not receive any incentives for participating in the interview process of the study.

Researchers should uphold ethical research and integrity practices to protect each participant (Goodrich \& Luke, 2017). Bauman (2013) described integrity as a term of identity-conferring commitments to ethical, unethical, or personal principles. Elements such as bias, intuition, experience, emotion, social awareness, and colleagues' input need to be avoided by the researcher (Heyler et al., 2016). As a researcher, the goal is to gain the trust and cooperation of the participants who may otherwise be reluctant to provide information (Berger, 2015). The names of the participants and organization remained anonymous. Each contributor to the interview process received the opportunity to review their feedback before inclusion in the study. I studied the National Institutes of Health Office of Extramural Research and received the required certification to properly engage in the research involving human subjects (Appendix C).

Rapport development allows the researcher to create a connection with the participant, regardless of the complexity and dilemmas that may surround the relationship (Stahl, 2016). Scholars should understand and follow the process of participant consent, the protection of privacy, storage requirements of data, and the scope of sharing data (Brett, O’Neill, \& O’Gorman, 2014). Providing transparency is imperative in reporting, preparing analyses, disclosing conditions, sharing data, and sharing research materials (Steegen, Tuerlinckx, Gelman, \& Vanpaemel, 2016). I communicated and ensured transparency characteristics with the participants by following the procedure outlined throughout the table of contents and included appendices. I researched the data to 
establish and maintain a trusting relationship. The appendices of this study include (a) Appendix A, interview questions; (b) Appendix B, invitation to participate; (c) Appendix C, National Institutes of Health Office of Extramural Research certificate; and (d) Appendix D, interview protocol.

Each participant's information or any other identifiers associated with them from the collection of data will be maintained in a locked cabinet for 5 years to protect the rights of the participants. After the 5-year period, I will destroy all information from the participants by shredding data in a cross-cut shredder and erasing any audio data from an electronic device. I did not collect data for this research study before receiving approval from the Walden University's IRB without an identification number and expiration date (06-06-17-0580697 and Jun 15, 2018). The importance of protecting the identity of the participant and organization was essential to secure and protect privacy rights. For privacy protection, all organizational information remained confidential, the participants remained confidential, and each participant was assigned a random identifier code of (P1P5).

\section{Data Collection Instruments}

A researcher conducts qualitative research and acts as the primary data collection instrument to interpret a phenomenon that stems from a surrounding environment (De Lima Ferreira \& Bertotti, 2016). Types of data collected by the researcher may include observations, interviews, or the review of organizational documentation (Specht et al., 2015). Ali, Zevenbergen, and Tuladhar (2014) further noted that data collection involves the researcher examining, categorizing, tabulating, or recombining the evidence. Through 
semistructured interviews, a researcher can act as the data collection instrument through open discussions with participants and in exploring new topics that may arise during the process (Leng, MacDougall, \& McKinstry, 2016). As the data collection instrument, I used semistructured, open-ended, and in-depth interview questions to gather data for this study. I investigated organizational documents that included administrative memorandums for the past 5 years (2012-2016).

The interview process involves the researcher acting as the data collection instrument and in safeguarding there is concentration on the research topic (Paradis, O’Brien, Nimmon, Bandiera, Martimianakis, 2016). The researcher also ensures anonymity of the participants during all stages of data collection process (De Lima Ferreira \& Bertotti, 2016). A researcher should create interview questions as open-ended and appropriately expressed, with a direct relation to the topic of study (Hermes \& Metzger, 2017). As documented by Yin (2015), company data consist of documents, archived records, interviews, and direct observations. I developed an interview instrument consisting of nine open-ended questions for managers of a small retail business to provide their responses (Appendix A). Each open-ended interview question aligns with the central research question developed for the study. I reviewed company data, such as organizational charts, job description criteria, and managerial reports that related to successful employee engagement.

A researcher ensures reliability and validity of the data collection process using member checking to prevent misinterpretations of the information (Killawi, Heisler, Hamid, \& Padela, 2015). Member checking is a process where the researcher shares the 
interview transcripts, analytical thoughts, and drafts of the final study with the participants to ensure their input are accurate (Mitchell, Schuster, Smith, Pronovost, \& Wu, 2015). Årlin, Börjeson, and Östberg (2015) shared how a researcher uses member checking as a process to test data collection, a validation to the interpretations as an overview of the pros and cons, and as a tool to check preliminary results to increase validity and credibility. Directly following the interview process, I incorporated member checking to confirm the validity of each participant's responses. By validating the correct interpretation of each participants' data, I solidified the credibility and ensured the truthfulness of the information to eliminate any potential interview misinterpretations.

The interview protocol process is one where the researcher conducts key in-depth interviews through informed consent and plans the stages of the research procedure (Zea et al., 2015). A researcher uses the interview protocol to build rapport through drafted questioning to provide an investigative interview of the chosen participants (Paulo et al., 2015). The planned stages of the method allow the researcher to use an interview protocol to ensure the interview questions align with the research question, to construct an inquiry-based conversation, to receive feedback on interview protocols, and to pilot the interview protocol throughout the study (Mansour, 2015). Employing an interview protocol (Appendix D) with each participant enabled me to control inaccuracies in the data collection process and provide consistency throughout the study.

\section{Data Collection Technique}

Individual interviews allow the researcher an opportunity to make observations that naturally occur from the voice of a participant (Petrie, 2016). Stein et al. (2016) 
recommended a researcher obtain an audio recording of the interview to ensure data is complete and as reliable as possible. Researchers use semistructured interviews as both a data collection strategy and a research method (McIntosh \& Morse, 2015). I chose a date, time, and interview location setting for the interview to ensure data collection suffices with interest and focus on the study. A suitable meeting location with each participant in a quiet environment allowed me to provide a successful completion of each semistructured audio recording of the interview. To collect data for this study, I used the semistructured interview method in audio recorded face-to-face communications of openended questions and organizational documents. When using a script or interview protocol, a researcher must remember to notify the participant of the informed consent form and obtain a signed consent to participate (Drake et al., 2016). In following the interview protocol (Appendix D), I ensured to be consistent in asking each participant to sign the consent form prior to collecting interview data and give the individuals a hard copy of the consent form before starting the interview.

The interview process was the principal foundation of data collection for this study. As the data collection instrument, both advantages and disadvantages occurred. One advantage is in how interviewers ask open-ended and relevant questions during the interview process (Chan et al., 2013). Another advantage is that an interviewer can observe the reactions of participants and make assumptions of the freely-given responses by the individuals (Saunders \& Townsend, 2016). A disadvantage, as described by Paulo et al. (2015), is a participants' attitude and failure to release information could be a deterrent to the progression of the research. Another disadvantage is the researcher's 
tendency to misinterpret nonverbal cues during the interview process and make incorrect assumptions (Lin et al., 2016). I ensured the incorporation of the potential advantages and disadvantages to the interview process. To prevent misinterpretations, I asked the participants to clarify their response to the interview questions (Appendix A) and encouraged them to provide any additional information. I also checked the audio recordings, prior to leaving the interview to confirm the recording device worked as expected.

Pilot studies are defined as feasibility studies and are small scale versions, or trial runs the researcher uses to conduct a pretest of the research instrument (Van Teijlingen \& Hundley, 2015). Cullen, Brennan, Manly, and Evans (2016) documented the researcher validates preliminary evidence towards the legitimacy of data through pilot studies. Another purpose of the pilot study is for the researcher to find possible revisions to the interview questions and collected data to ensure alignment with the purpose of the research (Zea et al., 2015). Since I followed the rigors of the interview protocol (Appendix D), I did not need to conduct a pilot study after IRB approval.

Member checking allows the researcher to reflect on the results of the participants' perspectives and verify the accuracy and depth of the information (Tong \& Dew, 2016). The purpose of member checking is to ensure trustworthiness and credibility of data collection process (Matthews et al., 2016). Through member checking, the researcher can (a) request participants to approve the transcripts, (b) identify themes and codes from the responses, and (c) address transferability by keeping data on file and available upon request (Saeieh et al., 2016). To achieve member checking, I emailed or 
met with each participant within a week of the interview and attempted to prevent potential inaccuracies in the data collected.

\section{Data Organization Technique}

The data organization technique is the open coding, creation of categories, and abstraction of data to confirm conformality and credibility of the researcher's study (Elo et al., 2014). Researchers use digitization technology to connect the different services and the automation of many processes and electronic devices (Delsing, 2017). Male (2016) recommended for a researcher to organize and store the collected data in a computer processing software program to easily locate data to code for themes or categories. A researcher should create folders with structures relating to each participant and include the type of data and results of data analysis (Bigdely-Shamlo, Makeig, \& Robbins, 2016). After collecting data, I categorized the information and created electronic folders based on (a) the type of written document or recorded interview, (b) the file name of the document, (c) data collected, (d) any recorded journals or logs, (e) analysis of data, and (f) the findings. I labeled each folder with the designated code and complied with confidentiality requirements throughout the research.

Raw data are the primary data a researcher collects from available sources (Vähä-Ypyä, Vasankari, Husu, Suni, \& Sievänen, 2015). Kroon-Batenburg, Helliwell, McMahon, and Terwilliger (2017) revealed that a researcher should store raw data for later retrieval and determine a balance between archiving and discarding the raw data in the future. Chen, Won, Stoleru, and Xie (2015) suggested a researcher take advantage of cloud computing resources to store raw data because of the large computation and storage 
capabilities. Yin and Kaynak (2015) noted a researcher could use a typical database software tool to capture, store, manage, and analyze the raw data throughout the project and prevent the loss of valuable information. To comply with the Walden DBA program requirements, I plan to ensure participant privacy during the process of my study and hold onto all records for 5 years, after the study is complete. After 5 years, I will erase electronic data and shred any paper documents.

\section{Data Analysis}

A qualitative single case study is the complex investigation by a researcher to understand the activity within important circumstances (Yaghmaei \& Brem, 2015). Researchers use a case study to develop theoretical propositions to guide data collection and analysis with the inclusion of multiple sources of evidence for triangulation (Green et al., 2015). Triangulation results in the researcher accomplishing a final analysis grid with specific categories that takes the form of a series of questions used to analyze data (SaintJacques et al., 2016). I performed triangulation by interviewing five retail managers on the topic for the study. Data analysis occurred when I gathered the information from the participants, applied codes to the specified categories that resulted from the interview questions, and attained the desired data saturation requirements.

In the first step of the process for data analysis, I gathered and grouped the written information by using sense making techniques and created themes from the data. Paillé, Chen, Boiral, and Jin (2014) proposed the researcher reduce the number of data items for each construct. Therefore, in the next step and upon the completion of the interview and member checking process, I reviewed data and removed superfluous information with no 
value to the study. Kim et al. (2014) postulated there are many probable sources of data for use in case study research, including documents, archival records, interviews, direct observation, participant-observation, and physical artifacts. NVivo is Computer Assisted Qualitative Data Analysis Software (CAQDAS) that the researcher uses to organize and manage interview data transcripts and audio files (Zamawe, 2015). Once I removed the irrelevant information, I then uploaded the interviews, recorded documents, and audio data into NVivo 11 and created codes that were consistent with the interview questions to reach data saturation. To comply with privacy requirements, I coded participants with the letter "P" and assigned a number to the letter. The number correlated to the order of the participants' interview. For example, the third managerial participant received a code of P3. Coding is a process of sense making of data, concealing the privacy of the participants, dividing data into text or image segments, labeling the segments with codes, examining the codes for any overlap or redundancy, and collapsing the codes into broad themes (Baghurst, Murray, Jayne, \& Carter, 2014). When I completed the interviews, I implemented member checking to permit the participants the opportunity to elucidate and corrected any erroneous information found in my transcriptions. The process of triangulation allowed me to assemble facts from the participant interviews and included company documents such as strategic managerial memorandums and organizational spreadsheets on successful engagement practices.

There are 15 different CAQDAS programs available to researchers that can code, retrieve functions, and utilize pragmatic and methodological considerations for the researchers' use (Silver \& Lewins, 2014). A researcher can use Microsoft Excel, along 
with coded interviews and analyze data in NVivo 11 (Thomas, 2016). NVivo software runs in accordance with the modified van Kaam data analysis method, and the researcher can use this software to identify common themes and patterns (Baghurst et al., 2014). I used NVivo 11, as there was a 30-day free trial available from the manufacturer and a student discount available for purchase, should I need to extend the software trial. With NVivo, I input data from the organizational documents, archival records, interviews, and direct observations. Houghton et al. (2016) resolved NVivo can assist the researcher in enhancing and illustrating the rigorous processes of the data analysis. Wilson et al. (2016) noted NVivo not only allows the researcher to import data for analysis but also provides a second copy for archive purposes and offers organization to data analysis process. Mind mapping is a technique used by individuals who wish to analyze complex case study data collected from face-to-face semistructured interviews during a research project (Schwab et al., 2017). A researcher can use mind maps to identify mind structures regarding the topic and the concepts associated with those concepts in a visual representation (Sümen \& Çalışıc1, 2016).

A researcher is the primary data collection instrument in qualitative research when exploring a phenomenon under study (Baghurst et al., 2014). Coding data around themes is a key characteristic of qualitative researchers (Castleberry, 2014). Houghton et al. (2016) determined themes encompass drawn explanations and descriptions that are found by the researcher. In content analysis, data of similar types are grouped by the investigator who uses certain codes and themes to organize and later interpret the information for readers to easily follow (Sümen \& Çalışıcı, 2016). To accomplish 
focusing on key themes, correlate the key themes in the literature, and align with the conceptual framework of the study, I used the interrelated themes found from data analysis and reported the findings. I presumed as the study progressed, similar themes were bound to surface through new studies published by other researchers on successful management strategies for productive work practices, employee engagement, and organizational commitment.

\section{Reliability and Validity}

The researcher measures the qualities of reliability and validity through data collection (Bråndal, Eriksson, Wester, \& Lundin-Olsson, 2016). A researcher writes a case study while comparing the viability of themes and explanations, member checking them against the collected data, and recognizing if they need to collect more or different data (Marshall \& Rossman, 2016). Establishing and reporting content validity evidence consists of three established types, such as (a) content, (b) criterion, and (c) construct validity (Chiarotto, 2016). Construct reliability and validity is a 4-step framework for establishing the standards of minimal qualifications, inter-reviewer reliability, factorial validity, and measurement reliability (Magill et al., 2016). I ensured the proposal for this study consists of conversant elucidation on the research design, data collection procedure, and data analysis process. A description of how I accomplished this goal to ensure reliability and validity follow in the next sections

\section{Reliability}

Reliability is the agreement of consistency in classifying content that is crucial to content analysis (Su et al., 2017). Venkatesan, Schotanus, and Hendrickx (2016) 
concluded that a researcher should evaluate the reliability and construct validity for a dependable outcome. The investigators' accuracy and reliability of the research are dependent upon the sample size (Schiefele et al., 2016). Lishner (2015) noted the researcher should (a) examine existing literature, (b) determine theoretical implications, (c) develop a research design, (d) collect data, (e) analyze data, and (f) disseminate the findings through a dependable, reliable, and truthful presentation. My proposal consisted of a collection of thorough details towards the alignment of the central research question and in conjunction with the research method and design; as well as the interview process. A researchers' selection of participants, concept definitions, and choice of data collection and analysis all contribute to purposeful sampling and dependability to identify common patterns across the variations (Palinkas et al., 2015). I attested reliability by providing an exhaustive argument regarding the research information, data assembly procedures, and data analysis process.

Dependability is a strategy that researchers use to discover a consistency of explanations and conformability (Nenonen, Möller, \& Storbacka, 2017). In a recent study, Birt, Scott, Cavers, Campbell, and Walter (2016) recommended qualitative researchers conduct member checking to ensure participant or respondent validation by continually checking and confirming the results. The researchers' strategies towards dependability contribute to member checking and an audit trail to enhance trustworthiness in case study research (Ang et al., 2016). Through member checking, participants validated the information and advised me of any corrections. I addressed the written proposal with detailed information, which was in alignment with the research 
question of the research design, research processes, methodology, and semistructured interviews. For reliability in the research, I provided details of the interview discussion, data collection processes, and data analysis.

\section{Validity}

Validity is the extent to which a contributory interpretation occurs by the researcher (Leviton, 2016). Through validity, a researcher must prove to be of value and accomplish the intended goals within the set paradigm (Baskerville \& Wood-Harper, 2016). Validity can also be obtained by the researcher using member checking and allowing the participants to review the interview transcripts (Wilson et al., 2016). The widely-used criteria of trustworthiness in qualitative research are credibility, transferability, and confirmability (Carr et al., 2016). By examining data, a researcher can illuminate problems through member checking and create integrity of the empirical findings (Lishner, 2015). Credibility is revealed by a confidence in the truth, on behalf of the researcher, and on the findings based on the research design, participants, and context (Moon, Brewer, Januchowski-Hartley, Adams, \& Blackman, 2016).). A pilot test provides preliminary data on the efficacy of data (Timmons-Mitchell, Levesque, Harris, Flannery, \& Falcone, 2016). Random samples of participants allow the researcher to describe the experiences of implementation as credible resources (Palinkas et al., 2015). Triangulation occurs when the researcher uses more than one method of data collection (Kim et al., 2014). A methodological triangulation includes multiple measures of data and methodological triangulation, member checking, and audit trail to establish 
trustworthiness (Green et al., 2015). I demonstrated credibility through methodological triangulation.

Transferability allows for the future usage by other researchers because of the criterion of dependability of the research process details and adherence to validity (Sundler, Eide, Dulmen, \& Holmström, 2016). To enhance transferability, the researcher can address the research question and provide adequate data within the study (Entsieh \& Hallström, 2016). Santiago-Delefoss et al. (2016) addressed transferability and stated that the level of generalizability of the results must be specified by the researcher and reference back to the credibility and confrontation with other literature. I ensured transferability by providing a rich description of the participants' responses to the interview questions, research framework, data analysis, and all discoveries. By providing rich data in my study, I presented the groundwork for future readers and scholars to make well-informed decisions based on the transferability of this data.

Confirmability is when the investigators' findings and interpretations link to data (Tong \& Dew, 2016). To achieve confirmability, researchers must demonstrate clear results that connect to the conclusions in a manner that follows through a process and eventually replicate (Moon et al., 2016). Au, Lo, Cheong, Wang, and Van (2016) posited confirmability is when the researchers' study results derive from characteristics of the participants and the context of the study. I used member checking so the participants can review the transcripts for accuracy. A researcher uses queries to audit the findings and check that propositions are grounded in data (Houghton et al., 2016). Therefore, I 
performed an audit trail using NVivo 11 to analyze the input data from the interview transcripts and other collected information to justify data analysis.

Data saturation occurs when the analysis and data collection return no new information to the codebook created by the researcher (Tran, Porcher, Falissard, \& Ravaud, 2016). Data saturation can be influenced by unforeseen limitations outside of the researchers' or participants' control and may need to be estimated by the investigator (Zhao et al., 2016). Gharib, Zolfaghari, Mojtahedzadeh, Mohammadi, and Gharib (2016) established a researcher could reach data saturation by including additional participants until no new insights are recognized. To reach data saturation, I interviewed all managers until I no longer found new evidence or located any additional codes within the data.

\section{Transition and Summary}

In Section 2, I provided an accurate account of the qualitative research study process, including the justification for a qualitative case study research design and methodology. I described the role of the researcher, participants, and the sampling technique for the study. I presented the explanation and application of ethical research and provided an overview of the data collection instrument and techniques I used for the organization of data analysis process. Finally, I discussed the importance of data reliability and the validity of qualitative research, as well as strategic methods to enhance the reliability and validity of the study.

In Section 3, I presented the findings of this study. The findings included a detailed description of the analysis of the semistructured interview responses of the participants, documents review, themes that emerged from the collected data, and 
presentation of the findings of other peer-reviewed studies from the literature review. In addition, in Section 3 I provided a detailed dialogue on the application of the findings of the managerial strategies used within the business. There were implications regarding effective strategies managers use to engage employees in the workplace; therefore, these implications helped the managers to improve productivity and may affect a positive social change within the surrounding communities. 
Section 3: Application to Professional Practice and Implications for Change

Section 3 consists of an introduction of the study and a presentation of the findings. In addition, this section encompasses the application to professional practice and the implications for social change. A discussion also provides leaders and managers with recommendations for actions. Section 3 further includes recommendations for further research on employee engagement. In the reflections, I describe my experiences during this doctoral study journey. I conclude the study with a synopsis addressing the importance of implementing effective strategies to improve employee engagement.

\section{Introduction}

The purpose of this qualitative descriptive study was to explore strategies that some small retail business leaders use to engage employees in the workplace. I posed nine interview questions (see Appendix A) to gain knowledge of the strategies managers use to engage employees in the workplace. Each participant interview lasted 30 minutes, and all interviews took place in a private office in the company's location in Orlando, Florida. Participants had experience implementing strategies to improve employee engagement; all participants (P1-P5) held in managerial positions for at least one year.

Other sources of data evaluated were the company's memorandums, job description criteria, central email software, and online employee reviews by the company's customers. Before the interviews, participants reviewed and signed consent forms. After conducting the interviews, I found the managers improved employee engagement by implementing a supportive workplace environment, expressing interpersonal communication, and conducting employee training. 
In Section 3, I provide an overview of the purpose of the study, the central research question, and a presentation of the findings. I completed the five-step process, which Yin (2014) indicated consists of (a) compiling, (b) disassembling, (c) reassembling, (d) interpreting, and (e) concluding of the data. Also included in this section are the applications to the professional practice of my research, implications for social change, and recommendations for action and further study, and the reflections of my journey through this doctoral study. Finally, I conclude with a closing statement that encompassed the conclusion of the study.

\section{Presentation of the Findings}

The overarching research question for this qualitative descriptive study was: What strategies do some small retail business leaders use to engage employees in the workplace? The study consisted of five retail managers from a small Orlando business who had implemented effective strategies to engage their employees successfully. The data emanated from semistructured interviews with the participants and in reviewing of the company's memorandums, job description criteria, central email software, and online employee reviews by the company's customers. I uploaded the audio files, transcribed the interviews, and then uploaded the interview data, and the policies and documentation from the company into the NVivo 11 software. NVivo software was used to organize the text data, code the text, and manipulate the text data to display the desired codes. Finally, I generated themes from the node attributes and queries from the participant responses through the NVivo 11 program. After analyzing the data in NVivo 11, three major themes emerged. These three themes included (a) supportive leadership improved employee 
engagement, (b) direct communication improved employee engagement, and (c) training improved employee performance.

\section{Theme 1: Supportive Leadership Improved Employee Engagement}

Supportive leadership improved employee engagement was the first theme that emerged from exploring the participants' responses. The participants' articulated that supportive leadership, as a strategy, is important to improve employee engagement. All managers $(\mathrm{P} 1, \mathrm{P} 2, \mathrm{P} 3, \mathrm{P} 4$, and $\mathrm{P} 5)$ shared that they dedicated time to support and engage the employees in their job duties. To engage employees, each manager $(\mathrm{P} 1, \mathrm{P} 2, \mathrm{P} 3, \mathrm{P} 4$, and P5) held weekly meetings with their teams to encourage staff in understanding and performing their duties. The meetings allowed employees to express concerns and ask questions and permitted the managers to provide support toward future goals. P1 stated, "In my department, I am trying to build long-lasting, long-term employees so they remain in their job. A relationship of supportive leadership helps to build engagement on the job." P2 stated that they support their employee team by taking part in job-site projects. P3 noted, "Employees don't have to go through supervisors or tiers of authority to speak to me, it is an open-door policy." According to P5, "We work as a team and everyone shares their knowledge, so they understand they have support to perform their job."

According to P1, supportive managers listen to and help direct employees towards engagement. Managerial support in the workplace goes beyond implementing rules and regulations where managers present positive contributions to the organization and a feeling of value to the employees (Shuck \& Reio, 2014). All managers in the company demonstrated their support to employees by working alongside or helping to guide the 
employees in their work role (P1, P2, P3, P4, and P5). Bechmann (2017) discovered that supportive managers nurture their employees and encourage employees toward engagement in their work roles. P2 found working alongside employees provided a strategic atmosphere of teamwork. Research findings reveal that the outcomes associated with supportive leadership are positive. Hollis (2015) found that supportive managers present a productive workplace environment where employees can engage in their duties. More recently, Shuck et al. (2016) noted that supportive managers discuss and clarify employee concerns to improve employee engagement.

The findings in the study identified the described theme of supportive leadership and improved employee engagement. Employee engagement, according to Karatepe and Aga (2016), has a positive effect on the workplace environment. All participants (P1, P2, P3, P4, and P5) demonstrated supportive leadership by building effective working relationships and by listening to their employees and encouraging teamwork. Most of the participants (P1, P2, P4, and P5) shared that the employees accomplished their tasks efficiently because managers dedicated time to the employees through constant discussions and guidance. Several of the participants revealed that employee engagement is identified when the employee becomes a benefit to the business by completing their job assignments through managerial support (P1, P2, and P4). Byrne et al. (2017) revealed that supportive leaders engage employees to perform effectively and produce higher results that benefit the employee and the company.

In case studies, researchers use archival records, interviews, direct observations, and physical artifacts, such as memorandums as data collection techniques (Kim et al., 
2014). I reviewed company memorandums on the managerial support and employee engagement from the past 5 years (2012-2016). In the first memorandum, P1 summarized the importance of using supportive leadership as a strategy to improve employee engagement. In the first memorandum, P1 referenced that engagement increased over $60 \%$ over the past 5 years, because of attentive leadership strategies. In the second memorandum, P2 stated, "Communication with employees is met through being a supportive manager and encouraging my employees." P3 noted that in 2012, employee engagement was very low and around $25 \%$. This percentile aligns with the reporting of only $30 \%$ engagement in the workplace (U.S. Merit Systems Protection Board, 2015). P4 revealed in the third memorandum that manager availability to the employee builds supportive applications to the workflow relationships and engagement. P5 stated the team had grown between 2014 and 2014, but employee engagement had not improved much. The five memorandums supported the findings that managers may accomplish effective employee engagement through supportive leadership strategies, such as employee attentiveness and work role support.

Based on a comprehensive review of company memorandums on employee engagement, managers documented these improvements based on their supportive leadership. Figure 1 reflects the organization's 5 years (2012-2016) of engagement. 


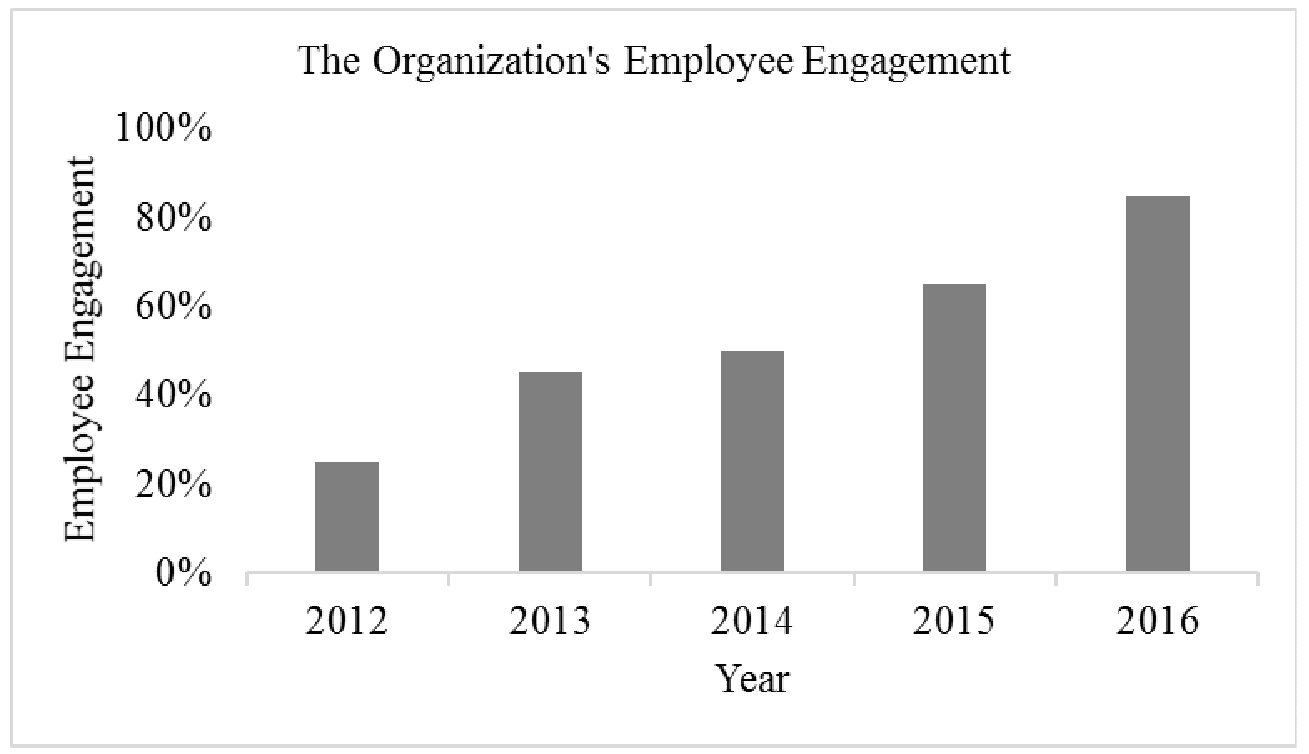

Figure 1. 5-year (2012-2016) employee engagement increases in the company.

The data in Figure 1 shows that the overall engagement levels drastically improved from 2012 during the next 5 years. The data in Figure 1 shows that the employee engagement levels in 2012 was $25 \%$. In 2013, the engagement was 40\%, which is an increase of $15 \%$. In 2014 , the engagement was $50 \%$, which is an increase of $10 \%$. In 2015 , the engagement was $60 \%$, which is an increase of $10 \%$. In 2016 , the engagement was $80 \%$, which is an increase of $20 \%$. The improvement in employee engagement over the past 5 years is due to managers listening, discussing, and working alongside of their employees (P1, P2, P3, P4, and P5). All managers revealed that employee engagement improved by $60 \%$ during a 5-year period (P1, P2, P3, P4, and P5).

Correlation to the literature. The findings noted in Theme 1 aligned with the findings of Ruck et al. (2017) that supportive managers provide discussions about the job to offer employees a sense of belonging and help build job awareness. Furthermore, Tucker (2017) identified that attentive managers set aside time to answer questions and 
observe team/project activities with employees. Ruck, Welch, Menara (2017) found supportive managers promote commitment to the company and build awareness of the employees' environment. Heyden, Fourné, Koene, Werkman, and Ansari (2017) investigated employee engagement for change and found successful managers implement, execute, and support employees toward workplace change to improve engagement. Shuck et al. (2016) asserted that additional research may include other criterion, such as a researcher interviewing employees.

Correlation to the conceptual framework. Theme 1 relates to Shuck and Reio's (2011) framework for employee engagement because the three facets of engagement are reliant on Kahn's (1990) theory on personal engagement where supportive leaders translate organizational systems, acknowledge their employees, and create a supportive environment. Albrecht et al. (2015) associated high-levels of employee engagement with enhanced job performance, affective commitment, and organizational citizenship. The findings are consistent with Anitha's (2014) study results, who concluded that the engagement level of employees in the organization affect the levels of their organizational engagement.

The findings represented in this theme convey that supportive managers dedicate time with employees through documented memorandums, open discussions, and in their guidance in job-site duties. The supportive strategies used by these managers helped to improve the company's effective business practices on employee engagement over five years (2012-2016). Shuck and Reio (2014) noted that managerial support provides a positive contribution to the organization and a feeling of value to the employees. Anitha 
(2014) found that managers who offer a positive perception of the work environment present a supportive workplace for employee engagement. Therefore, managers who engage their employees through a thoughtful change intervention provide a benefit to the entire organization (Shuck \& Reio, 2011).

\section{Theme 2: Direct Communication Improved Employee Engagement}

Direct communication improved employee engagement was the second theme that emerged from investigating the participants' responses. All five leaders (P1, P2, P3, $\mathrm{P} 4$, and P5) referred to direct communication as a strategy to improve their employee engagement through face-to-face, text messaging, and company email communications. The managers (P1, P2, P3, P4, and P5) relayed that direct communication to the employee provided encouragement for the employee to engage on the job. P1 stated, "Direct communication as a strategy permitted the employees to express themselves to the managers and to relay important messages regarding work tasks.” Effective managers should be quick to communicate and provide direct and positive responses to their employees (P1). According to some of the participants (P1, P2, and P4), managers used direct verbal communication reinforcements with their employees to vocally guide and achieve employee engagement. P3 noted, "I do not resort to fear, threats, sarcasm, or belittlement, because it is not motivating to the employee." According to P5, "We use a central email program to keep notes that may help the team respond faster and efficiently."

Job descriptions posted on the company's website provided insight into the expectations of what managers were looking for in their employees These job 
descriptions included terms such as dedication, great attitude, team player, and integrity. The company's career opportunities allowed the managers to communicate with employees and increase the company's productivity through job performance requirements. Managers (P1, P2, P3, P4, and P5) used the job descriptions to communicate and address employee job motivation, behavior, productivity, and engagement. According to the participants (P1, P2, P3, P4, and P5), most of the employees have remained with the company for well over 10 years and continue to adhere to the job descriptions.

Direct communication is crucial when a manager desires to gain employee engagement and build trust with an employee (P2). Another participant (P3) believed that clear and direct communication is an effective strategy to engage their employees and a forum for "sharing business strategies and innovative processes of success." P3 noted that there is an open-door policy where employees can express their concerns at any time and directly communicate with the manager. P4 used email as a direct communication strategy to interact with the company employees. P5 used direct communication to encourage their employees to share vital company information and improve customer relations. The participants $(\mathrm{P} 1, \mathrm{P} 2, \mathrm{P} 3, \mathrm{P} 4$, and $\mathrm{P} 5)$ in this study understood the importance of effective communication to improve employee engagement. Each participant (P1, P2, P3, P4, and P5) shared that direct communication articulated a strategic leadership style to build employee engagement.

Correlation to the literature. The findings represented in Theme 2 aligned with the findings of Shuck et al. (2016) that employee engagement affects all work groups in 
the organization and requires direct communication from managers and employees. P1 used a calm speaking voice as a gentle approach of direct communication to give instructions to employees. Most participants (P1, P2, and P5) praised their employees with direct and immediate communication as the employee performed their job function. P5 preferred the employees directly communicate with each other and share information with the group so everyone could learn together. Each manager (P1, P2, P3, P4, and P5) expressed an understanding of the process of direct communication and positively encouraged their employees to engage in their work.

Direct communication creates behaviors to develop an employee's social capital outcome and build trust in the organization (Lapointe \& Vandenberghe, 2016). Honest communication creates trust between the employee and manager and provides for a healthy workplace environment (Hollis, 2015). The findings of direct communication in the workplace were consistent with the literature from Byrne et al. (2017) who revealed that strategic managers work with employees to expand their skills and help employees learn effective communication skills to improve engagement.

Correlation to the conceptual framework. Theme 2 corresponded to Fredrickson's (1998) framework for employee engagement because of the broaden-andbuild theory of positive employee emotions towards engagement. Shuck and Reio (2011) expanded on Fredrickson's theory, as well as Kahn's (1990) theory of engagement to improve the workplace climate, employee engagement, and the employee's well-being. The participants each used an open-door policy to allow for direct communication from their employees, and therefore, set a positive workplace environment where employees 
could freely communicate with their manager. Managers at this company understood and implemented Barrick et al.'s (2015) three key constructs of the employee engagement theory of (a) cognitive engagement, (b) emotional engagement, and (c) behavioral or physical engagement in the workplace.

The findings represented in Theme 2 expose that direct communication improved employee engagement. Effective business practices, such as direct communication, present a cohesive work environment and allow for engaged employees to effectively perform their roles. Direct communication, according to Men and Hung-Baesecke (2015), can be conducted by managers through technology or face-to-face communication for employee engagement. Kumar and Pansari (2016) found that managers should give immediate attention to and recognize areas for improved employee engagement. According to Gordon et al. (2015), direct communication helps employees perform their work tasks and enhance their professional development. Ford et al. (2015) shared that communication of the manager's knowledge allows for knowledge sharing of the company's procedures with employees and enhances workplace engagement. Therefore, managers who engage their employees in direct communication may improve business practices which lead to highly engaged employees in the workplace.

\section{Theme 3: Training Improved Employee Performance}

Training improved employee performance was the third theme that emerged from the participants' responses. According to the participants (P1, P2, P3, P4, and P5), the company covers customer service training programs, if the training pertains to the employee's job or the employee's intention of moving to another position within the 
company. P1, P2, and P3 stressed the importance of the company providing or supporting customer service training programs for employees wishing to advance their careers within the company. P2 revealed that, "My employees expressed interest in learning more about their jobs and want to grow within the company." Training programs such as elearning or professional licensing classes allowed managers to provide employees with opportunities to expand and improve customer service performance (P3). P4 stated, "We now have an internship program where drivers can train for three months with an experienced employee and learn more of what we expect." P5 noted, "When managers provide company training opportunities for improved customer service, employees learn something new in their job and feel more connected to each other."

According to P1, "Employees want to grow in their job and managers are faced with a challenge to find innovative methods to provide training." Employee job shadowing allowed the manager to strategically train employees through experienced workers (P1). P2 noted, "My employees attend state training courses to improve their skills, obtain industry licensing, and remain relevant in their field of work." P2 further conveyed that employees felt valued when the company invested in training programs towards customer service or reimbursed the employee for industry licenses. P3 revealed that license reimbursement from the company encouraged employees to develop their skills through continual training programs for their desired professional license. As reported by P5, "Employees take turns learning advanced customer service skills through different training programs on the topic.” Most managers (P1, P2, P4, and P5) encouraged the employees to attend customer service training programs to learn how to 
speak to a customer over the phone and interact with customers in a professional online environment. P5 further revealed that the employees share their customer service knowledge from training programs with the team so they each can perform well on the job.

Conferring with Shuck and Reio’s (2014) employee engagement theory, a working relationship exists between employee engagement and job performance. Engaged employees may strive to improve their skills at work and meet or exceed the job requirements more effectively through a positive environment or financial reward system (Lu et al., 2014). Managers at the company offered a $\$ 25.00$ paycheck bonus to any employee who received a positive online customer review. Customers who post online employee reviews on websites such as Google, Yelp, and Facebook provided insight on how the employees' training skills provided improved service to the company's customers (P3). P3 further explained that the bonus program encouraged employees to extend their customer service skills they learned in customer service training programs.

According to all participants (P1, P2, P3, P4, and P5), employee performance improved by the staff attending training programs through e-learning and outside classroom participation on customer service enhancement. Charlier et al. (2016) found that many companies have changed to e-learning programs and relied on the employees to train themselves. Moreover, the findings aligned with Stephan et al. (2016), who revealed that managers who motivate, train, and encourage employees improve organizational productivity. 
The findings aligned with the study by Samnani and Singh (2014) where the researchers found performance-enhancing compensation practices helped to increased employee productivity through greater accountability. Additionally, the findings from the participants aligned with Kumar and Pansari’s (2016) review of how effective training may encourage employees to communicate with customers through listening, servicing, and treating the customer in the most effective manner. Nel et al. (2101) noted that training programs result in positive performance towards successful employee performance. Therefore, the findings revealed that employee training may build a direct line of knowledge between the employee and customer towards the utilization of effective customer service practices to improve employee performance.

Correlation to the literature. The findings in Theme 3 aligned with the findings of $\mathrm{Nel}$ et al. (2015) that company training improved employee performance because training created stability, safety, and psychological meaning to the employees' work tasks. According to Lloyd, Bond, and Flaxman (2017), employees perceived intrinsic value in attending training programs and were more apt to learn and use the training material on the job. Albrecht et al. (2015) found that employee engagement influences the organizational climate when managers implement strategic practices such as training and development. Furthermore, Kane (2017) discovered that employers are offering employees with opportunities of organizational grow through technical training and carefully curated work experiences towards career development.

Correlation to the conceptual framework. The findings of Theme 3 aligned with the conceptual framework because of managerial strategies for employee training. 
Anitha (2014) found that managers who train employees improve their customer service effectiveness. Additionally, Charlier et al. (2016) revealed managers can use e-learning programs to train employees. Similarly, managers may implement what Sarti (2014) identified as employee opportunities for development in learning and personal growth and how training could improve employee engagement. Therefore, managers can enhance employee improvement through company training programs as a strategic means to fulfill the company's goals and vision (Nel et al., 2015).

The findings tie to the existing literature on effective business practices because the managers strategically use training programs to help improve employee engagement to fulfill the company's mission of excellent customer service. Each manager believed job training improved employee performance by developing the employees; customer service skills (P1, P2, P3, P4, and P5). Albrecht et al. (2015) identified that strategic managers device employee training plans as an important workplace strategy to create an improved organizational environment. According to Stephan et al. (2016), organizations can potentially create positive social change by motivating and training employees. Company training as a management strategy assists managers in focusing on developing and improving employee engagement to create socially-responsible employees inside and outside of the workplace (Crane et al., 2014).

\section{Applications to Professional Practice}

Since disengagement causes a personal, individual cost to the employee, it also is a disparaging loss of revenue to the organization (Shuck \& Reio, 2014). As noted by Hollis (2015), workplace disengagement costs American institutions \$64 billion every 
year. Disengaged workers present a critical element for managers to recognize and strategically work to achieve a productive and sustainable organization (Kim et al., 2016). Researchers use the disengagement theory to examine the relationship between a supervisor's disengagement and employee engagement perceptions of ethical leadership (Bonner et al., 2016).

Disengagement reduces creativity and participation in the workplace and hinders innovation (Martinez, 2015). Employee disengagement was observed by Karatepe and Aga (2016) to have had a negative effect on the profitability and productivity of small retail businesses. Productive and successful organizational cultures are therefore comprised of skillfully engaged employees who perform duties with knowledge of the company processes and have a full understanding of the daily business operations (Charlier et al., 2016). A review of the literature showed that by reducing employee disengagement, managers and leaders could increase workplace engagement, which leads to organizational productivity as the result of increased performance.

Efficacious organizations train their employees and develop opportunities that can convey positive social change to the communities they serve (Stephan et al., 2016). Successful managers can use effective employee engagement strategies to improve the productivity and revenue status of the organization within its community. Even though most managers are aware that employee disengagement has adverse effects on an organization, leaders can still benefit by gaining new insight on strategies successful leaders use to reduce employee disengagement effectively. 
Although there are numerous strategies managers use to increase engagement, the findings from the participants revealed engagement strategies of managerial support, direct communication, and continual training opportunities for the employees to decrease disengagement. Gawke et al. (2017) identified managers who understand the benefits associated with using effective strategies can gain a competitive advantage and improve the organization's revenue. More importantly, small retail managers can use the findings of this study to gain new knowledge, which might be beneficial in the implementation of a company's employee engagement strategy. The findings are conducive to Ford et al. (2015) who found managers who communicate their knowledge allow for knowledge sharing of the company's procedures and effectively engage with their employees.

The information shared by the participants might provide small retail managers, leaders, and other business professionals with the valuable information they can use to improve employee engagement within their organizations. In addition, the strategies shared by the participants are not only effective in their organization, but provide a costeffective means for other managers to implement and increase productivity, improve sustainability, and approach survivability in a competitive marketplace. Researchers suggested evidence-based strategies where managers can empower employees and emphasize individual contributions toward organizational goals as relevant procedures in producing a positive and productive workplace environment towards engagement (Gilbert et al., 2010). My goal was that the findings from this study might provide small retail managers and leaders with the new revelation on effective engagement strategies 
among their employees and reduce disengagement factors that hinder organizational profitability and productivity.

\section{Implications for Social Change}

This qualitative descriptive case study on employee engagement is meaningful to social change because small retail managers can use the findings to improve employee engagement through the implementation of effective strategies. The primary objective of this research was to explore effective strategies used by managers to improve employee engagement in the retail industry. Employee disengagement is a threat to organizational profitability and productivity (Hollis, 2015) and affects the company's ability to contribute to their communities. The work environment, leadership personnel, team and co-worker relationships, training, organizational policies, and workplace well-being are the driving factors towards employee engagement (Anitha, 2014).

Researchers suggest an emotional level of engagement in work-related tasks was directly related to employee engagement on the job (Shuck \& Reio, 2014). Researchers further suggested leadership as one of the principal factors affecting employee observations and their workplace engagement actions (Popli \& Rizvi, 2016). Managers can use the strategies that emerged from the data analysis towards implementing effective employee engagement strategies to promote productivity and profitability within the organization's business environment. These strategies may lead to new employment opportunities and promote prosperity for local families and the community. Cultivating employee engagement empowers leaders within an organization to develop company 
profitability and productivity, which in turn can lead to new opportunities in employment and sustainability efforts to serve low-income families and their communities.

\section{Recommendations for Action}

Small retail managers can use the information in this study to implement effective strategies to engage the employees in their organizations. By managers implementing some or all the strategies shared by the participants, leaders can improve employee engagement, which might benefit improved profitability, productivity, and sustainability. The knowledge shared by the participants in this research may contribute toward the success of other retail organizations experiencing disengaged employee in the workplace.

The data may present leaders with different or new strategies similar managers considered effective to improve employee engagement. In addition, by improving employee engagement in the workplace, small retail managers can promote organizational productivity and profitability. The findings from this study also provide small retail managers experiencing employee disengagement beneficial data, such as how to implement and increase productivity, improve sustainability, and approach survivability in a competitive marketplace.

Implementing effective strategies to improve employee engagement may assist in retaining quality and knowledgeable employees who are dedicated to their work duties and provide excellent customer service through knowledge sharing. I recommend small retail business leaders and managers review the findings of this study and espouse some of the strategies that are feasible for application in their businesses. To promote 
distribution of the findings of this study, dissemination of this research occurred through numerous methods.

Participants from the partner organization received the opportunity to receive a two-page summary of the study results. The summary allowed each participant to disseminate among peers, other business managers, leaders, and employees. This study is available through the ProQuest/UMI dissertation database for future scholars and other organizations. Retail managers may also find useful strategies to engage employees and reduce the disengagement problem in North America. I will submit and request approval to present the study results with business related forums, organizational training committees, and leadership conferences.

\section{Recommendations for Further Research}

The purpose of this qualitative descriptive study was to explore strategies that some small retail business leaders use to engage employees in the workplace. While the participants interviewed provided valuable insight and feedback to engage employees effectively, further research is recommended. The limitations identified in Section 1, Limitations, can be addressed in future research by scholars through alternative interview questions. Some of the participants appeared nervous in the recording of their responses. A participant may experience limitations in their response by not recollecting all the specifics related to the strategies used to implement employee engagement. Another limitation can be a participant's episodic memory, which may have limited the participant to accurately reconstruct their response, based on memory (Szpunar et al., 2013). The lack to recollect from memory may create a false response during the interview. The 
limitations in replicating past events can be time-consuming and present challenges to the early researchers' findings (Clement et al., 2015).

Although the findings of this study extend to existing research on employee engagement, employee disengagement was not always the same for each person. Employee engagement contains a human element and creates a complex business problem that future qualitative scholars should explore. A researcher should consider other effective strategies to improve employee engagement. Future research may include the interviewing of employees as an additional means to explore their perceptions of effective strategies that may provide valuable insight on this topic.

Recommendations for further qualitative descriptive research also includes the exploration of effective engagement strategies in different geographical locations and diverse types of retail industries. By exploring employee engagement in diverse geographical locations and industries, future researchers may contribute to the understanding of employee engagement in the workplace. Future qualitative researchers should consider examining employee engagement within the office environment or the external field environment. Further research may provide managers and leaders with valuable insight to improve employee engagement which may increase productivity, improve sustainability, and approach survivability in a competitive market.

\section{Reflections}

Throughout my experiences within the DBA Doctoral Study process, I came against a few obstacles. In April 2015, my husband experienced a heart attack and after I had completed my first couple of courses, I took a two-month break from my studies. The 
focus required of me to continue was not a part of my being. Once I returned to my studies after this break, I engulfed myself once again with coursework. I developed a topic of study during my first residency program after speaking with Dr. Freda Turner. However, once I began to apply the doctoral study process, I changed my topic several weeks into the program and had to start over. The process and application of the information Dr. Turner provided helped get my new problem statement drafted.

There have been several instances where I wanted to give up on this journey. I had lost my job in October 2015 and felt this degree would not make a difference to anyone but myself. Even then, I was unsure if a DBA degree would matter to me. As I continued in interview after interview for jobs I knew I was well-qualified, it appeared I was over-qualified everywhere I applied. Employers either viewed my education and me as too expensive to hire or over-educated. The assumptions came without an opportunity to defend myself and get my foot in the door.

My husband has been my biggest fan and continued to encourage me through this entire journey. My husband's persistent encouragement and belief in me were what pushed me to continue. Could I have done this without him? I am unsure of the answer to this question of continuing, as I have asked it many times. I am thankful my husband is still alive and still experience emotions of unbelief and surreal events. Because of my persistence in continuing onward, I finally obtained a position in May 2017, that encompassed every qualification and desire that ignites my passion. Unfortunately, in August of the same year, the employer had to lay several people off due to budget constraints. This lay-off affected our household in a huge way as my husband had 
accepted a position with the same company and lost his new job as well. To discuss our emotions now is difficult, but we know our worth and know the right job will present itself. Finally, after two months of continual searching, my husband accepted a wonderful opportunity.

The research of this study has been one of learning and expanding my knowledge in employee engagement in the workplace. I was fortunate to interview participants who were willing to assist me in gathering the data. Scheduling the interviews was not an easy task. Instead of setting up calendar events, I had to approach and call each manager throughout the weeks and catch them between tasks. The participants were managers who came to their office early in the morning and spent the remainder of their day out in the field.

In my role as the researcher, once I began the interviews, I witnessed each participant rethinking their management strategies as they answered the interview questions. The process was one of the ethical considerations on both sides of the table, as well as respect for each other's time involved. The participants provided patterns of thought processes and were not quick to respond. Each manager gave the interview questions deep attention and showed a genuine concern for their employees. Some of the participants appeared nervous to the audio recording, and one thought I was conducting recorded videos. I handed each participant the Consent Form and read through the form and answered any questions. Once the interview was completed, I thanked the participant for their time and began analyzing the data through NVivo 11. 
I faced a challenge while carrying out this research by keeping my personal biases to myself. When I conducted the interviews, I had to ensure that my personal biases did not interfere with the data collection or data interpretation. I believe it is important for a qualitative researcher to be careful during the interview and data interpretation processes. Therefore, a researcher needs to be aware of not introducing personal biases into their research.

I understood throughout the interview process to keep bias from creeping into the conversation and only aided the participants in clarifying the interview questions. The process has shed light on employee engagement from what I knew as an employee and opened my eyes to how managers view employee engagement. The managers at the company I interviewed appeared to enjoy the role they represented. Each manager incorporated supportive leadership styles, direct communication, and company-supported training to engage employees and improve the organizational environment.

\section{Conclusion}

The findings from this qualitative descriptive study revealed that supportive leaders, direct communication, and company training as a management strategy improved employee engagement. According to research findings, disengaged employees represent more than $70 \%$ of the workforce in the United States (U.S. Merit Systems Protection Board, 2015). Through investigative research, Shuck and Reio (2016) found engaged employees are more likely to be productive, remain longer with their current employer, and positively interact with customers. Employee engagement through a critical lens is one of privilege and power on who (a) controls the context of the work, (b) determines 
the experience of engagement, (c) defines the value of engagement, and (d) benefits from high levels of engagement (Shuck et al., 2016).

The findings from this descriptive case study revealed that small retail managers could improve employee engagement by focusing on the supportive leadership styles, exercising direct communication, and investing in company training as a management strategy. Based on the participants' experiences, managers should implement the above strategies to improve organization's employee engagement strategy. The findings of this study also indicated that by managers applying the strategies that emerged from the participants' responses, organizational leaders could increase employee engagement, which leads to organizational productivity as the result of increased performance. Most importantly, implementing these strategies is cost-effective and managers can integrate these recommendations into the organizational engagement strategy.

Managers who are interested in improving employee engagement strategies may not produce the exact results of this study because of the situational and circumstantial intricacy of employee engagement and leadership styles. By implementing the strategies recommended under Recommendations for Action, managers may improve employee engagement which can benefit improved profitability, productivity, and sustainability. Archived records, such as company memorandums, may help the manager understand that company employees value their position and want to engage in the company. The knowledge shared by the participants in this research may contribute toward the success of other retail organizations experiencing disengaged employees. Peer-reviewed sources used throughout this study provided insight, definitions, and solidification on each 
terminology on employee engagement strategies for leaders to follow. Furthermore, strategic managers show concern for employees and in return, inspire employees to follow the leader. Successful employee engagement supports improved organizational performance through focused job satisfaction for business competitiveness and industry survival. 


\section{References}

Abildgaard, J., Saksvik, P. \& Nielsen, K. (2016). How to measure the intervention process? An assessment of qualitative and quantitative approaches to data collection in the process evaluation of organizational interventions. Frontiers in Psychology, 7(1380), 1-10. doi:10.3389/fpsyg.2016.01380

Adams, C. A., Potter, B., Singh, P. J., \& York, J. (2016). Exploring the implications of integrated reporting for social investment (disclosures). The British Accounting Review, 48, 283-296. doi:10.1016/j.bar.2016.05.002

Agarwal, U. A. (2014). Linking justice, trust and innovative work behaviour to work engagement. Personnel Review, 43, 41-73. doi:10.1108/PR-02-2012-0019

Airila, A., Hakanen, J. J., Schaufeli, W. B., Luukkonen, R., Punakallio, A., \& Lusa, S. (2014). Are job and personal resources associated with work ability 10 years later? The mediating role of work engagement. Work \& Stress, 28, 87-105. doi:10.1080/02678373.2013.872208

Albrecht, S. L., Bakker, A. B., Gruman, J. A., Macey, W. H., \& Saks, A. M. (2015). Employee engagement, human resource management practices and competitive advantage: An integrated approach. Journal of Organizational Effectiveness: People and Performance, 2, 7-35. doi:10.1108/JOEPP-08-2014-0042

Ali, Z., Zevenbergen, J., \& Tuladhar, A. (2014). Assessing the quality land administration system in Pakistan using systematic approach of case study methodology. American Journal of Rural Development, 2, 40-45. doi:10.12691/ajrd-2-3-1 
Anitha, J. (2014). Determinants of employee engagement and their impact on employee performance. International Journal of Productivity and Performance Management, 63, 308-323. doi:10.1108/IJPPM-01-2013-0008

Årlin, C., Börjeson, L., \& Östberg, W. (2015). Participatory checking and the temporality of landscapes: Increasing trust and relevance in qualitative research. The Oxford Handbook of Historical Ecology and Applied Archaeology, 1-15. Advance online publication. doi:10.1093/oxfordhb/9780199672691.013.19

Au, M. L., Sao Lo, M., Cheong, W., Wang, S. C., \& Van, I. K. (2016). Nursing students' perception of high-fidelity simulation activity instead of clinical placement: A qualitative study. Nurse Education Today, 39, 16-21. doi:10.1016/j.nedt.2016.01.015

Babalola, M. T., Stouten, J., Euwema, M. C., \& Ovadje, F. (2016). The relation between ethical leadership and workplace conflicts: The mediating role of employee resolution efficacy. Journal of Management, 1-27. Advance online publication. doi:10.1177/0149206316638163

Baghurst, T., Murray Jr, E., Jayne, C., \& Carter, D. (2014). Leadership and management skills of junior college athletic directors. The Sport Journal, 17, 1-21. Retrieved from http://thesportjournal.org/

Bakker, A. B. (2011). An evidence-based model of work engagement. Current Directions in Psychological Science, 20, 265-269. doi:10.1177/10963721411414534

Bakker, A. B., Demerouti, E., \& Sanz-Vergel, A. I. (2014). Burnout and work engagement: The JD-R approach. Annual Review of Organizational 
Psychological and Organizational Behavior, 1, 389-411. doi:10.1146/annurevorgpsych-031314-091235

Balunde, A. \& Paradnike, K. (2016). Resources linked to work engagement: The role of high performance work practices, employees' mindfulness, and self-concept clarity. Social Inquiry into Well-Being, 2, 55-62. doi:10.13165/SIIW-16-2-2-06

Barrick, M. R., Thurgood, G. R., Smith, T. A., \& Courtright, S. H. (2015). Collective organizational engagement: Linking motivational antecedents, strategic implementation, and firm performance. Academy of Management Journal, 58, 111-135. doi:10.5465/amj.2013.0227

Baskerville, R. L., \& Wood-Harper, A. T. (2016). A critical perspective on action research as a method for information systems research. Enacting Research Methods in Information Systems, 2, 169-190. doi:10.1007/978-3-319-29269-4_7

Bauman, D. C. (2013). Leadership and the three faces of integrity. Leadership Quarterly, 24, 414-426. doi:10.1016/j.leaqua.2013.01.005

Beckmann, E. A. (2017). Leadership through fellowship: Distributed leadership in a professional recognition scheme for university educators. Journal of Higher Education Policy and Management, 39, 155-168. doi:10.1080/1360080X.2017.1276663

Belmont Report. (1979). Ethical principles and guidelines for the protection of human subjects of research. Retrieved from http://www.hhs.gov

Benoot, C., Hannes, K., \& Bilsen, J. (2016). The use of purposeful sampling in a qualitative evidence synthesis: A worked example on sexual adjustment to a 
cancer trajectory. BMC Medical Research Methodology, 16(1), 1-12.

doi:10.1186/s12874-016-0114-6

Berger, R. (2015). Now I see it, now I don't: Researcher's position and reflexivity in qualitative research. Qualitative Research, 15, 219-234.

doi:10.1177/1468794112468475

Bernard, M. (2016). The impact of social media on the B2B CMO. Journal of Business \& Industrial Marketing, 31, 955-960. doi:10.1108/JBIM-10-2016-268

Bigdely-Shamlo, N., Makeig, S., \& Robbins, K. A. (2016). Preparing laboratory and realworld EEG data for large-scale analysis: a containerized approach. Frontiers in Neuroinformatics, 10(7), 1-14. doi:10.3389/fninf.2016.00007

Birt, L., Scott, S., Cavers, D., Campbell, C., \& Walter, F. (2016). Member checking a tool to enhance trustworthiness or merely a nod to validation? Qualitative Health Research, 1-10. Advance online publication. doi:10.1177/1049732316654870

Bonner, J. M., Greenbaum, R. L., \& Mayer, D. M. (2016). My boss is morally disengaged: The role of ethical leadership in explaining the interactive effect of supervisor and employee moral disengagement on employee behaviors. Journal of Business Ethics, 137, 731-742. doi:10.1007/s10551-014-2366-6

Borromeo, R. M., Laurent, T., Toyama, M., \& Amer-Yahia, S. (2017). Fairness and transparency in crowdsourcing, 466-469. Advance online publication. doi:10.5441/002/edbt.2017.46

Brammer, S., He, H., \& Mellahi, K. (2015). Corporate social responsibility, employee organizational identification, and creative effort: The moderating impact of 
corporate ability. Group \& Organization Management, 40, 323-352.

doi: $10.1177 / 1059601114562246$

Bråndal, A., Eriksson, M., Wester, P., \& Lundin-Olsson, L. (2016). Reliability and validity of the Swedish fatigue assessment scale when self-administered by persons with mild to moderate stroke. Topics in Stroke Rehabilitation, 23, 90-97. doi:10.1080/10749357.2015.1112057

Breevaart $^{1}$, K., \& Bakker, A. B. (2017). Daily job demands and employee work engagement: The role of daily transformational leadership behavior. American Psychological Association, 1-41. Advance online publication. doi:10.1037/ocp0000082

Brett, V., O’Neill, A., \& O’Gorman, B. (2014). Observing entrepreneurs in networks: Reflecting on the relationship between the researcher and the participants. International Journal of Entrepreneurship and Small Business, 21, 275-287. doi:10.1504/IJESB.2014.060892

Brown, G., Strickland-Munro, J., Kobryn, H., \& Moore, S. A. (2017). Mixed methods participatory GIS: An evaluation of the validity of qualitative and quantitative mapping methods. Applied Geography, 79, 153-166. doi:10.1016/j.apgeog.2016.12.015

Buckingham, M.\& Coffman, C. (1999). Break all the rules. London: Simon \& Shuster. Bufquin, D., DiPietro, R., Orlowski, M., \& Partlow, C. (2017). The influence of restaurant co-workers' perceived warmth and competence on employees' turnover 
intentions: The mediating role of job attitudes. International Journal of Hospitality Management, 60, 13-22. doi:10.1016/j.ijhm.2016.09.008

Butler, N., Delaney, H., \& Spoelstra, S. (2017). The gray zone: Questionable research practices in the business school. Academy of Management Learning \& Education, 16, 94-109. doi:10.5465/amle.2015.0201

Byrne, Z., Albert, L., Manning, S., \& Desir, R. (2017). Relational models and engagement: An attachment theory perspective. Journal of Managerial Psychology, 32, 30-44. doi:10.1108/JMP-01-2016-0006

Campbell, K. (2015). Flexible work schedules, virtual work programs, and employee productivity (Doctoral dissertation). Retrieved from ProQuest Dissertations \& Theses Full Text database. (UMI No. 3700954)

Carr, E. C., Briggs, E. V., Briggs, M., Allcock, N., Black, P., \& Jones, D. (2016). Understanding factors that facilitate the inclusion of pain education in undergraduate curricula: Perspectives from a UK survey. British Journal of Pain, 10, 100-107. doi:10.1177/2049463716634377

Castleberry, A. (2014). NVivo 10 [software program]. Version 10. QSR International; 2012. American Journal of Pharmaceutical Education, 78, 1-2. doi:10.5688/ajpe 78125

Charlier, S. D., Guay, R. P., \& Zimmerman, R. D. (2016). Plugged in or disconnected? A model of the effects of technological factors on employee job embeddedness. Human Resource Management, 55, 109-126. doi:10.1002/hrm.21716 
Chen, C. A., Won, M., Stoleru, R., \& Xie, G. G. (2015). Energy-efficient fault-tolerant data storage and processing in mobile cloud. IEEE Transactions on Cloud Computing, 3, 28-41. doi:10.1108/TCC.2014.2326169

Chen, Y. S., Chen, Y. S., Huang, S. Y., \& Huang, S. Y. (2016). A conservation of resources view of personal engagement in the development of innovative behavior and work-family conflict. Journal of Organizational Change Management, 29, 1030-1040. doi:10.1108/JOCM-11-2015-0213

Chiarotto, A., Maxwell, L. J., Terwee, C. B., Wells, G. A., Tugwell, P., \& Ostelo, R. W. (2016). Roland-Morris disability questionnaire and Oswestry disability index: Which has better measurement properties for measuring physical functioning in nonspecific low back pain? Systematic review and meta-analysis. Physical therapy, 96, 1620-1637. doi:10.2522/ptj.20150420

Christian, J. S., \& Ellis, A. P. J. (2014). The crucial role of turnover intentions in transforming moral disengagement into deviant behavior at work. Journal of Business Ethics, 119, 193-208. doi:10.1007/s10551-013-1631-4

Chughtai, A., Byrne, M., \& Flood, B. (2015). Linking ethical leadership to employee well-being: The role of trust in supervisor. Journal of Business Ethics, 128, 653663. doi:10.1007/s10551-014-2126-7

Clement, S., Schauman, O., Graham, T., Maggioni, F., Evans-Lacko, S., Bezborodovs, N., ... \& Thornicroft, G. (2015). What is the impact of mental health-related stigma on help-seeking? A systematic review of quantitative and qualitative studies. Psychological medicine, 45, 11-27. doi:10.1017/S00332917140000129 
Cohn, A., Fehr, E., Herrmann, B., \& Schneider, F. (2014). Social comparison and effort provision: Evidence from a field experiment. Journal of the European Economic Association, 12, 877-898. doi:10.1111/jeea.12079

Crane, A., Palazzo, G., Spence, L. J., \& Matten, D. (2014). Contesting the value of “creating shared value.” California Management Review, 56, 130-153. doi:10.1525/cmr.2014.56.2.130

Cullen, B., Brennan, D., Manly, T., \& Evans, J. J. (2016). Towards validation of a new computerised test of goal neglect: Preliminary evidence from clinical and neuroimaging pilot studies. PloS One, 11(1), 1-12. doi:10.1371/journal.pone,0148127

De Lima Ferreira, J., \& Bertotti, G. R. (2016). Continuing education for professional development in higher education teaching. Creative Education, 7, 1425-1435. doi:10.4236/ce.2016.710148

De Massis, A., \& Kotlar, J. (2014). The case study method in family business research: Guidelines for qualitative scholarship. Journal of Family Business Strategy, 5, 1529. doi:10.1016/j.jfbs.2014.01.007

Deb, S., Austin, P. C., Tu, J. V., Ko, D. T., Mazer, C. D., Kiss, A., \& Fremes, S. E. (2016). A review of propensity-score methods and their use in cardiovascular research. Canadian Journal of Cardiology, 32, 259-265. doi:10.1016/j.cjca.2015.05.015

Delsing, J. (2017). 1 Towards industrial and societal automation and digitisation. In IoT Automation: Arrowhead Framework (pp. 1-26). doi:10.1201/9781315367897-2 
Dong, Y., Bartol, K. M., Zhang, Z. X., \& Li, C. (2016). Enhancing employee creativity via individual skill development and team knowledge sharing: Influences of dual-focused transformational leadership. Journal of Organizational Behavior, 38, 439-458. doi:10.1002/job.2134

Donnelly, P. F., Gabriel, Y., \& Özkazanç-Pan, B. (2013). Untold stories of the field and beyond: Narrating the chaos. Qualitative Research in Organizations and Management: An International Journal, 8, 4-15. doi:10.1108/17465641311327540

Doody, O., \& Noonan, M. (2013). Preparing and conducting interviews to collect data. Nurse Researcher, 20, 28-32. doi:10.7748/nr2013.05.20.5.28e327

Downey, S. N., Werff, L., Thomas, K. M., \& Plaut, V. C. (2015). The role of diversity practices and inclusion in promoting trust and employee engagement. Journal of Applied Social Psychology, 45, 35-44. doi:10.1111/jasp.12273

Drake, B. F., Brown, K. M., Gehlert, S., Wolf, L. E., Seo, J., Perkins, H., Goodman, M. S., \& Kaphingst, K. A. (2016). Development of plain language supplemental materials for the biobank informed consent process. Journal of Cancer Education, 1-9. Advance online publication. doi:10.1007/s13187-016-1029-y

Duan, N., Bhaumik, D. K., Palinkas, L. A., \& Hoagwood, K. (2015). Optimal design and purposeful sampling: Complementary methodologies for implementation research. Administration and Policy in Mental Health and Mental Health Services Research, 42, 524-532. doi:10.1007/s10488-014-0596-7 
Eisenhardt, K. M., Graebner, M. E., \& Sonenshein, S. (2016). Grand challenges and inductive methods: Rigor without rigor mortis. Academy of Management Journal, 59, 1113-1123. doi:10.5465/amj.2016.4004

Elo, S., Kääriäinen, M., Kanste, O., Pölkki, T., Utriainen, K., \& Kyngäs, H. (2014). Qualitative content analysis. Sage Open, 4(1), 1-10. doi: $10.1177 / 2158244014522633$

Entsieh, A. A., \& Hallström, I. K. (2016). First-time parents' prenatal needs for early parenthood preparation - A systematic review and meta-synthesis of qualitative literature. Midwifery, 39, 1-11. doi:10.1016/j.midw.2016.04.006

Evangeline, E. T., \& Ragavan, V. G. (2016). Organisational culture and motivation as instigators for employee engagement. Indian Journal of Science and Technology, 9(2) 1-4. doi:10.17485/ijst/2016/v9i2/86340

Everett, J. A., \& Earp, B. D. (2015). A tragedy of the (academic) commons: Interpreting the replication crisis in psychology as a social dilemma for early-career researchers. Frontiers in Psychology, 6(1152), 1-4. doi:10.3389/fpsyg.2015.01152

Fallon, L. M., Collier-Meek, M. A., Maggin, D. M., Sanetti, L. M., \& Johnson, A. H. (2015). Is performance feedback for educators an evidence-based practice? A systematic review and evaluation based on single-case research. Exceptional Children, 81, 227-246. doi:10.1177/0014402914551738

Farago, B., Zide, J. S., \& Shahani-Denning, C. (2013). Selection interviews: Role of interviewer warmth, interview structure, and interview outcome in applicants' 
perceptions of organizations. Consulting Psychology Journal: Practice \& Research, 65, 224-239. doi:10.1037/a0034300

Ford, D., Myrden, S. E., \& Jones, T. D. (2015). Understanding “disengagement from knowledge sharing": Engagement theory versus adaptive cost theory. Journal of Knowledge Management, 19, 476-496. doi:10.1108/JKM-11-2014-0469

Fortenberry Jr., J. L., \& McGoldrick, P. J. (2016). Internal marketing: A pathway for healthcare facilities to improve the patient experience. International Journal of Healthcare Management, 9, 28-33. doi:10.1179/2047971915Y.0000000014

Fredrickson, B. L. (1998). What good are positive emotions? Review of General Psychology, 2, 300-319. doi:10.1037/1089-2680.2.3.300

Frese, M., \& Keith, N. (2015). Action errors, error management, and learning in organizations. Annual review of psychology, 66, 661-687. doi:10.1146/annurevpsych-010814-015205

Frijda, N. H. (2016). The evolutionary emergence of what we call "emotions." Cognition and Emotion, 30, 609-620. doi:10.1080/02699931.2016.1145106

Frins, W., van Ruysseveldt, J., van Dam, K., \& van den Bossche, S. N. (2016). Older employees' desired retirement age: A JD-R perspective. Journal of Managerial Psychology, 31, 34-49. doi:10.1108/JMP-05-2013-0133

Fusch, P. I., \& Ness, L. R. (2015). Are we there yet? Data saturation in qualitative research. The Qualitative Report, 20, 1408-1416. Retrieved from http://nsuworks.nova.edu/tqr/ 
Gabel-Shemueli, R., Dolan, S. L., Suárez Ceretti, A., \& Nuñez del Prado, P. (2015). Burnout and engagement as mediators in the relationship between work characteristics and turnover intentions across two Ibero-American nations. Stress and Health, 32, 597-606. doi:10.1002/smi.2667

Gale, N. K., Heath, G., Cameron, E., Rashid, S., \& Redwood, S. (2013). Using the framework method for the analysis of qualitative data in multi-disciplinary health research. BMC Medical Research Methodology, 13(117), 1-8. doi:10.1186/14712288-13-117

Garg, R. (2016). Methodology for research I. Indian Journal of Anaesthesia, 60, 640-645. doi:10.4108.0019-5049.190619

Gawke, J. C., Gorgievski, M. J., \& Bakker, A. B. (2017). Employee intrapreneurship and work engagement: A latent change score approach. Journal of Vocational Behavior, 100, 88-100. doi:10.1016/j.jvb.2017.03.002

George, G., \& Joseph, B. (2014). A study on employees' engagement level in travel organisations with reference to Karnataka. Indian Journal of Commerce and Management Studies, 5, 8-15. Retrieved from http://scholarshub.net

Gharib, M., Zolfaghari, M., Mojtahedzadeh, R., Mohammadi, A., \& Gharib, A. (2016). Promotion of critical thinking in e-learning: A qualitative study on the experiences of instructors and students. Advances in Medical Education and Practice, 7, 271-279. doi:10.2147/AMEP.S105226

Gilbert, S., Laschinger, H. K., \& Leiter, M. (2010). The mediating effect of burnout on the relationship between structural empowerment and organizational citizenship 
behaviours. Journal of Nursing Management, 18, 339-348. doi:10.1111/j.13652834.2010.01074.X

Gill, R. (2015). Why the PR strategy of storytelling improves employee engagement and adds value to CSR: An integrated literature review. Public Relations Review, 41, 662-674. doi:10.1016/j.pubrev.2014.02.012

Glavas, A. (2016). Corporate social responsibility and employee engagement: Enabling employees to employ more of their whole selves at work. Frontiers in Psychology, 7(796), 1-10. doi:10.3389/fpsyg.2016.00796

Glymour, M. M., \& Rudolph, K. E. (2016). Causal inference challenges in social epidemiology: Bias, specificity, and imagination. Social Science \& Medicine, 1-8. doi:10.1016/j.socscimed.2016.07.045

Goldenberg, S. M., Brouwer, K. C., Jimenez, T. R., Miranda, S. M., \& Mindt, M. R. (2016). Enhancing the ethical conduct of HIV research with migrant sex workers: Human rights, policy, and social contextual influences. PLoS One, 11(5), 1-21. doi:10.1371/journal.pone.0155048

Goodrich, K. M., \& Luke, M. (2017). Ethical issues in the research of group work. The Journal for Specialists in Group Work, 42, 108-129. doi:10.1080/01933922.2016.1267826

Gordon, H. J., Demerouti, E., Bipp, T., \& Le Blanc, P. M. (2015). The job demands and resources decision making (JD-R-DM) model. European Journal of Work and Organizational Psychology, 24, 44-58. doi:10.1080/1359432X.2013.842901 
Green, C. A., Duan, N., Gibbons, R. D., Hoagwood, K. E., Palinkas, L. A., \& Wisdom, J. P. (2015). Approaches to mixed methods dissemination and implementation research: Methods, strengths, caveats, and opportunities. Administration and Policy in Mental Health and Mental Health Services Research, 42, 508-523. doi:10.1007/s10488-014-0552-6

Groeneveld, S., Tummers, L., Bronkhorst, B., Ashika li, T., \& Van Thiel, S. (2015). Quantitative methods in public administration: Their use and development through time. International Public Management Journal, 18, 61-86. doi:10.1080/10967494.2014.972484

Guercini, S. (2014). New qualitative research methodologies in management. Management Decision, 52, 662-674. doi:10.1108/MD-11-2013-0592

Gustafsson, I., Nyström, M., \& Palmér, L. (2017). Midwives’ lived experience of caring for new mothers with initial breastfeeding difficulties: A phenomenological study. Sexual \& Reproductive Healthcare, 12, 9-15. doi:10.1016/j.srhc.2016.12.003

Hackman, J. R., \& Oldham, G. R. (1976). Motivation through the design of work: Test of a theory. Organizational Behavior and Human Performance, 16, 250-279. doi:10.1016/0030-5073(76)90016-7

Hamarat, E. (2016). Capturing pre-service social studies teachers' perceptions about the concept of election through metaphor analysis. Educational Research and Reviews, 11, 174-181. doi:10.5897/ERR2015.2606 
Hamdani, M. R., Valcea, S., \& Buckley, M. R. (2014). The relentless pursuit of construct validity in the design of employment interviews. Human Resource Management Review, 24, 160-176. doi:10.1016/j.hrmr.2013.07.002

Hammel, J., Magasi, S., Heinemann, A., Gray, D. B., Stark, S., Kisala, P., ... \& Hahn, E. A. (2015). Environmental barriers and supports to everyday participation: Aa qualitative insider perspective from people with disabilities. Archives of Physical Medicine and Rehabilitation, 96, 578-588. doi:10.1016/j.apmr.2014.12.008

Harju, L. K., Hakanen, J. J., \& Schaufeli, W. B. (2016). Can job crafting reduce job boredom and increase work engagement? A three-year cross-lagged panel study. Journal of Vocational Behavior, 95, 11-20. doi:10.1016/j.jvb.2016.07.001

Harland, T. (2014). Learning about case study methodology to research higher education. Higher Education Research \& Development, 33, 1113-1122. doi:10.1080/07294360.2014.911253

Hartley, J., Alford, J., Knies, E., \& Douglas, S. (2017). Towards an empirical research agenda for public value theory. Public Management Review, 19, 670-685. doi:10.1080/14719037.2016.1192166

Haustein, S., \& Larivière, V. (2015). The use of bibliometrics for assessing research: Possibilities, limitations and adverse effects. In Incentives and Performance, 121139. doi:10.1007/978-3-319-09785-5_8

Hernes, M. I., \& Metzger, M. J. (2017). Understanding local community's values, worldviews and perceptions in the Galloway and southern Ayrshire biosphere 
reserve, Scotland. Journal of Environmental Management, 186, 12-23.

doi:10.1016/j.jenvman.2016.10.040

Hernandez, M., \& Guarana, C. L. (2016). An examination of the temporal intricacies of job engagement. Journal of Management, 54(7), 1-25. Advance online publication. doi:10.1177/0149206315622573

Heyden, M. L., Fourné, S. P., Koene, B. A., Werkman, R., \& Ansari, S. S. (2017). Rethinking 'top-down'and 'bottom-up'roles of top and middle managers in organizational change: Implications for employee support. Journal of Management Studies, 1-45. Advance online publication. doi:10.1111/joms.12258

Heyler, S. G., Armenakis, A. A., Walker, A. G., \& Collier, D. Y. (2016). A qualitative study investigating the ethical decision making process: A proposed model. The Leadership Quarterly, 27(5), 1-14. doi:10.1016/j.leaqua.2016.05.003

Hillon, Y. C., \& Boje, D. M. (2017). The dialectical development of "storytelling" learning organizations: A case study of a public research university. The Learning Organization, 24(4), 1-11. doi:10.1108/TLO-02-2017-0010

Hollis, L. P. (2015). Bully university? The cost of workplace bullying and employee disengagement in American higher education. SAGE Open, 5(2), 1-11. doi: $10.1177 / 2158244015589997$

Hott, B. L., Limberg, D., Ohrt, J. H., \& Schmit, M. K. (2015). Reporting results of single-case studies. Journal of Counseling \& Development, 93, 412-417. doi:10.1002/jcad.12039 
Houghton, C., Murphy, K., Meehan, B., Thomas, J., Brooker, D., \& Casey, D. (2016). From screening to synthesis: Using NVivo to enhance transparency in qualitative evidence synthesis. Journal of Clinical Nursing, 1-21. Advance online publication. doi:10.1111/jocn.13443

Høyland, S., Hollund, J. G., \& Olsen, O. E. (2015). Gaining access to a research site and participants in medical and nursing research: A synthesis of accounts. Medical Education, 49, 224-232. doi:10.1111/medu.12622

Huang, Y. H., Lee, J., McFadden, A. C., Murphy, L. A., Robertson, M. M., Cheung, J. H., \& Zohar, D. (2016). Beyond safety outcomes: An investigation of the impact of safety climate on job satisfaction, employee engagement and turnover using social exchange theory as the theoretical framework. Applied Ergonomics, 55, 248-257. doi:10.1016/j.apergo.2015.10.007

Ibrahim, S., \& Sidani, S. (2015). Fidelity of intervention implementation: A Review of Instruments. Health, 7, 1687-1695. doi:10.4236/health.2015.712183

Isgett, S. F., Algoe, S. B., Boulton, A. J., Way, B. M., \& Fredrickson, B. L. (2016). Common variant in OXTR predicts growth in positive emotions from lovingkindness training. Psychoneuroendocrinology, 73, 244-251. doi:10.1016/j.psyneuen.2016.08.010

Iversen, M. M., Graue, M., Leksell, J., Smide, B., Zoffmann, V., \& Sigurdardottir, A. K. (2016). Characteristics of nursing studies in diabetes research published over three decades in Sweden, Norway, Denmark and Iceland: A narrative review of 
the literature. Scandinavian Journal of Caring Sciences, 30, 241-249.

doi:10.1111/scs. 12259

Janský, P., \& Prats, A. (2015). International profit-shifting out of developing countries and the role of tax havens. Development policy review, 33, 271-292. doi:10.1111/dpr.12113

John, L. K., Loewenstein, G., \& Rick, S. I. (2014). Cheating more for less: Upward social comparisons motivate the poorly compensated to cheat. Organizational Behavior and Human Decision Processes, 123, 101-109. doi:10.1016/j.objdp.2013.08.002

Johnston, C. M., Wallis, M., Oprescu, F. I., \& Gray, M. (2017). Methodological considerations related to nurse researchers using their own experience of a phenomenon within phenomenology. Journal of Advanced Nursing, 73, 574-584. doi:10.1111/jan.13198

Kahn, W. A. (1990). Psychological conditions of personal engagement and disengagement at work. Academy of Management Journal, 33, 692-724. doi: $10.2307 / 256287$

Kane, G. (2017). The evolutionary implications of social media for organizational knowledge management. ScienceDirect, 27, 37-46. doi:10.1016/j.infoandorg.2017.01.001

Karatepe, O. M., \& Aga, M. (2016). The effects of organization mission fulfillment and perceived organizational support on job performance: The mediating role of work engagement. International Journal of Bank Marketing, 34, 368-387. doi:10.1108/IJBM-12-2014-0171 
Karimi, M., Brazier, J., \& Paisley, S. (2017). How do individuals value health states? A qualitative investigation. Social Science \& Medicine, 172, 80-88. doi:10.1016/j.socscimed.2016.11.027

Katz, J. (2015). A theory of qualitative methodology: The social system of analytic fieldwork. Méthod(e)s: African Review of Social Sciences Methodology, 1, 131146. doi:10.1080/23754745.2015.1017282

Khan, S. A., Tang, J., \& Joshi, K. (2014). Disengagement of nascent entrepreneurs from the start-up process. Journal of Small Business Management, 52, 39-58. doi:10.1111/jsbm.12032

Khidir, A., Asad, H., Abdelrahim, H., Elnashar, M., Killawi, A., Hammoud, M., ... Fetters, M. D. (2016). Patient responses to research recruitment and follow-up surveys: Findings from a diverse multicultural health care setting in Qatar. $B M C$ Medical Research Methodology, 16(1), 1-14. doi:10.1186/s12874-016-0109-3

Killawi, A., Heisler, M., Hamid, H., \& Padela, A. I. (2015). Using CBPR for health research in American Muslim mosque communities: Lessons learned. Progress Community Health Partnerships, 9, 65-74. doi:10.1353/cpr.2015.0007

Kim, W., Khan, G. F., Wood, J., \& Mahmood, M. T. (2016). Employee engagement for sustainable organizations: Keyword analysis using social network analysis and burst detection approach. Sustainability, 8(7), 1-11. doi:10.3390/su8070631

Kish-Gephart, J., Detert, J., Treviño, L. K., Baker, V., \& Martin, S. (2014). Situational moral disengagement: Can the effects of self-interest be mitigated? Journal of Business Ethics, 125, 267-285. doi:10.1007/s10551-013-1909-6 
Klein, R. A., Ratliff, K. A., Vianello, M., Adams Jr, R. B., Bahník, Š., Bernstein, M. J., ... Cemalcilar, Z. (2014). Investigating variation in replicability. Social Psychology, 45, 142-152. doi:10.1027/1864-9335/a000178

Koenitz, H., Ferri, G., Haahr, M., Sezen, D., \& Sezen, T. İ. (Eds.). (2015). Interactive digital narrative: History, theory, and practice. New York, NY: Routledge. Kouchaki, M., \& Gino, F. (2015). Dirty deeds unwanted: The use of biased memory processes in the context of ethics. Current Opinion in Psychology, 6, 82-86. doi:10.1016/j.copsyc.2015.02.003

Kroon-Batenburg, L. M., Helliwell, J. R., McMahon, B., \& Terwilliger, T. C. (2017). Raw diffraction data preservation and reuse: Overview, update on practicalities and metadata requirements. IUCrJ, 4(1), 1-13. doi:10.1107/S2052252516018315

Kumar, V., \& Pansari, A. (2016). Competitive advantage through engagement. Journal of Marketing Research, 53, 497-514. doi:10.1509/jmr.15.0044

Lapointe, É., \& Vandenberghe, C. (2016). Trust in the supervisor and the development of employees' social capital during organizational entry: A conservation of resources approach. The International Journal of Human Resource Management, 1-21. Advance online publication. doi:10.1080/09585192.2016.1244097

Larkin, I., \& Pierce, L. (2016). Compensation and employee misconduct: The inseparability of productive and counterproductive behavior in firms. Organizational Wrongdoing, 10, 1-27. Advance online publication. doi:10.1017/CB09781316338827.011 
Leng, S., MacDougall, M., \& McKinstry, B. (2016). The acceptability to patients of video-consulting in general practice: Semi-structured interviews in three diverse general practices. Journal of Innovation in Health Informatics, 23, 493-500. doi:10.14236/jhi.v23i2.141

Leviton, L. C. (2017). Generalizing about public health interventions: A mixed-methods approach to external validity. Annual Review of Public Health, 38(16), 1-16. doi:10.1146/annurev-publhealth-031816-044509

Lewis, S. (2015). Qualitative inquiry and research design: Choosing among five approaches. Health Promotion Practice, 16, 473-475. doi:10.1177/1524839915580941

Li, Y., Wang, W., Wu, Q., Van Velthoven, M. H., Chen, L., Du, X., .. Car, J. (2014). Increasing the response rate of text messaging data collection: A delayed randomized controlled trial. Journal of the American Medical Informatics Association, 22, 51-64. doi:10.1136/amiajnl-2014-002845

Lin, Z., Chen, Y., \& Filieri, R. (2017). Resident-tourist value co-creation: The role of residents' perceived tourism impacts and life satisfaction. Tourism Management, 61, 436-442. doi:10.1016/j.tourman.2017.02.013

Lin, P. I., Hsieh, C. D., Juan, C. H., Hossain, M. M., Erickson, C. A., Lee, Y. H., \& Su, M. C. (2016). Predicting aggressive tendencies by visual attention bias associated with hostile emotions. PloS One, 11(2), 1-8. doi:10.1371/journal.pone,0149487

Lind, S. E., Williams, D. M., Bowler, D. M., \& Peel, A. (2014). Episodic memory and episodic future thinking impairments in high-functioning autism spectrum 
disorder: An underlying difficulty with scene construction or self-projection? Neuropsychology, 28, 55-67. doi:10.1037/neu0000005

Lishner, D. A. (2015). A concise set of core recommendations to improve the dependability of psychological research. Review of General Psychology, 19, 5268. doi:10.1037/gpr0000028

Lloyd, K., Bilous, R., Clark, L., Hammersley, L., Baker, M., Coffey, E., \& RawlingsSanaei, F. (2017). Exploring the reciprocal benefits of community-university engagement through PACE. In Learning Through Community Engagement (pp. 245-261). doi:10.1007/978-981-10-0999-0_16

Lloyd, J., Bond, F. W., \& Flaxman, P. E. (2017). Work-related self-efficacy as a moderator of the impact of a worksite stress management training intervention: Intrinsic work motivation as a higher order condition of effect. Journal of Occupational Health Psychology, 22, 115-127. doi:10.1037/ocp0000026

Lu, C. Q., Wang, H. J., Lu, J. J., Du, D. Y., \& Bakker, A. B. (2014). Does work engagement increase person-job fit? The role of job crafting and job insecurity. Journal of Vocational Behavior, 84, 142-152. doi:10.1016/j.jvb.2013.12.004

Lupia, A., \& Elman, C. (2014). Openness in political science: Data access and research transparency. PS: Political Science \& Politics, 47, 19-42. doi:10.1017/S1049096513001716

Mabery, M. J., Gibbs-Scharf, L., \& Bara, D. (2013). Communities of practice foster collaboration across public health. Journal of Knowledge Management, 17, 226236. doi:10.1108/13673271311315187 
MacFarlane, I. M., Veach, P. M., Grier, J. E., Meister, D. J., \& LeRoy, B. S. (2016). Effects of anxiety on novice genetic counseling students' experience of supervised clinical rotations. Journal of Genetic Counseling, 25, 742-766. doi:10.1007/s10897-016-9953-X

Magill, M., Apodaca, T. R., Walthers, J., Gaume, J., Durst, A., Longabaugh, R., ... \& Carroll, K. M. (2016). The alcohol intervention mechanisms scale (AIMS): Preliminary reliability and validity of a common factor observational rating measure. Journal of Substance Abuse Treatment, 70, 28-34. doi:10.1016/j.sat.2016.07.012

Male, T. (2015). Analysing qualitative data. In I. Palaiologou, D. Needham and T. Male (Eds). Doing Research in Education: Theory and Practice, 177-191. London: Sage.

Mansour, N. (2015). Science teachers' views and stereotypes of religion, scientists and scientific research: A call for scientist-science teacher partnerships to promote inquiry-based learning. International Journal of Science Education, 37, 17671794. doi:10.1080/09500693.2015.1049575

Marshall, B., Cardon, P., Poddar, A., \& Fontenot, R. (2013). Does sample size matter in qualitative research? A review of qualitative interviews in IS research. Journal of Computer Information Systems, 54, 11-22. doi:10.1080/08874417.2013.11645667

Marshall, C., \& Rossman, G. B. (2016). Designing qualitative research (6th ed.). Thousand Oaks, CA: Sage. 
Marshall, P. A., Adebamowo, C. A., Adeyemo, A. A., Ogundiran, T. O., Strenski, T., Zhou, J., \& Rotimi, C. N. (2014). Voluntary participation and comprehension of informed consent in a genetic epidemiological study of breast cancer in Nigeria. BMC medical ethics, 15(1), 1-11. doi:10.1186/1472-6939-15-38

Martí, J. (2016). Measuring in action research: Four ways of integrating quantitative methods in participatory dynamics. Action Research, 14, 168-183. doi: $10.1177 / 1476750315590883$

Martinez, M. G. (2015). Solver engagement in knowledge sharing in crowdsourcing communities: Exploring the link to creativity. Research Policy, 44, 1419-1430. doi:10.1016/j.respol.2015.05.010

Matthews, D. C., McNeil, K., Brillant, M., Tax, C., Maillet, P., McCulloch, C. A., \& Glogauer, M. (2016). Factors influencing adoption of new technologies into dental practice A qualitative study. JDR Clinical \& Translational Research, 1(1), 1-9. doi:10.1177/2380084415627129

McIntosh, M. J., \& Morse, J. M. (2015). Situating and constructing diversity in semistructured interviews. Global Qualitative Nursing Research, 2(0), 1-12. doi:10.1177/2333393615597674.

McLean, K. C., Shucard, H., \& Syed, M. (2017). Applying the master narrative framework to gender identity development in emerging adulthood. Emerging Adulthood, 5, 93-105. doi:10.1177/2167696816656254

Men, L. R., \& Hung-Baesecke, C. J. F. (2015). Engaging employees in China: The impact of communication channels, organizational transparency, and authenticity. 
Corporate Communications: An International Journal, 20, 448-467.

doi:10.1108/CCIJ-11-2014-0079

Mikulincer, M., \& Shaver, P. R. (2017). Augmenting the sense of attachment security in group contexts: The effects of a responsive leader and a cohesive group.

International Journal of Group Psychotherapy, 67, 161-175.

doi:10.1080/00207284.2016.1260462

Miles, S. J., \& Van Clieaf, M. (2017). Strategic fit: Key to growing enterprise value through organizational capital. Business Horizons, 60, 55-65. doi:10.1016/j.bushor.2016.08.008

Mitchell, I., Schuster, A., Smith, K., Pronovost, P., \& Wu, A. (2015). Patient safety reporting: A qualitative study of thoughts and perceptions of experts 15 years after 'To err is human'. BMJ Quality \& Safety, 25, 92-99. doi:10.1136/bmjqs2015-004405

Molina-Azorin, J. F. (2016). Mixed methods research: An opportunity to improve our studies and our research skills. European Journal of Management and Business Economics, 25, 37-38. doi:10.1016/j.redeen.2016.05.001

Moon, K., Brewer, T., Januchowski-Hartley, S., Adams, V., \& Blackman, D. (2016). A guideline to improve qualitative social science publishing in ecology and conservation journals. Ecology and Society, 21(3), 1-17. doi:10.5751/ES-08663210317

Moustakas, C. (1994). Phenomenological research methods. Thousand Oaks, CA: Sage. 
Nel, T., Stander, M. W., \& Latif, J. (2015). Investigating positive leadership, psychological empowerment, work engagement and satisfaction with life in a chemical industry. SA Journal of Industrial Psychology, 41(1), 1-13. doi:10.4102/sajip.v4i1.1243

Nenonen, S., Möller, K., \& Storbacka, K. (2017). Market innovation: Renewal of traditional industrial networks. Innovating in Practice, 59-81. doi:10.1007/978-3319-43380-6_4

Nilsson, U., Jaensson, M., Dahlberg, K., Odencrants, S., Grönlund, Å., Hagberg, L., \& Eriksson, M. (2016). RAPP, a systematic e-assessment of postoperative recovery in patients undergoing day surgery: Study protocol for a mixed-methods study design including a multicentre, two-group, parallel, single-blind randomised controlled trial and qualitative interview studies. BMJ open, 6(1), 1-8. doi:10.1136/bmjopen-2015-009901

Nimon, K., Shuck, B., \& Zigarmi, D. (2016). Construct overlap between employee engagement and job satisfaction: A function of semantic equivalence? Journal of Happiness Studies, 17, 1149-1171. doi:10.1007/s10902-015-9636-6

Offord, M., Gill, R., \& Kendal, J. (2016). Leadership between decks: A synthesis and development of engagement and resistance theories of leadership based on evidence from practice in royal Navy warships. Leadership and Organization Development Journal, 37, 289-304. doi:10.1108/LODJ-07-2014-0119

Olafsen, A. H., Halvari, H., Forest, J., \& Deci, E. L. (2015). Show them the money? The role of pay, managerial need support, and justice in a self-determination theory 
model of intrinsic work motivation. Scandinavian Journal of Psychology, 56, 447-457. doi:10.1111/sjop.12211

Olsen, D. P., Lehto, R. H., \& Chan, R. R. (2016). Ethical case study of the researcherparticipant relationship in end-of-life research. Western Journal of Nursing Research, 38, 1205-1220. doi:10.1177/0193945916639590

Paillé, P., Chen, Y., Boiral, O., \& Jin, J. (2014). The impact of human resource management on environmental performance: An employee-level study. Journal of Business Ethics, 121, 451-466. doi:10.1007/s10551-013-1732-0

Palinkas, L. A., Horwitz, S. M., Green, C. A., Wisdom, J. P., Duan, N., \& Hoagwood, K. (2015). Purposeful sampling for qualitative data collection and analysis in mixed method implementation research. Administration and Policy in Mental Health and Mental Health Services Research, 42, 533-544. doi:10.1007/s10488-013-0528-y

Paradis, E., O'Brien, B., Nimmon, L., Bandiera, G., \& Martimianakis, M. A. (2016). Design: Selection of data collection methods. Journal of Graduate Medical Education, 8(2), 263-264. doi:10.4300/JGME-D-16-00098.1

Parker, L. D., \& Northcott, D. (2016). Qualitative generalising in accounting research: Concepts and strategies. Accounting, Auditing \& Accountability Journal, 29, 1100-1131. doi:10.1108/AAAJ-04-2015-2026

Paulo, R. M., Albuquerque, P. B., Saraiva, M., \& Bull, R. (2015). The enhanced cognitive interview: Testing appropriateness perception, memory capacity and error estimate relation with report quality. Applied Cognitive Psychology, 29, 536543. doi:10.1002/acp.3132 
Pedersen, M. J., \& Nielsen, C. V. (2016). Improving survey response rates in online panels: Effects of low-cost incentives and cost-free text appeal interventions. Social Science Computer Review, 34, 229-243. doi:10.1177/0894439314563916

Peng, A. C., Lin, H. E., Schaubroeck, J., McDonough III, E. F., Hu, B., \& Zhang, A. (2016). CEO intellectual stimulation and employee work meaningfulness: The moderating role of organizational context. Group \& Organization Management, 41, 203-231. doi:10.1177/1059601115592982

Petrie, K. (2016). Coming unstuck as an interviewer. Waikato Journal of Education, 11, 107-120. doi:10.15663/wje.v11i1.322

Petrou, P., Bakker, A. B., \& den Heuvel, M. (2016). Weekly job crafting and leisure crafting: Implications for meaning-making and work engagement. Journal of Occupational and Organizational Psychology, 1-24. doi:10.1111/joop.12160

Petrou, P., Demerouti, E., \& Schaufeli, W. B. (2016). Crafting the change. The role of employee job crafting behaviors for successful organizational change. Journal of Management, 1-27. Advance online publication. doi:10.1177/0149206315624961

Polikoff, M. S., \& Porter, A. C. (2014). Instructional alignment as a measure of teaching quality. Educational Evaluation and Policy Analysis, 36, 399-416. doi:10.3102/0162373714531851

Popli, S., \& Rizvi, I. A. (2016). Drivers of employee engagement: The role of leadership style. Global Business Review, 17, 965-979. doi:10.1177/0972150916645701 
Popli, S., \& Rizvi, I. A. (2017). Leadership style and service orientation: The catalytic role of employee engagement. Journal of Service Theory and Practice, 27, 292310. doi:10.1108/JSTP-07-2015-0151

Qureshi, M. I., Iftikhar, M., Janjua, S. Y., Zaman, K., Raja, U. M., \& Javed, Y. (2015). Empirical investigation of mobbing, stress and employees' behavior at work place: Quantitatively refining a qualitative model. Quality \& Quantity, 49, 93113. doi:10.1007/s1135-013-9976-4

Råheim, M., Magnussen, L. H., Sekse, R. J. T., Lunde, Å., Jacobsen, T., \& Blystad, A. (2016). Researcher-researched relationship in qualitative research: Shifts in positions and researcher vulnerability. International Journal of Qualitative Studies on Health and Well-being, 11(0), 1-12. doi:10.3402/qhw.v11.30996

Rajini, G. (2016). Fostering employee engagement: Factors contributing to quality of services in hospitality sector. Advance online publication. doi:10.2139/ssrn.2909695

Rana, S., Ardichvili, A., \& Tkachenko, O. (2014). A theoretical model of the antecedents and outcomes of employee engagement: Dubin's method. Journal of Workplace Learning, 26, 249-266. doi:10.1108/JWL-09-2013-0063

Rao, M. S. (2017). Innovative tools and techniques to ensure effective employee engagement. Industrial and Commercial Training, 49, 127-131. doi:10.1108/ICT06-2016-0037 
Reis, G., Trullen, J., \& Story, J. (2016). Perceived organizational culture and engagement: The mediating role of authenticity. Journal of Managerial Psychology, 31, 1091-1105. doi:10.1108/JMP-05-201-0178

Reunanen, T., Penttinen, M., \& Borgmeier, A. (2017). "Wow-Factors" for boosting business. In Advances in Human Factors, Business Management, Training and Education, 498, 589-600. doi:10.1007/978-3-319-42070-7

Ritchie, J., Lewis, J., Nicholls, C. M., \& Ormston, R. (Eds.). (2013). Qualitative research practice: A guide for social science students and researchers. Thousand Oaks, CA: Sage.

Robinson, O. C. (2014). Sampling in interview-based qualitative research: A theoretical and practical guide. Qualitative Research in Psychology, 11, 25-41. doi:10.1080/14780887.2013.801543

Rodríguez-Sánchez, A. M., Devloo, T., Rico, R., Salanova, M., \& Anseel, F. (2016). What makes creative teams tick? Cohesion, engagement, and performance across creativity tasks. A three-wave study. Group \& Organization Management, 1-27. Advance online publication. doi:10.1177/1059601116636476

Rose, K., Shuck, B., Twyford, D., \& Bergman, M. (2015). Skunked an integrative review exploring the consequences of the dysfunctional leader and implications for those employees who work for them. Human Resource Development Review, 14, 64-90. doi: $10.1177 / 1534484314552437$

Roulston, K. (2014). Analysing interviews. The SAGE handbook of qualitative data analysis. Thousand Oaks, CA: Sage. 
Roulston, K., \& Shelton, S. A. (2015). Reconceptualizing bias in teaching qualitative research methods. Qualitative Inquiry, 21, 332-342. doi: $10.1177 / 1077800414563803$

Ruck, K., Welch, M., \& Menara, B. (2017). Employee voice: An antecedent to organisational engagement? Public Relations Review, 1-11. Advance online publication. doi:10.1016/j.pubrev.2017.04.008

Rucker, M. R. (2017). Workplace wellness strategies for small businesses. International Journal of Workplace Health Management, 10, 55-68. doi:10.1108/IJWHM-072016-0054

Saeieh, S. E., Nasrabadi, A. N., Ebadi, A., Moghadam, Z. B., Mohraz, M., Jozani, Z. B., \& Rezaei, E. (2016). Contraception use among Iranian women with HIV: A qualitative study. Global Journal of Health Science, 8, 199-207. doi:10.5539/gjhs.v8n1p199

Saint-Jacques, M. C., Godbout, E., Gherghel, A., Parent, C., Drapeau, S., \& Robitaille, C. (2016). Stepfamily break-up: A qualitative analysis of trajectories and processes. Journal of Divorce \& Remarriage, 57, 517-541.

doi:10.1080/10502556.2016.1233787

Saks, A. M., \& Gruman, J. A. (2014). What do we really know about employee engagement? Human Resource Development Quarterly, 25, 155-182. doi:10.1002/hrdq.21187

Santiago-Delefosse, M., Gavin, A., Bruchez, C., Roux, P., \& Stephen, S. L. (2016). Quality of qualitative research in the health sciences: Analysis of the common 
criteria present in 58 assessment guidelines by expert users. Social Science \& Medicine, 148, 142-151. doi:10.1016/j.socscimed.2015.11.007

Santos, F., Pache, A. C., \& Birkholz, C. (2015). Making Hybrids Work. California Management Review, 57(3), 36-58. doi:10.1525/cmr.2015.57.3.36

Sarti, D. (2014). Job resources as antecedents of engagement at work: Evidence from a long-term care setting. Human Resource Development Quarterly, 25, 213-237. doi:0.1002/hrdq.21189

Saunders, M. N., \& Townsend, K. (2016). Reporting and justifying the number of interview participants in organization and workplace research. British Journal of Management, 27(4), 1-17. doi:10.1111/1467-8551.12182

Saxena, V., \& Srivastava, R. K. (2015). Impact of employee engagement on employee performance - Case of manufacturing sectors. International Journal of Management Research and Business Strategy, 4(2), 139-174. Retrieved from http://www.ijmrbs.com/

Schaufeli, W. B., \& Taris, T. W. (2014). A critical review of the job demands-resources model: Implications for improving work and health. In Bridging Occupational, Organizational and Public Health (pp. 43-68). doi:10.1007/978-94-007-5640-3_4

Schiefele, A. K., Lutz, W., Barkham, M., Rubel, J., Böhnke, J., Delgadillo, J., ... Lambert, M. J. (2016). Reliability of therapist effects in practice-based psychotherapy research: A guide for the planning of future studies. Administration and Policy in Mental Health and Mental Health Services Research, 1-16. Advance online publication. doi:10.1007/s10488-016-0736-3 
Schoenherr, T., Ellram, L. M., \& Tate, W. L. (2015). A note on the use of survey research firms to enable empirical data collection. Journal of Business Logistics, 36, 288300. doi:10.1111/jbl.12092

Schwab, M., Strobelt, H., Tompkin, J., Fredericks, C., Huff, C., Higgins, D., ... \& Pfister, H. (2017). booc. io: An education system with hierarchical concept maps and dynamic non-linear learning plans. IEEE Transactions on Visualization and Computer Graphics, 23, 571-580. doi:10.1109/TVCG.2016.2598518

Seidman, I. (2013). Interviewing as qualitative research: A guide for researchers in education and the social sciences. New York, NY: Teachers College Press.

Shaukat, R., Yousaf, A., \& Sanders, K. (2017). Examining the linkages between relationship conflict, performance and turnover intentions: Role of job burnout as a mediator. International Journal of Conflict Management, 28, 4-23. doi:10.1108/IJCMA-08-2015-0051

Shuck, B., Adelson, J. L., \& Reio, T. G. (2016). The employee engagement scale: Initial evidence for construct validity and implications for theory and practice. Human Resource Management, 1-25. Advance online publication. doi: $10.1002 / \mathrm{hrm} .21811$

Shuck, B., Collins, J. C., Rocco, T. S., \& Diaz, R. (2016). Deconstructing the privilege and power of employee engagement: Issues of inequality for management and human resource development. Human Resource Development Review, 15, 208229. doi: $10.1177 / 1534484316643904$ 
Shuck, B., \& Reio, T. G. (2011). The employee engagement landscape and HRD: How do we link theory and scholarship to current practice? Advances in Developing Human Resources, 13, 419-428. doi:10.1177/1523422311431153

Shuck, B., \& Reio, T. G. (2014). Employee engagement and well-being a moderation model and implications for practice. Journal of Leadership \& Organizational Studies, 21, 43-58. doi:10.1177/1548051813494240

Shuck, B., \& Rose, K. (2013). Reframing employee engagement within the context of meaning and purpose: Implications for HRD. Advances in Developing Human Resources, 15, 341-355. doi:10.1177/1523422313503235

Silver, C., \& Lewins, A. (2014). Using software in qualitative research: A step-by-step guide (2nd ed.). Thousand Oaks, CA: Sage.

Silverman, D. (2013). Doing qualitative research: A practical handbook. Thousand Oaks, CA: Sage.

Simpson, G. W., Byrne, P., Gabbay, M. B., \& Rannard, A. (2015). Understanding illness experiences of employees with common mental health disorders. Occupational Medicine, 65, 367-372. doi:10.1093/occmed/kqv047

Specht, A., Guru, S., Houghton, L., Keniger, L., Driver, P., Ritchie, E. G., Lai, K. \& Treloar, A. (2015). Data management challenges in analysis and synthesis in the ecosystem sciences. Science of the Total Environment, 534, 144-158. doi:10.1016/j.scitotenv.2015.03.092 
Ssali, A., Poland, F., \& Seeley, J. (2016). Exploring informed consent in HIV clinical trials: A case study in Uganda. Heliyon, 2(11), 1-26. doi:10.1016/j.heliyon.2016.e00796

Stahl, G. (2016). Relationship-building in research: Gendered identity construction in researcher-participant interaction. Gender identity and research relationships, 14, 145-165. doi:10.1108/S1042-319220160000014020

Steegen, S., Tuerlinckx, F., Gelman, A., \& Vanpaemel, W. (2016). Increasing transparency through a multiverse analysis. Perspectives on Psychological Science, 11, 702-712. doi:10.1177/1745691616658637

Stein, R. C., Dunn, J. A., Bartlett, J. M., Campbell, A. F., Marshall, A., Hall, P., ... Makris, A. (2016). Methods: Recruitment and study of personalized care in the treatment of women with early breast cancer. Health Technology Assessment, 20(10), 1-236. doi:10.3310/hta20100

Stephan, U., Patterson, M., Kelly, C., \& Mair, J. (2016). Organizations driving positive social change: A review and an integrative framework of change processes. Journal of Management 42, 1250-1281. doi:10.1177/0149206316633268

Su, L. Y. F., Cacciatore, M. A., Liang, X., Brossard, D., Scheufele, D. A., \& Xenos, M. A. (2017). Analyzing public sentiments online: Combining human-and computerbased content analysis. Information, Communication \& Society, 20, 406-427. doi:10.1080/1369118X.2016.1182197

Sullivan, G. B. (2015). Wittgenstein's later philosophy and "pictures" of mixed-method research in psychology: A critical investigation of theories and accounts of 
methodological plurality. Theory \& Psychology, 25, 473-493.

doi:10.1177/0959354315586092

Sümen, Ö. Ö., \& Çalışıcı, H. (2016). Pre-service teachers' mind maps and opinions on STEM education implemented in an environmental literacy course. Educational Sciences: Theory \& Practice, 16(2), 459-476. doi:10.12738/estp.2016.2.0166

Sun, J., \& Schechter, D. (2015). Investigating the effect of improved fracture conductivity on production performance of hydraulically fractured wells: Fieldcase studies and numerical simulations. Journal of Canadian Petroleum Technology, 54(6), 1-8. doi:10.2118/169866-MS

Sundler, A. J., Eide, H., Dulmen, S., \& Holmström, I. K. (2016). Communicative challenges in the home care of older persons-a qualitative exploration. Journal of Advanced Nursing, 72, 2435-2444. doi:10.1111/jan.12996

Suriyankietkaew, S., \& C. Avery, G. (2014). Employee satisfaction and sustainable leadership practices in Thai SMEs. Journal of Global Responsibility, 5, 160-173. doi:10.1108/JGR-02-2014-0003

Svensson, L., \& Doumas, K. (2013). Contextual and analytic qualities of research methods exemplified in research on teaching. Qualitative Inquiry, 19, 441-450. doi: $10.1177 / 1077800413482097$

Szpunar, K. K., Addis, D. R., McLelland, V. C., \& Schacter, D. L. (2013). Memories of the future: New insights into the adaptive value of episodic memory. Frontiers in behavioral neuroscience, 7(47), 1-3. doi:10.3389/fnbeh.2013.00047 
Taneja, S., Sewell, S. S., \& Odom, R. Y. (2015). A culture of employee engagement: A strategic perspective for global managers. Journal of Business Strategy, 36, 46-56. doi:10.1108/JWL-09-2013-0070

Tessier, A., Francour, P., Charbonnel, E., Dalias, N., Bodilis, P., Seaman, W., \& Lenfant, P. (2015). Assessment of French artificial reefs: due to limitations of research, trends may be misleading. Hydrobiologia, 753(1), 1-29. doi:10.1007/s10750-0152213-5

Thomas, G. (2016). The royal welsh show: Facilitating rural buzz. Regional Studies, Regional Science, 3, 429-437. doi:10.1080/21681376.2016.1239224

Timmons-Mitchell, J., Levesque, D. A., Harris, L. A., Flannery, D. J., \& Falcone, T. (2016). Pilot test of standup, an online school-based bullying prevention program. Children \& Schools, 71-79. doi:10.1093/cdw010.

Tong, A., \& Dew, M. A. (2016). Qualitative research in transplantation: Ensuring relevance and rigor. Transplantation, 100, 710-712. doi:10.1097/TP. 0000000000001117

Tran, V. T., Porcher, R., Falissard, B., \& Ravaud, P. (2016). Point of data saturation was assessed using resampling methods in a survey with open-ended questions. Journal of Clinical Epidemiology. doi:10.1016.j.jclinepi.2016.07.014

Trépanier, S. G., Fernet, C., Austin, S., Forest, J., \& Vallerand, R. J. (2014). Linking job demands and resources to burnout and work engagement: Does passion underlie these differential relationships? Motivation and Emotion, 38, 353-366. doi:10.1007/s11031-013-9384-z 
Tucker, E. (2017). Engaging employees: Three critical roles for managers. Strategic HR Review, 16(3), 107-111. doi:10.1108/SHR-03-2017-0018

U.S. Merit Systems Protection Board. (2015). Managing for engagement Communication connection and courage. Retrieved from http://www.mspb.gov

Ugwu, F. O., Onyishi, I. E., \& Rodríguez-Sánchez, A. M. (2014). Linking organizational trust with employee engagement: The role of psychological empowerment. Personnel Review, 43, 377-400. doi:10.1108/PR-11-2012-0198

Vaara, E., Sonenshein, S., \& Boje, D. (2016). Narratives as sources of stability and change in organizations: Approaches and directions for future research. The Academy of Management Annals, 10, 495-560.

doi:10.1080/19416520.2016.1120963

Vähä-Ypyä, H., Vasankari, T., Husu, P., Suni, J., \& Sievänen, H. (2015). A universal, accurate intensity-based classification of different physical activities using raw data of accelerometer. Clinical Physiology and Functional Imaging, 35, 64-70. doi:10.1111/cpf.12127

Valentin, C. (2014). The extra mile deconstructed: A critical and discourse perspective on employee engagement and HRD. Human Resource Development International, 17, 475-490. doi:10.1080/13678868.2014.932091

Van Teijlingen, E., \& Hundley, V. (2015). Pilot studies in family planning and reproductive health care. Journal of Family Planning and Reproductive Health Care, 31, 219-221. doi:10.1783/1471189054483735 
Vannest, K. J., \& Ninci, J. (2015). Evaluating intervention effects in single-case research designs. Journal of Counseling \& Development, 93, 403-411. doi:10.1002/jcad.12038

Venkatesan, S., Schotanus, M. G., \& Hendrickx, R. P. (2016). Dutch translation of the Manchester-Oxford foot questionnaire: Reassessment of reliability and validity. The Journal of Foot and Ankle Surgery, 55, 1199-1201.

doi:10.1053/j.jfas.2016.07.015

Vitt, L. A. (2014). Raising employee engagement through workplace financial education. New Directions for Adult and Continuing Education, 141, 67-77. doi:10.1002/ace.20086

Vogel, E. (2016). Ongoing endings: Migration, love, and ethnography. Journal of Contemporary Ethnography, 45, 673-691. doi:10.1177/0891241616654542

Warner, L. R. (2016). Invited reflection contested interpretations and methodological choices in quantitative research. Psychology of Women Quarterly, 40, 342-346. doi:10.1177/0361684316655453

Weible, D., Christoph-Schulz, I., Salamon, P., \& Zander, K. (2016). Citizens’ perception of modern pig production in Germany: A mixed-method research approach. British Food Journal, 118, 2014-2032. doi:10.1108/BFJ-12-2015-0458

Wilson, R. C., Butters, O. W., Clark, T., Minion, J., Turner, A., \& Murtagh, M. J. (2016). Digital methodology to implement the ECOUTER engagement process. F1000Research, 5(1307), 1-8. doi:10.12688/f1000research.8786.1 
Wong, S., \& Cooper, P. (2016). Reliability and validity of the explanatory sequential design of mixed methods adopted to explore the influences on online learning in Hong Kong bilingual cyber higher education. International Journal of Cyber Society and Education, 9, 45-66. doi:10.7903/ijcse.1475

Wong, W. P., Hassed, C., Chambers, R., \& Coles, J. (2016). The effects of mindfulness on persons with mild cognitive impairment: Protocol for a mixed-methods longitudinal study. Frontiers in Aging Neuroscience, 8(156), 1-15. doi:10.3389/fnagi.2016.00156

Wong, W. P., Soh, K. L., Chong, C. L., \& Karia, N. (2015). Logistics firms performance: Efficiency and effectiveness perspectives. International Journal of Productivity and Performance Management, 64, 686-701. doi:10.1108/IJPPM-12-2013-0205

Wright, S., O'Brien, B. C., Nimmon, L., Law, M., \& Mylopoulos, M. (2016). Research design considerations. Journal of graduate medical education, 8, 97-98. doi:10.4300/JGME-D-15-00566.1

Yaghmaei, E., \& Brem, A. (2016). Case study research to reflect societal and ethical issues: Introduction of a research implementation plan for icts. $A C M S I G C A S$ Computers and Society, 45, 306-312. doi:10.1145/2874239.2874284

Y1lmaz, O. (2016). A phenomenological study on Turkish language teachers' views on characters in children's books. Journal of Education and Training Studies, 4, 194201. doi:10.11114/jets.v4i3.1284

Yin, R. K. (2014). Case study research: Designs and methods (5th ed.). Thousand Oaks, CA: Sage. 
Yin, R. K. (2015). Qualitative research from start to finish (2nd ed.). New York, NY: Guilford Publications.

Yin, S., \& Kaynak, O. (2015). Big data for modern industry: Challenges and trends [Point of view]. Proceedings of the IEEE, 103, 143-146.

doi:10.1109/JPROC.2015.2388958

Young, T., Rohwer, A., van Schalkwyk, S., Volmink, J., \& Clarke, M. (2015). Patience, persistence and pragmatism: Experiences and lessons learnt from the implementation of clinically integrated teaching and learning of evidence-based health care - A qualitative study. PloS One, 10(6), 1-28.

doi:10.1371/journal.pone, 0131121

Yragui, N. L., Demsky, C. A., Hammer, L. B., Van Dyck, S., \& Neradilek, M. B. (2016). Linking workplace aggression to employee well-being and work: The moderating role of family-supportive supervisor behaviors (FSSB). Journal of Business and Psychology, 32,179-197. doi:10.1007/s10869-016-9443-z

Zamawe, F. C. (2015). The implication of using NVivo software in qualitative data analysis: Evidence-based reflections. Malawi Medical Journal, 27, 13-15. doi:10.4314/mmj.v27i1.4

Zea, M. C., Reisen, C. A., Del Río-González, A. M., Bianchi, F. T., Ramirez-Valles, J., \& Poppen, P. J. (2015). HIV prevalence and awareness of positive serostatus among men who have sex with men and transgender women in Bogotá, Colombia. American Journal of Public Health, 105, 1588-1595. doi:10.2105/AJPH.2014.302307 
Zhao, P., Lu, D., Wang, G., Wu, C., Huang, Y., \& Yu, S. (2016). Examining spectral reflectance saturation in landsat imagery and corresponding solutions to improve forest aboveground biomass estimation. Remote Sensing, 8(6), 1-26. doi: $10.3390 /$ rs 8060469

Zhu, W., Treviño, L. K., \& Zheng, X. (2016). Ethical leaders and their followers: The transmission of moral identity and moral attentiveness. Business Ethics Quarterly, 26, 95-115. doi:10.1017/beq.2016.11 
Appendix A: Interview Questions

Organization:

Interviewee:

Introductions:

Beginning Comments:

1. What engagement strategies do you use to engage the employees in your company?

2. How have the employees responded to the utilized engagement strategies?

3. How has employee engagement affected productivity?

4. What engagement strategies have you discovered to be the most successful?

5. What engagement strategies have you revealed to be the least successful?

6. How has employee engagement affected employee morale in their work tasks?

7. How do you assess the effectiveness of the strategies for employee engagement?

8. What barriers did you encounter to implementing the strategies, and how did you address the implementation barriers?

9. What additional information would you like to provide on the engagement strategies you utilize to improve employee engagement?

Other topics discussed:

Post interview comments: 
Appendix B: Invitation to Participate

Dear (XXXX XXXX):

My name is Janet Deskins, and I am a graduate student working on my doctoral study at Walden University. This doctoral study is about retail managers who use engagement strategies that could contribute to organizational productivity in the workplace. Research collected in this study will be used to explore small retail managers within your organization who use strategic employee engagement practices to improve the productivity in the workplace.

The only requirements for your participation will be to meet with me for approximately 60 minutes at your facility to answer some interview questions about your experiences which you use to implement successful engagement strategies within the employee workforce.

Your identity and the identity of your company will be kept confidential and will not be disclosed in the study. As a participant in the study, you will receive a copy of the research, when completed. The copy of the research may provide information that you can incorporate into your business to enhance your business practices or boost the profitability of your business.

I would like to speak with you by phone or in person to further explain the study or to answer any questions that you may have and your potential participation in this study. The call will only take 5 to 10 minutes of your time.

I will call you at your office number on (INSERT DATE AND TIME). If you prefer to call me at a different time or to a different number; please notify me by replying to this email.

Regards,

Janet Deskins

janet.deskins@waldenu.edu

Tel: $352-989-6322$ 
Appendix C:

National Institutes of Health Office of Extramural Research Certificate

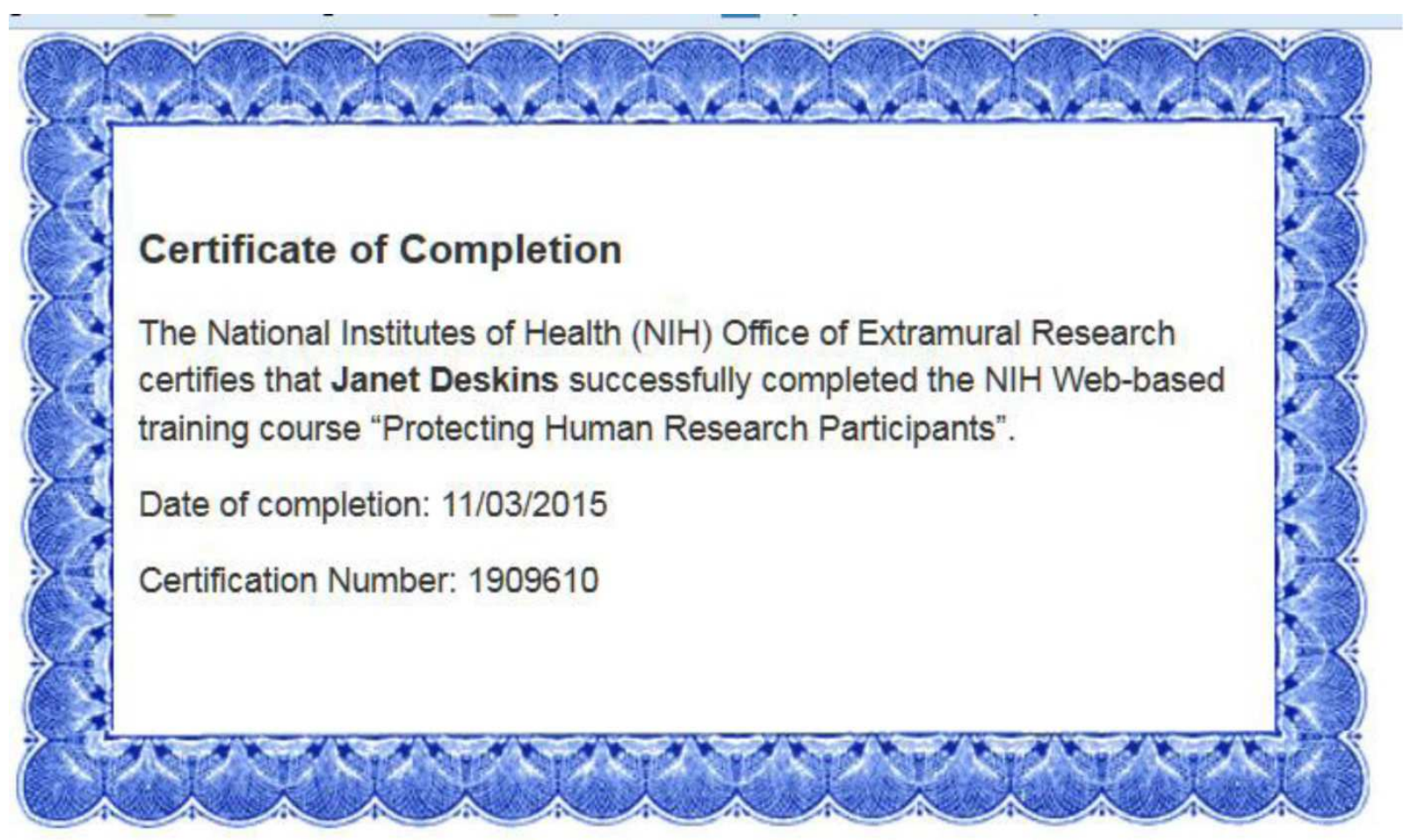


Appendix D: Interview Protocol

Interview Title: An exploration of retail managers' perceptions regarding employee engagement and the use of strategic practices to improve productivity.

1. A set of interview questions will proceed the greeting and introduction.

2. Each participant will receive the consent form and provide their contact information, in agreement with the requirements. Upon receipt of the informed consent, I will thank each participant for their agreement to provide information toward this study.

3. The member checking process will follow the interview session. I will summarize the interpretations from the interview data and validate accuracy. If any participant finds any errors in the interpreted communication, the participant may provide clarification of the corrected information, and it will be recorded by myself and transcribed for accuracy and validity.

4. Upon use of an audio recorder, I will announce the date, time, and location of the interview.

5. Each participant will be allowed ample time to respond to the interview questions and any potential follow-up responses.

6. At the end of the interview, I will thank the participant for giving of their time and participation in the study. 